\title{
مستقبل صناعة الصديد والصلب في مصر
}

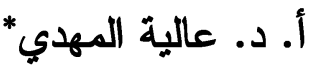

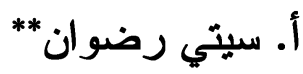

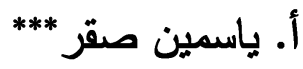

مقدمة

بدأت صناعة الحديد و الصلب في مصر في الأربعينيات من القرن الماضي؛ يمكن القول إن البداية الفعلية كانت عام 1947. كان الهدف الأساسي وراء الدخول في هذه الصناعة هو استغلال الخردة التي كانت منتشرة بشكل كبير في الصحر اء الغربية بعد الحرب العالمية الثانية. كانت البداية إنثاء ثلاث شركات صلب وهم شركات: الدلتا و النحاس والأهلية؛ عملت هذه الثركات الثلاث على صهر الخردة في أفران تعمل بالوقود ثم صبها يدوياً في قو الب تمهيداً لتثكيلها وتقطيعها إلى قضبان حديد تسليح. وما لبثت هذه الثركات حتى لدق بها التطوير وتم إدخال أفران الصهر بالقوس الكهربي ووحدات الصب المستمر. في بداية عام 1957 بدأ استخدام خام الحديد لإنتاج حديد الصب أو حديد الزهر أو للحصول على الصلب السائل. وفي نهاية الخمسينات؛ تأسس في منطقة حلوان أول مصنع متكامل للصلب "ثركة الحديد و الصلب المصرية"، التي استخدت تكنولوجيا الأفران العالية ومعدات ألمانية لصهر خامات الحديد المستخرجة من أسوان ومن ثم صبها يدوياً ثم تشكيلها إلى منتجات صلب نهائي. بعد ذلك شهدت الثركة العديد من مر احل الإضافة و النطوير أهمها إنثاء مجمع الصلب الذي بدأ إنتاجه عام 1972 باستخدام نفس تكنولوجيا الأفران العالية بمعدات روسية حيث بلغت الطاقة الإنتاجية مليون طن سنوياً من كافة الأشكال الطولية و المسطحة للصلب. في أو ائل الثمانينات أنشأت شركة صلب جديدة بمنطقة الدخيلة بالإسكندرية بمشاركة مصرية، يابانية، إيطالية ودولية " شركة الإسكندرية الوطنية للحديد و الصلب". اعتمدت الثركة في علية إنتاج الصلب على التكنولوجيا المنطورة، واستخدت نوعيات عالية الجودة من خامات الحديد الاستخر اجية المستوردة

* * أستاذ الاقتصاد بكلية الاقتصاد و العلوم السياسية - جامعة القاهرة | * طالبة دكتوراه - كلية الاقتصاد و العلوم السياسية - جامعة القاهرة |**** طالبة الماجستير - كلية الاراسات العليا للبحوث الإحصائية - جامعة القاهرة 
وباستخدام الغاز الطبيعي (بدلا من الفحم). بدأت الشركة إنتاجها عام 1986 بطاقة تصميمية 800 ألف طن من حديد التسليح.

خلال الأعو ام التالية شهد قطاع الصلب في مصر نمواً مطرداً متتاسباً مع التطورات الاقتصادية وخطط التتمية وزيادة إنثاء البنية الأساسية في كافة المر افق و التي تعتمد على حديد التسليح حيث وصل الاستير اد من حديد التسليح خلال فترة الثمانينيات وأو ائل التسعينيات إلى حو الي 1.5 مليون طن في السنة. لذلك اتجه العديد من المستثمرين إلى اقتحام صناعة الصلب بدأ من مشروعات الدرفلة باستخدام عروق مسنوردة ثم النطور بإضافة وحدات صهر وشركات لإنتاج العروق و إنتاج ودرفلة المسطحات سواء للسوق المحلى أو للتصدير 1

\section{1- أهمية صناعة الحديد و الصلب}

تمتاز صناعة الحديد والصلب بأنها ذات قيمة اقتصادية هائلة لما لها من أثر مباشر وغير مباشر على

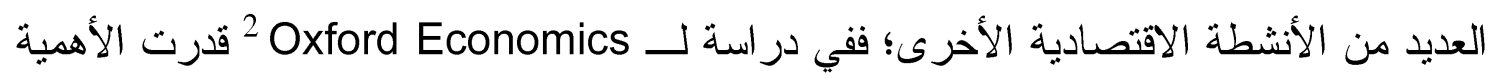
الاقتصادية لصناعة الحديد و الصلب كالتالي: يساهم كل دو لار أمريكي يتم إضافته لصناعة الحديد والصلب في توليد نحو 2.5 دو لار أمريكي قيمة مضافة بالقطاعات الأخرى التي تتكل سلاسل الأمداد لصناعة الحديد و الصلب منل (الآلات و المعدات، وسائل النقل، خامات الحديد، الغاز الطبيعي، الفحم، ...الخ) و القطاعات المستهلكة لمنتجات هذه الصناعة مثل (الإنثاءات، السيار ات و المركبات، و الماكينات و الآلات و المعدات، وقطاع الكهرباء...الخ). كما تساهم كل فرصة عمل يتم خلقها في صناعة الحديد و الصلب في خلق 6.5 فرصة عمل بالقطاعات الأخرى الني تشكل الرو ابط الأمامية و الخلفية للصناعة. تبلغ إنتاجية العامل بصناعة الحديد والصلب نحو 80 ألف دولار أمريكي وهو ما يفوق ثلاثة مرات التهاته إنتاجية العامل المنوسطة بكافة القطاعات الإنتاجية في العالم. تعد صناعة الحديد والصلب أحد المحركات الرئيسية لخلق القيمة المضافة وزيادة النمو الاقتصادي بكافة دول العالم. فالصلب ليس فقط مدخل أساسي لدعم التوسع العمراني و البنية التحتية (نحو 51\%

1 https://steel-network.com/index.php?g0=news\&more=2207 شبكة الحديد والصلب؛ ${ }^{2}$ Oxford Economics: https://www.worldsteel.org/steel-by-topic/statistics/Steel-industry-economic-impact.html 
من الاستهلاك العالمي للحديد والصلب عام 2019)، و إنما هو الداعم للقدرة التتافسية لعدد كبير من الصناعات التحويلية منّل صناعة السيار ات و الهندسة الميكانيكية وصناعة الأجهزة المنزلية وغير ها من

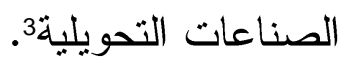
تثأثر القدرة التنافسية لمنتجات هذه الصناعات بجودة منتجات الصلب المستخدمة في تصنيعها سواء من المسطحات أو الأسياخ أو الأسلاك وخلافه. كما أن صناعة الحديد و الصلب محرك أساسي للعديد من الأنشطة الاقتصادية التي تمدها بالمدخلات اللازمة لتصنيع الصلب مثل (الآلات و المعدات، وسائل النقل، خامات الحديد، الغاز الطبيعي، الفحم، وقطاع الكهرباء ...الخ). إن الأبحاث العالمية التي عكفت على در اسة أهمية صناعة الحديد و الصلب في تحقيق التتمية الاقتصادية أوضحت وجود ارتباط بين كميات الإنتاج السنوية من الحديد والصلب في الدولة وقدرتها على تحقيق التنمية وخلق فرص عمل4. فمن الملاحظ الارتباط الوثيق بين إنتاج الصلب والناتج المحلي الإجمالي فكلاهما يسيران في نفس الاتجاه وبنفس الوثيرة؛ مما يدل على مدى أهمية إنتاج الصلب وتأثيره على الناتج المحلي الإجمالي للدول كما هو و اضح في الأشكال الثالاثة التالية لحالة الصين وفيتنام و العالم بوجه عام. شكل رقم (1): العلاقة بين الناتج المحلي الاجمالي وانتاج الصلب الخام

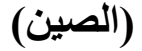

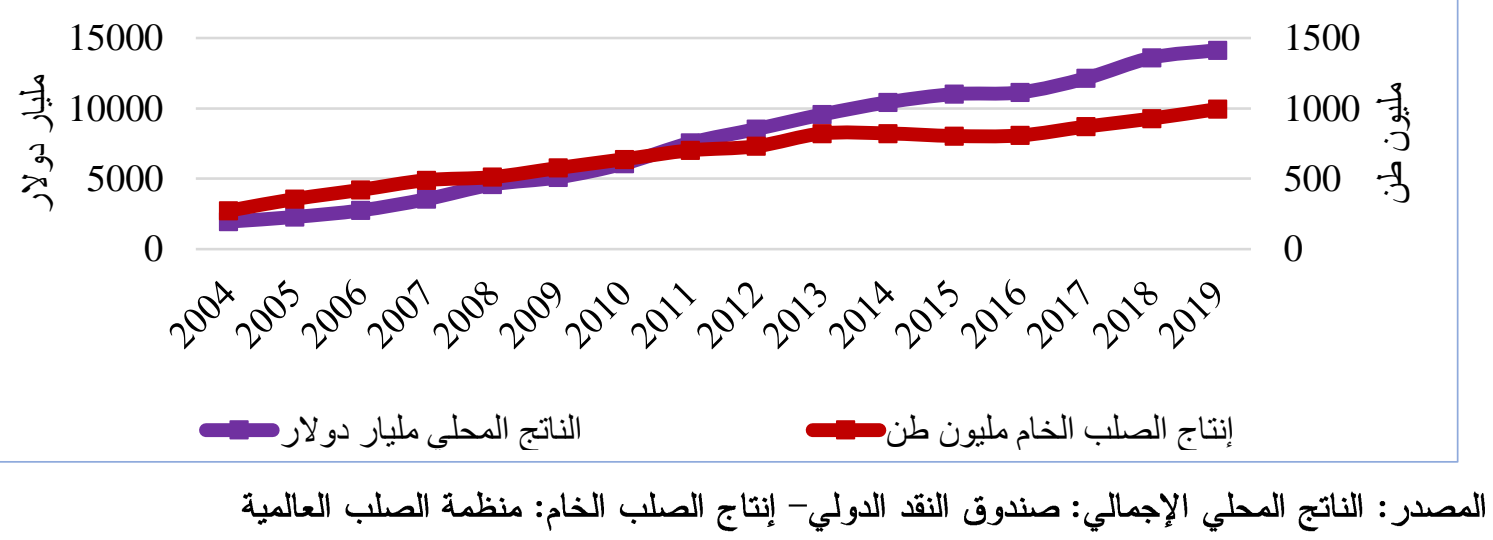

${ }^{3}$ Source: Oxford Economics:https://www.worldsteel.org/steel-by-topic/statistics/Steel-industry-economicimpact-.html

4 KONAK,A.,\& KAMACI,A.," Effects Of Iron-Steel Sector On Global Competition, Economic Growth And Unemployment", Manisa Celal Bayar Üniversitesi.2019. 


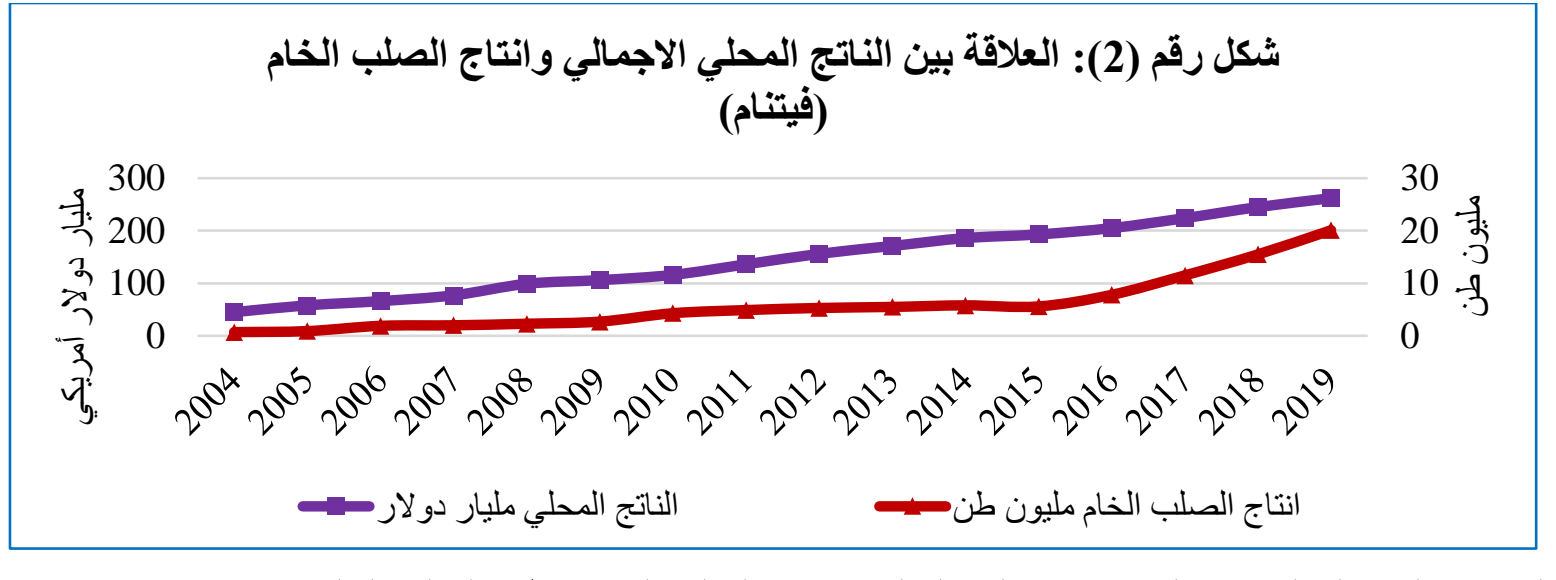

المصدر: الناتج المحلي الإجمالي: صندوق النقد الدولي - إنتاج الصلب الخام: منظمة الصلب العالمية

يوضـح الثكل رقم (3) قوة الارتباط بين الإنتاج العالمي للصلب و الناتج العالمي الإجمالي:

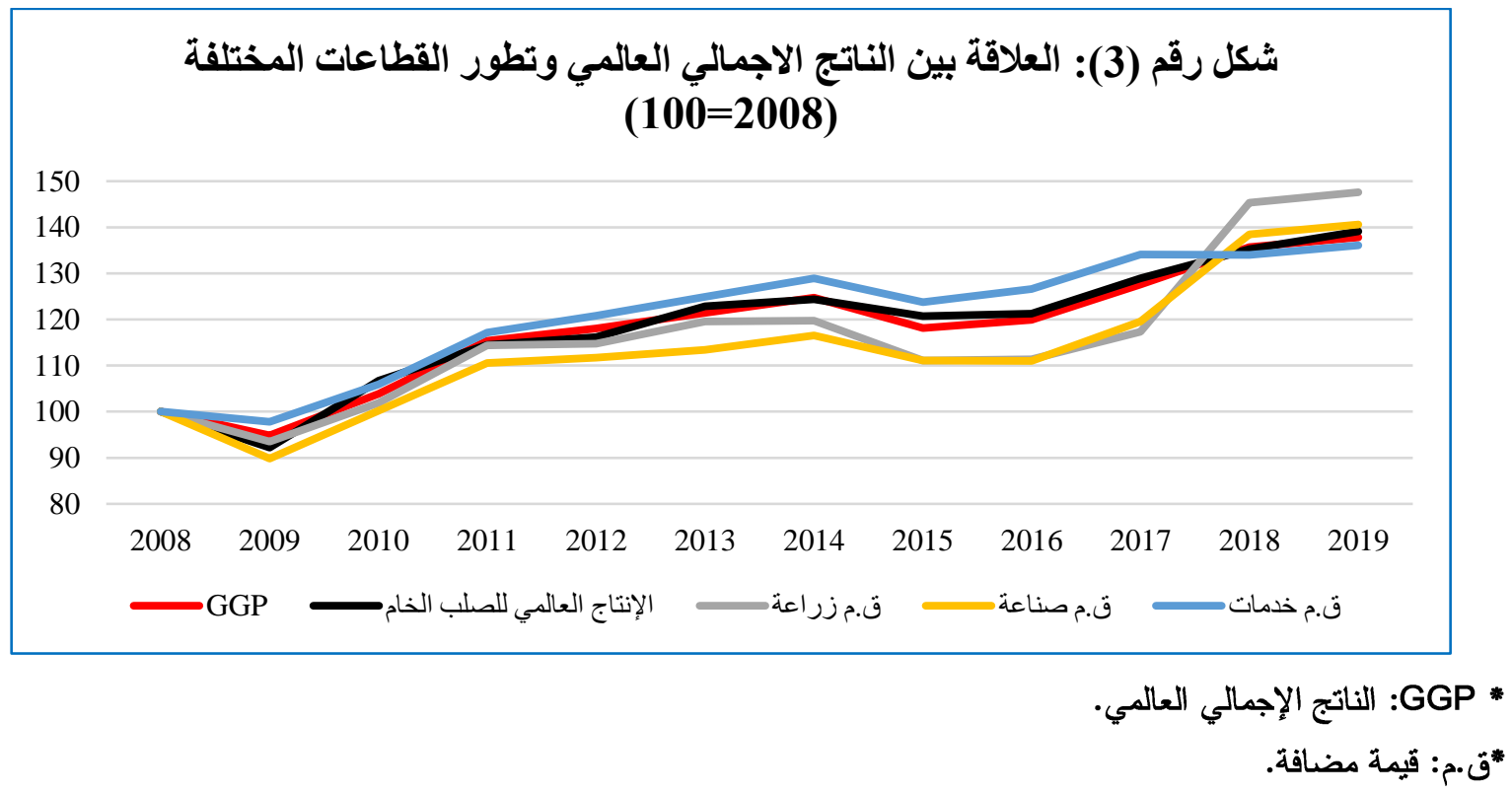

Source: World Bank, Databank, World Development Indicators,

https://databank.worldbank.org/source/world-development-indicators

نوجد أيضاً علاقة طردية بين متوسط كمبة استهلاك الفرد لمنتجات الحديد و الصلب ومعدلات النمو و التتمية الاقتصادية للدولة؛ حيث أنه يعد مؤشر أ لحجم المشاريع الإنشائية و التتموية التي تشهدها البلاد.5. ليس هذا فحسب بل إن مخلفات هذه الصناعة من خبث الحديد له قيمة اقتصادية كبيرة أيضاً؛ حيث يستخدم في صناعة بدائل للأسمنت ذات جودة عالية؛ بل إن استخدامه في صناعة التشييد و البناء بديلاً 
للأسمنت من شأنه أن يحقق تخفيض في تكلفة الإنشاءات بحوالي 22.61\%، كما انه يقي البيئة من أضر ار خبث الحديد حال عدم استخدامه6.

2- صناعة الصلب مقابل الدرفلة

تُصنف شركات الحديد و الصلب طبقاً لمر احل التصنيع إلى ثلاث مجمو عات:

المجموعة الأولى: الشركات المتكاملة

هي الشركات التي تقوم بجميع مراحل صناعة الصلب بدايةً من الحصول على خام الحديد وعملية الاختز ال وصو لاً إلى منتج الصلب في صورته لهُ النهائية. تمر هذه الشركات بأربع مر احل إنتاجية: > تبدأ المرحلة الأولى بخام الحديد (الذي يتو اجد في الطبيعة في صورة أكسيد الحديد)، بحيث يتم اختز ال أكاسيد الحديد للحصول على الحديد المختزل في أولى مر احل الصناعة، إما باستخدام الفحم في الأفران

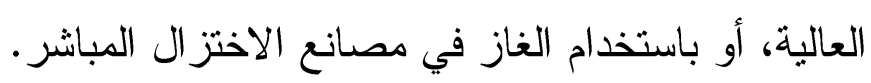

> في المرحلة الثانية يتم صهر الحديد المختزل لإنتاج صلب سائل من خلال الوسائل المختلفة، منل أفران القوس الكهربي.

> في المرحلة الثالثة يتم صب هذا الصلب السائل في صورة منتجات شبه مصنََّعَة ("بليت" أو "بلاطات").

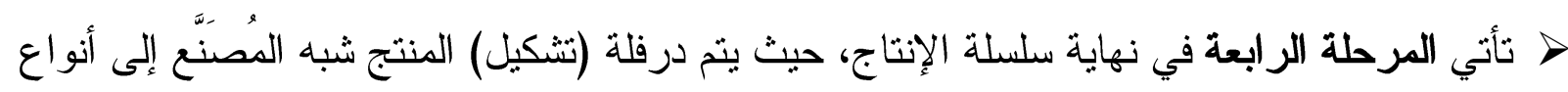
الصلب المختلفة (حديد تسليح أو صلب مسطح).

تبلغ الطاقات الإتتاجية لثركات الصلب المتكاملة 8 مليون طن حديد تسليح سنوياً - قبل قرار إغلاق شركة الحديد و الصلب المصرية-. تتمثل شركات الصلب المتكاملة في مصر في أربع شركات فقط بعد قر ار إغلاق شركة الحديد والصلب المصرية؛ وهم: شركة عز الدخيلة؛ شركة عز السويس للمسطحات؛ شركة بشاي للصلب و السويس للصلب.

وتعد شركة حديد عز الاخيلة نموذجاً لشركات الصلب المتكاملة في مصر والعالم؛ فهي تعد من أكبر شركات الصلب المتكاملة في العالم بطاقة إنتاجية 3.2 مليون طن سنوياً. تقوم الشركة باستير اد الخامات construction in AIP Conference Proceedings (Vol. 2158, No. 1, p. 020032). AIP Publishing LLC. 
ذات المو اصفات العالية، ثم القيام بعلية اختز ال الحديد باستخدام الغاز الطبيعي و الصهر بأفران الأقطاب الكهربائية لإنتاج المسطحات المدرفلة على الساخن وحديد التسليح؛ لتنتهي بتصنيع منتج مصري قادر

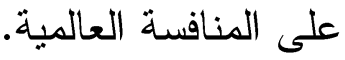

\section{المجموعة الثانية: الشركات شبه المتكاملة}

هي الثركات التي تبدأ عملية الإتتاج من صهر خردة الصلب المحلية أو استيراد خردة من الخارج

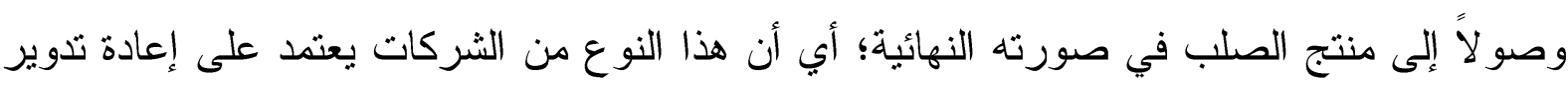
الصلب السابق استخدامه؛ - إك

تمر هذه الثركات بثلاث مر احل إنتاجية:

أولى مر احل هذه المصانع هي صهر الخردة في أفران القوس الكهربي لإنتاج الصلب السائل. في المرحلة الثانية، يتم صب هذا الصلب السائل في صورة بليت/بلاطات. ختنهي هذه المجموعة بنفس المرحلة النهائية (الثالثة لهذه المصانع) في سلسلة الإنتاج، وهي الدرفلة أو تشكيل المنتج النهائي.

تبلغ الطاقات الإنتاجية لنلك الثركات 2 مليون طن حديد نسليح سنوياً؛ و650 ألف طن عروق لمصانع

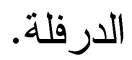

أبرز شركات الصلب شبه المتكاملة في مصر: مجموعة حديد المصريين؛ الدلتا للصلب؛ مصر الوطنية للصلب؛ المر اكبي للصلب؛ مصنع 100 حربي. الجدير بالذكر إن استهلالك صناعة الصلب المتكاملة وشبه المنكاملة من الكهرباء يوفر ميزة كبرى لقطاع الكهرباء الوطني. حيث يضمن معدلات استهلاك مستمرة للكهرباء على مدار اليوم، لو لاها لتأثر استقرار الشبكة القومية خارج ساعات الذروة. المجموعة الثالثة: مصانع الدرفلة و هي المصانع التي تقوم بشر اء عروق الصلب (بلاطات الصلب) أو ما يطلق عليه أسم ال وهو منتج شبه نهائي (شبه مصنع) من الثركات المتكاملة وشبه المتكاملة المحلية أو ستنير اده من الخارج ثم تقطيعه و إعادة تثكيلة لإنتاج منتجات الحديد والصلب بأشكاله المختلفة8. أي أن هذه الثركات تمر بمرحلة إنتاجية واحدة وهي المرحلة الر ابعة؛ مرحلة الدرفلة. 
عدد هذه المصانع في مصر يتجاوز22 مصنع يأتي في مقدمتها مجموعة الجارحي للارفلة ومصنع العشري للارفلة و الجيوشي للصلب. كما أن الطاقات الإنتاجية لمصانع الدرفلة في مصر تبلغ حوالي 5 مليون طن سنويا من حديد التسليح. يجدر بنا الإثارة إلى أن العطلية الإنتاجية المعرفة لصناعة الصلب هي إنتاج الصلب الخام، وليس تثكيل (درفلة) المنتج شبه المصنع (البيليت)؛ فعملية إنتاج الصلب تعرف على أنها تحويل خام الحديد، أو تدوير الخردة، للحصول على صلب خام Crude Steel، بحيث يمكن تثكيله إلى منتجات مختلفة. بناءً عليه، هناك فرق جوهري بين عملية إنتاج الصلب Steel Making، التي ينتج عنها الصلب الخام والتي تقوم به شركات الصلب المنكاملة وشبه المتكاملة9، و عملية تشكيل الصلب المنتج بالفعل Steel Rolling التي

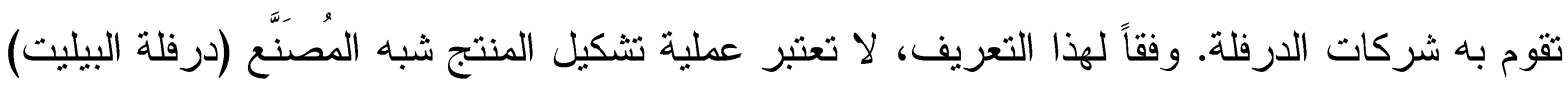
للحصول على حديد تسليح عملية إنتاج للصلب، و إنما عملية تثكيل لصلب تم إنتاجه بالفعل. إن إنتاج مصانع الدرفلة المصرية لا يدخل ضمن الطاقات الإنتاجية لمصر من الصلب. فالطاقات

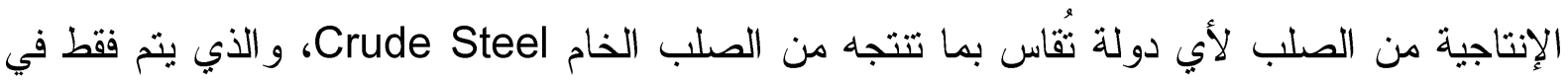

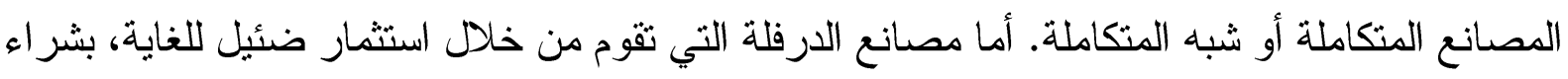

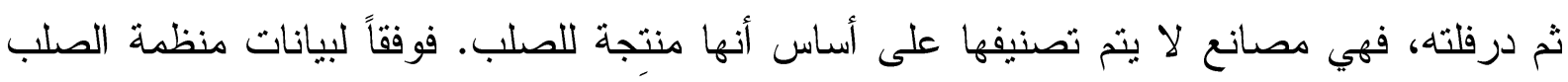
العالمية (World Steel Association) يبلغ الإنتاج المصري من الصلب عام 2018 حوالي 7.8 مليون طن، و هو ما يعادل فقط إنتاج مصر من الصلب السائل. بناءً عليه، لا تُخذِل المنظمة حديد التسليح المنتَج في مصر باستخدام مستورد (1.6 مليون طن حديد تسليح عام 2018) ضمن الطاقات الإنتاجية لمصر، و إنما يدخل البيليت المستخدَم لإنتاج هذه الكمية ضمن أرقام إنتاج الصلب الخاصة بالدول

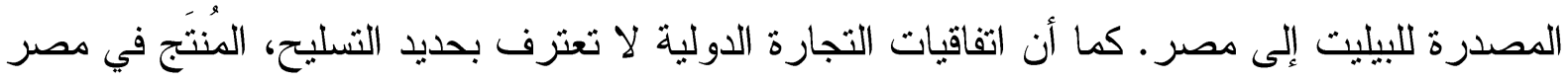

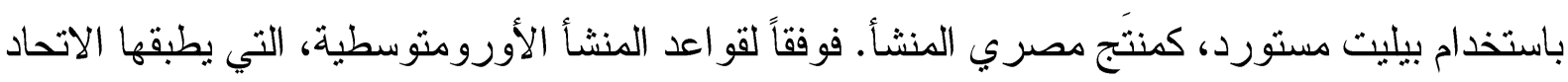
الأوروبي وحوض البحر المتوسط (و غيرها)، يكتسب منتج الصلب صفة منشأ الدولة فقط إذا بدأت عملية تصنيعه باستخدام الصلب السائل. وبالتالي، فإن حديد النسليح (بند جمركى 7213- 7214) المدرفل

9 تُقسم منظمة الصلب العالمية (World Steel Association) والتي تمثل أكبر تجمع لمنتجي الصلب في العالم (160 مُصنِّعا للصلب يمثلون

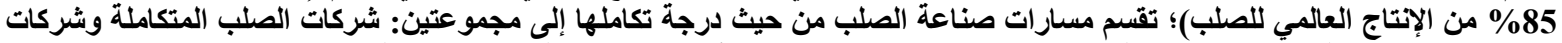

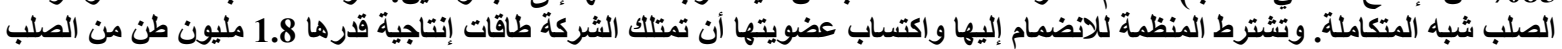


باستخدام بيليت غير مصري (بند جمركي 7207) لا يكتسب صفة المنشأ المصري داخل الأسواق الأوروبية، و لا يمكن تصديره. تُوَفِر مصانع الصلب المتكاملة وشبه المتكاملة و الذي يبلغ عددها حو الي 16 مصنع 80٪ من الطاقات الإنتاجية لحديد النسليح في مصر. تبلغ قيمتها المضافة في حدها الأدنى 60\%. نوظف أكثر من 26 ألف عامل. إجمالي استثمار اتها 150 مليار جنيه. صادراتها السنوية اقتربت من المليار دولار عام

$$
\text { 2017-2017. (لنظر جدول رقم 1) }
$$

في الدقابل شركات الدرفلة تعتمد على استيراد حديد نسليح مُصنع بنسبة 85\% لتقوم فقط بتشكيله

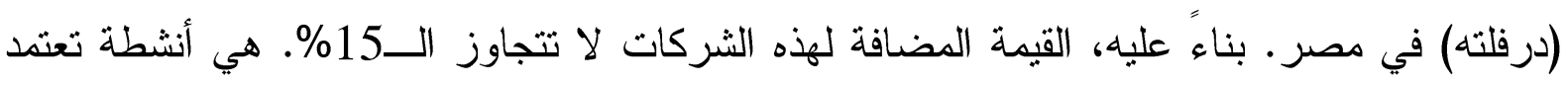
على الاستير اد بصورة أساسية. تستخدم تكنولوجيا قديمة من خلال مصانع مفككة. نوظف في مصر 3.5 ألف عامل. لا يمكنها تصدير إنتاجها للخارج، حيث لا يُعترَفَ به كمنتج ذي منشأ مصر لضألة

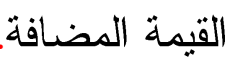

جدول رقم (1): مقارنة بين مصانع الصلب المتكاملة وشبه المتكاملة ومصانع الارفلة

\begin{tabular}{|c|c|c|c|}
\hline مصانع الدرفلة & وشبه المتكاملة المتكلة & & \\
\hline 3.6 & 26.8 & حجم العمالة (ألف عامل) & \multirow{2}{*}{ التشغيل } \\
\hline 12 & 88 & \% من إجمالي العمالة & \\
\hline 22 & 16 & & عدد الشركات \\
\hline 20 & 80 & \multicolumn{2}{|c|}{ المساهمة في إجمالي إنتاج صناعة الحديد والصلب المحلية (\%) } \\
\hline 15 & 60 & \multicolumn{2}{|c|}{ سبة القيمة المضافة إلى المنتج النهائي (\%\%) } \\
\hline 30 & $150+$ & \multicolumn{2}{|c|}{ حجم الاستثمارات (مليار جنيه مصري) } \\
\hline $\mathbf{0}$ & 798 & \multicolumn{2}{|c|}{ صنادرات مسطحات الصلب1 عام 2019 (الف طن) } \\
\hline $\mathbf{0}$ & 243 & \multicolumn{2}{|c|}{ صادرات حليد التسليح2 عام 2019 (الف طن) } \\
\hline
\end{tabular}

1- بنود جمركية (7208-7211)

2- بنود جمركية (7213-7214) بنودية

مصدر الصادرات والواردات: الهيئة العامة للرقابة على الصادرات والواردات

وقد استهلكت مصر في عام 2019 حو الي 7.4 مليون طن حديد تسليح؛ وفقاً لبيانات وزارة التموين و التجارة الداخلية و الهيئة العامة للرقابة على الصادرات و الواردات، ويعني استير اد هذه الكمية من الخارج بالكامل حال توقف الصناعة يعني أن تصل الواردات إلى قيمة لا تقل عن 4 مليار دولار، بما يفاقم من عجز الميزان التجاري؛ وبالتالي فإن صناعة الصلب المتكاملة وشبه المتكاملة في مصر نوفر على الدولة فاتورة استير اد ضخمة. هناك خسائر أخرى لا يمكن تقدير ها إذا ما توققت هذه الصناعة، 
على رأسها رهن حركة العمران في مصر بتقلبات سعر حديد التسليح في العالم، ومدى نزامن توريده مع الطلب المصري، مما قد يولد اختناقات في حركة البناء. كما أن صناعة الصلب المنكاملة تحقق أكثر من ع أضعاف القيمة المضافة التي تحققها مصانع الدرفلة لكل طن حديد تسليح يتم إنتاجه. فالجانب الأكبر من القيمة المضافة في إنتاج الصلب يتركز في المر احل الإنتاجية الأولى (اختز ال خام الحديد) و الثانية (صهر الحديد المختزل لإنتاج صلب سائل) و الثالثة (صب الصلب السائل في صورة منتجات شبه مصنعة). أقل قدر من القيمة المضافة يتم في مرحلة الدرفلة (تثكيل المنتجات شبه المصنعة). حيث تقتصر القيمة المضافة لمرحلة الدرفلة على 15\% فقط في حين تتعدى القيمة المضافة للصناعة المتكاملة 60\% من قيمة المنتج.

\section{3- التطور الاقتصادي لصناعة الحديد والصلب من سنة 2000 حتى 2020}

في مصر نجد أن صناعة الحديد و الصلب تساهم بنحو 88 مليار جنيه من الناتج المحلى الإجمالي 10 وهو ما يمثل نحو 1.6 \% منه عام 2019/2018. ويعمل بصناعة الحديد والصلب نحو 30 ألف عامل (عمالة مباشرة)، هذا بالإضافة إلى مئات الألاف من العمالة غير المباشرة التي تعمل بالعديد من القطاعات و الأنثطة الاقتصادية التي تثكل روابط الدفع الأمامية والخلفية لصناعة الحديد والصلب مثل التعدين،

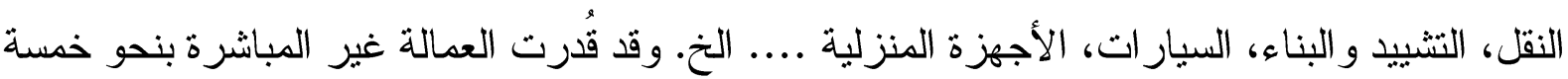

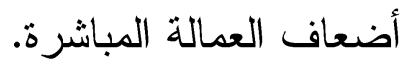
أ- الطاقات الإنتاجية لصناعة الحديد والصلب في مصر : تملك مصر العديد من الإمكانات التي تؤهلها لأن تصبح رائد صناعة الصلب في الدول العربية وأفريقيا. فقد بلغت الطاقة الإنتاجية الحالية لصناعة الصلب الخام المصرية نحو 15.6 مليون طن عام 2019 وهو ما يمثل نحو 36\% من الطاقات الإنتاجية المتاحة بقارة أفريقيا وذلك وفقا لبيانات منظمة التعاون الاقتصادي و التتمية 11. كما تصدرت مصر الدول العربية عام 2018، حيث استحوذت على نحو 26\% من الطاقات الإنتاجية العربية لصناعة الحديد و الصلب وفقاً لبيانات الاتحاد العربي للحديد و الصلب².

10 نشرة الإتتاج الصناعي السنوي، الجهاز المركزي للتعبئة العامة والإحصاء

${ }^{11}$ https://stats.oecd.org/Index.aspx?datasetcode=STI_STEEL_MAKINGCAPACITY

${ }^{12}$ https://aisusteel.org/archives/project/report-on-the-iron-and-steel-industry-in-the-arab-world 
بلغت الطاقات الإنتاجية بصناعة الصلب المتكاملة وشبه المتكاملة نحو 13.1 مليون طن سنوياً وهو ما يمثل نحو 84\% من الطاقات الإنتاجية لصناعة الصلب الخام المصرية عام 2019. تظهر بيانات منظمة التعاون الاقتصادي و التتمية OECD؛ زيادة في الطاقات الإنتاجية لصناعة الحديد في مصر . لتصل في عام 2019 إلى 15.6 مليون طن؛ مقارنة ب 15.3 مليون طن عام 2018 بنسبة

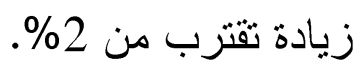

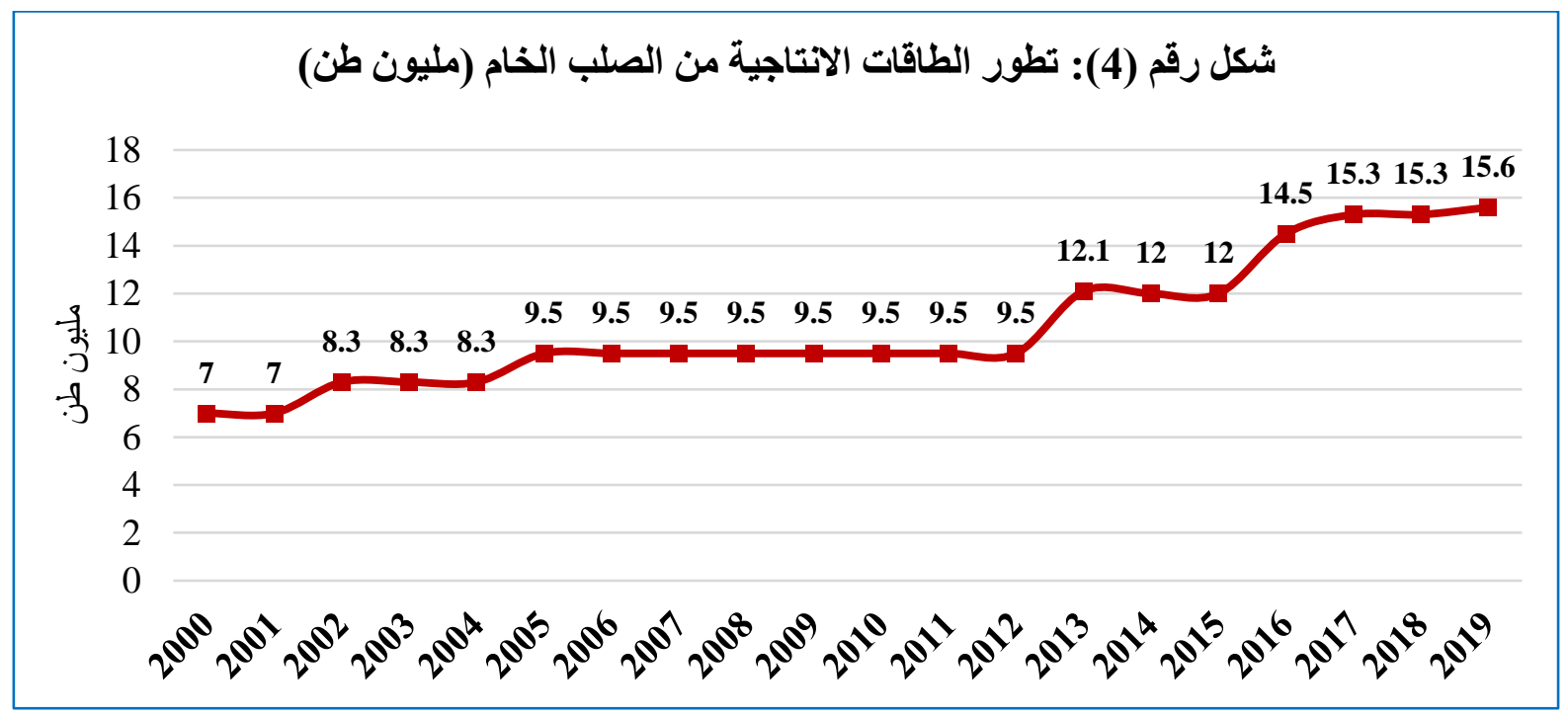

Source: OECD (2020), Steel capacity,

https://stats.oecd.org/Index.aspx?datasetcode=STI STEEL MAKINGCAPACITY

ب- تطور إنتاج الحديد والصلب: تحتل مصر المرتبة الأولى أفريقيا والثانية عربياً بعد المملكة العربية السعودية عام 2019 في إنتاج الصلب الخام. وقد وصل إنتاج مصر من الصلب الخام عام 20197.3 مليون طن بنسبة تر اجع 7\% عن عام 2018. 


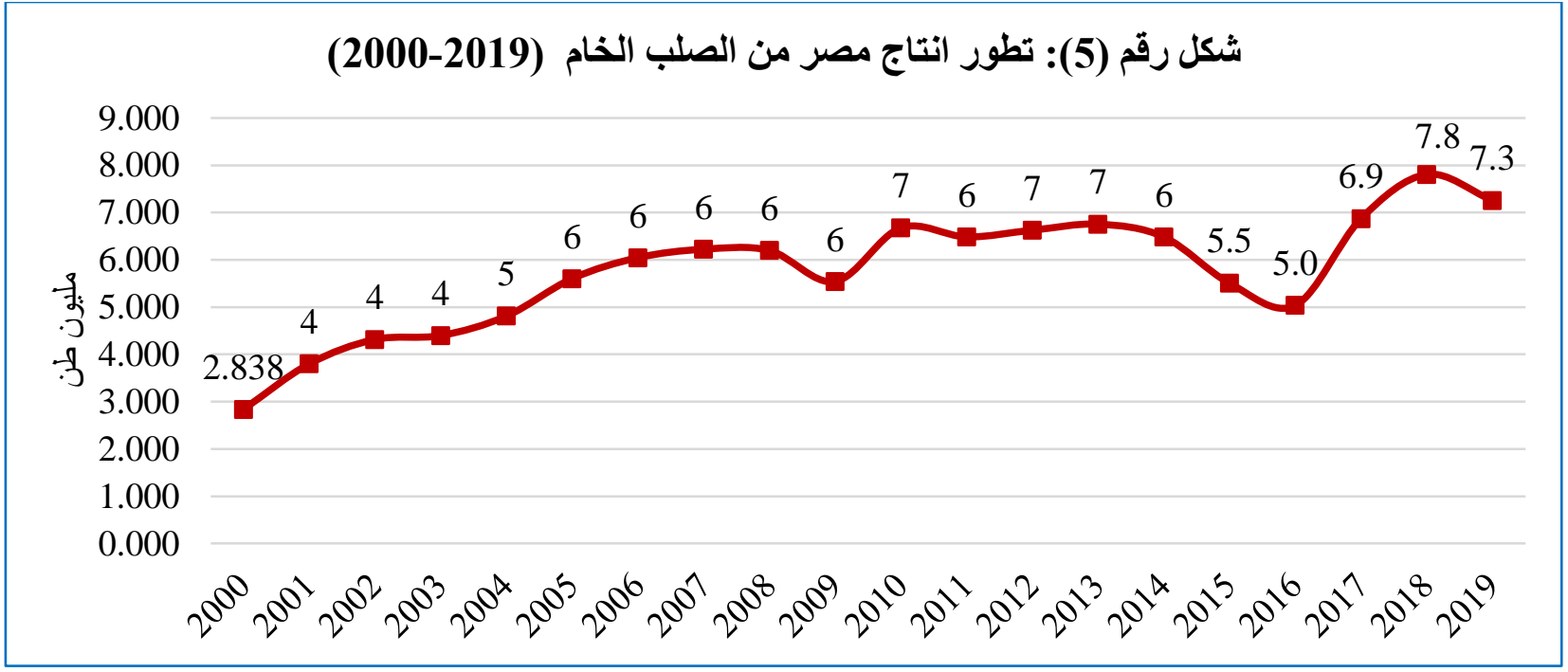

المصدر : منظمة الصلب العالمية

شهر عام 2020 تراجع في إنتاج مصر من حديد التسليح مقارنة بعام 2019 بنسبة تراجع 7.8\%، بسبب انكماش الطلب المحلي. ويمكن تفسير نر اجع الاستهلاك المحلي من حديد التسليح بسبيين رئيسيين: الأول: هو تداعيات تفشى وباء كورونا، والثاني: هو صدور قرار السيد الدكتور رئيس مجلس الوزراء بإيقاف إصدار تر اخيص البناء.

جدول رقم (2): تطور إنتاج حديد التسليح (ألف طن)

\begin{tabular}{|c|c|c|c|c|c|c|c|c|c|c|c|c|}
\hline $\begin{array}{r}\text { التغير } \\
\text { (2019) } \\
\text { (2019) }\end{array}$ & 2020 & 2019 & 2018 & 2017 & 2016 & 2015 & 2014 & 2013 & 2012 & 2011 & 2010 & \\
\hline-7.8 & 6892 & 7475 & 8119 & 7168 & 7043 & 6986 & 7286 & 7353 & 7130 & 6180 & 6568 & إلتناج \\
\hline
\end{tabular}

المصدر : وزارة التموين والتجارة الداخلية. 2021

ج- التجارة الخارجية لمصر من الحديد والصلب: شهد العقدين الأخيرين ارتفاع كبير في و اردات الحديد سجت قيمته 466 مليون دو لار عام 2001 ووصلت إلى 3.6 مليار دو لار أمريكي عام 2019، بمنوسط معدل نمو سنوي مركب 12\%. بينما ارتفعت الصادرات المصرية من منتجات الحديد والصلب من 136 مليون دولار عام 2001 إلى نحو 694 مليون دولار أمريكي عام 2019 بمتوسط معدل نمو سنوي مركب 9\%. ليرتقع العجز التجاري من هذه المنتجات من 330 مليون دولار إلى ما يقرب من 3 مليار دو لار (أنظر شكل رقم 6). كما يلاحظ أيضا إن صناعة الصلب استطاعت في 2007 إن تحقق تو ازن في الميزان التجاري للصلب بمعني أن الصادرات كانت مساوية للواردات وهو امر غير مسبوق. 


$$
\text { شكل رقم (6): تطور التجارة الخارجية لمصر من منتجات الصديا والصلب }
$$

6000

4000

2000

0

$-2000$

$-4000$

$-6000$

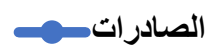

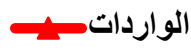

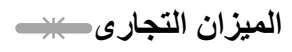

Sources: ITC calculations based on UN COMTRADE statistics.

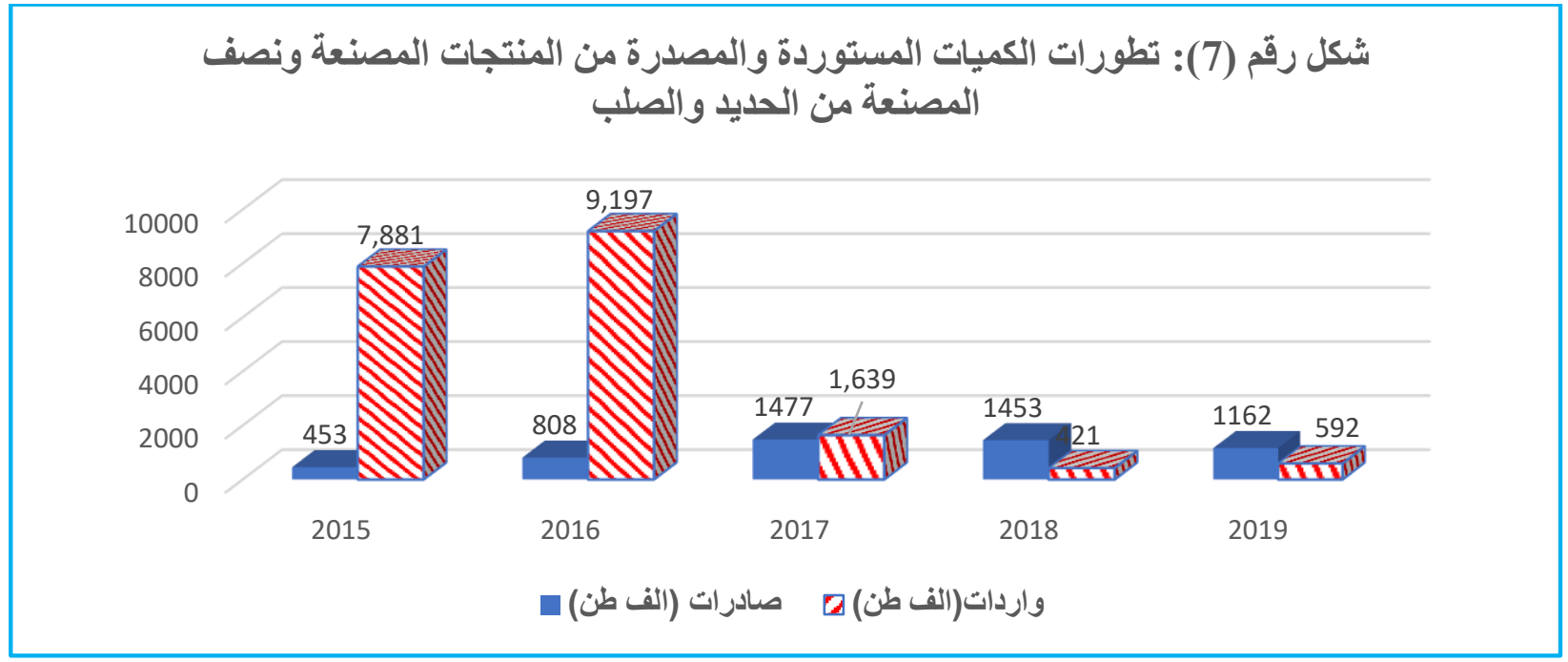

Source: World Steel Association(2021). Steel Statistical Yearbook

وتجدر الإثارة إلى أن ما يقرب من نصف الواردات المصرية من منتجات الحديد عام 2019 يأتي من روسيا (19\%)، تركيا (13\%) وأوكرانيا (13\%) (شكل 8-ب). 30\% من الواردات المصرية من منتجات الحديد و الصلب منتجات نصف جاهزة من الحديد (البيليت). أما الصادرات المصرية من منتجات الحديد و الصلب فأن 30\% منها تتوجه للمملكة العربية السعودية. و 41 من الصادر ات المصرية عام 2019 مسطحات مدرفلة على الساخن (أنظر شكل رقم 8.أ). 


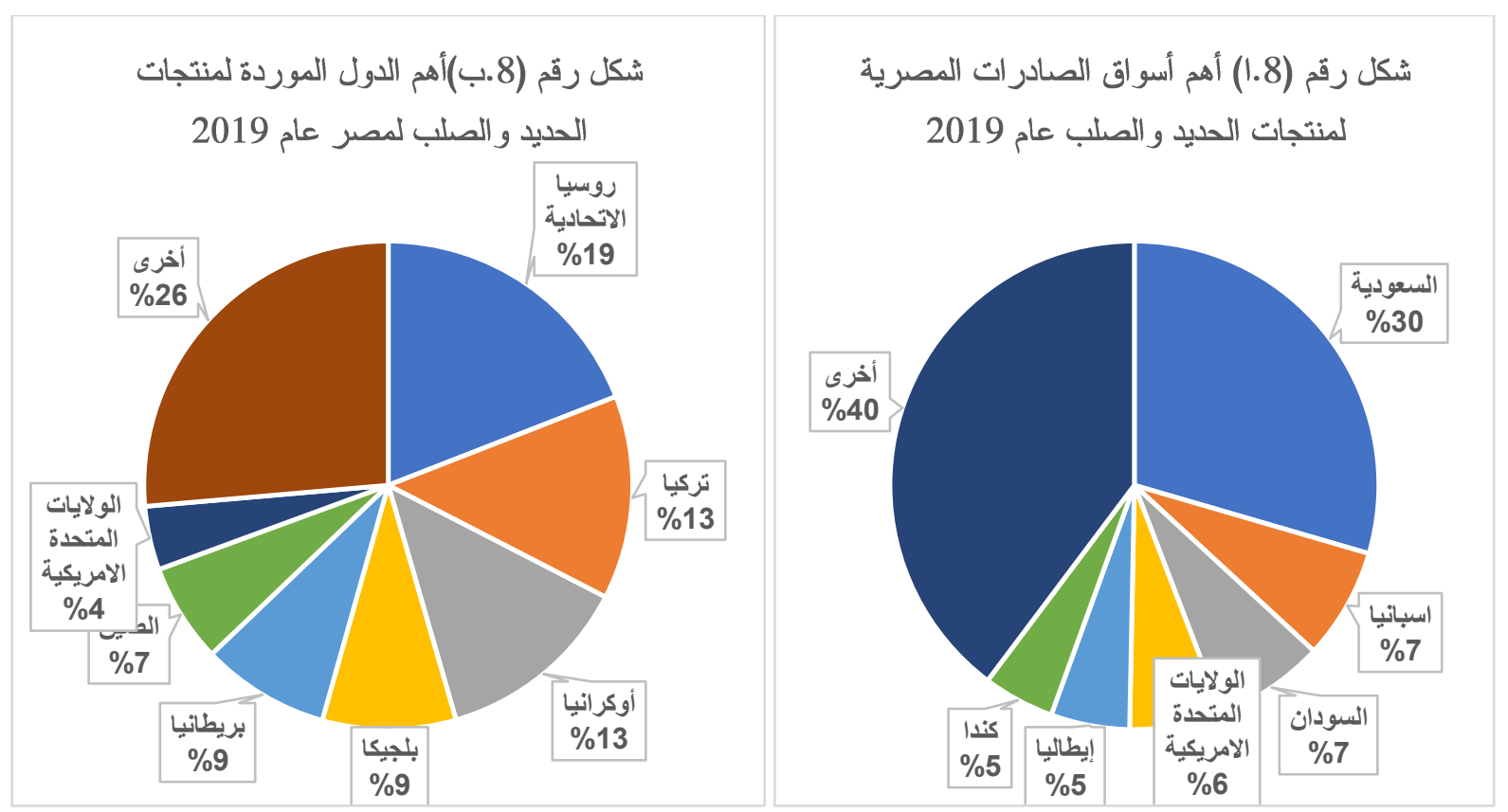

Sources: ITC calculations based on UN COMTRADE statistics.

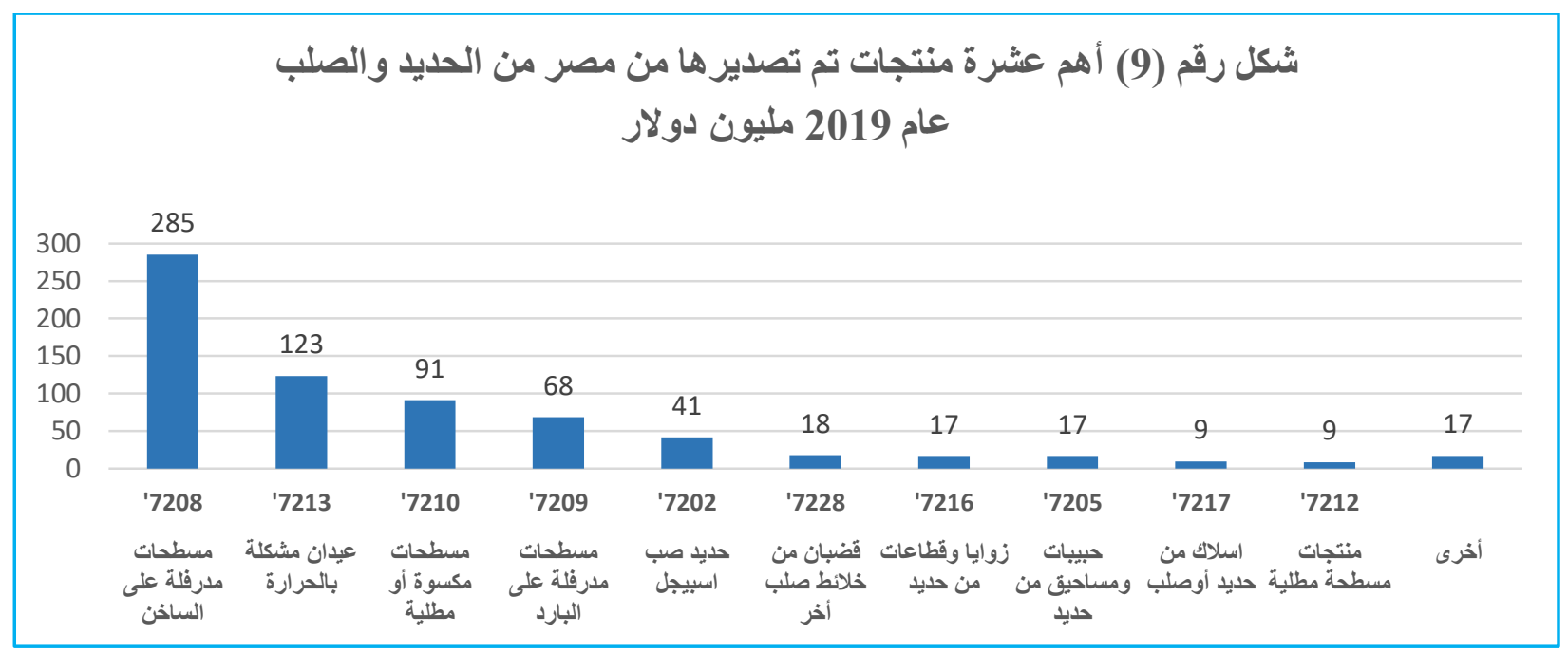

يوضح شكل رقم (6) إن إجمالي قيمة الصادرات المصرية من الحديد والصلب قد بلغ 694 مليون دو لار عام 2019، منها 41\% صادرات مسطحات الصلب الساخنة و23\% مسطحات باردة ومطلية. بينما بلغت نسبة صادر ات حديد التسليح 17.7\%. كما هو موضح بالثكل رقم (9). 


\section{شكل رقم (10): أهم عشرة منتجات مستوردة من الحديد والصلب عام 2019}

مليون دولار

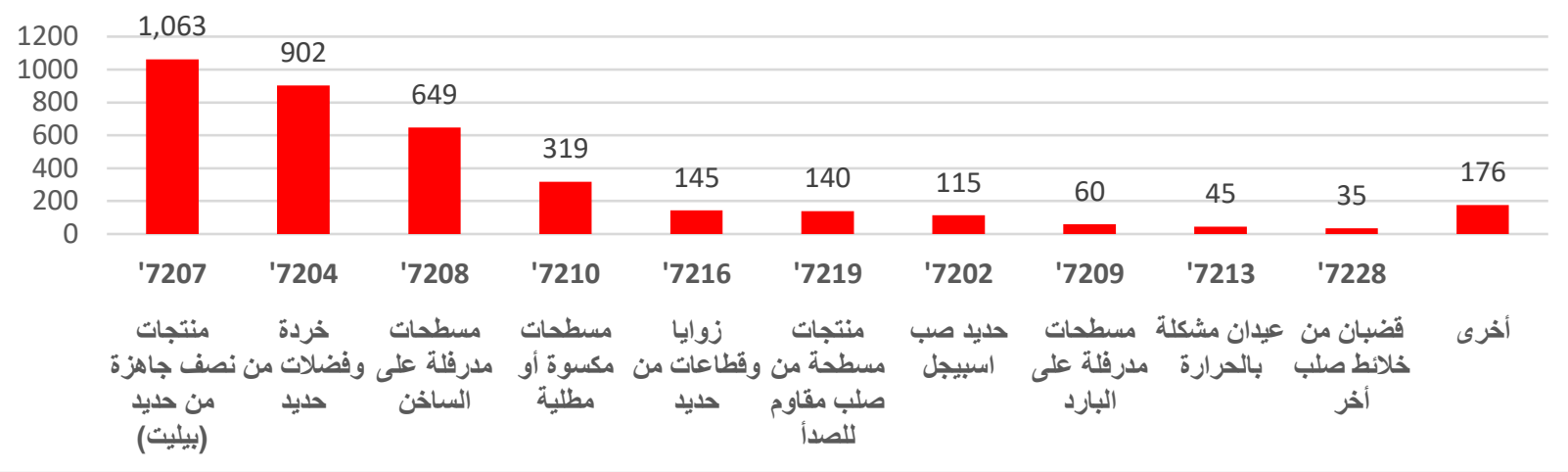

Sources: ITC calculations based on UN COMTRADE statistics.

دـ تحليل أسباب ارتفاع عجز الميزان التجاري للصلب

بلغت قيمة الواردات المصرية من منتجات الحديد والصلب عام 2019 نحو 3.6 مليار دو لار، بلغت نسبة واردات البيلت 30\% من إجمالي فاتورة الواردات المصرية من منتجات الحديد والصلب بينما بلغت نسبة الخردة من الحديد نحو 25\%. وبلغت نسبة واردات مصر من مسطحات الصلب الساخنة نحو 18\%، كما هو موضح من الشكل رقم (10)، وذلك على الرغم من تو افر بديل محلى يكفي لاحتياجات السوق ويفيض ويتم تصديره للخارج مما يدل على وجود ميزة تتافسية للمنتجات المصرية منه بالسوق العالمية. ولكن السبب الرئيسي لاستير اد البيليت و الصلب المسطح هو اتخاذ قرار بفتح أسواق مصر على مصر اعيها أمام منتجات الصلب من كل دول العالم بداية من عام 2008. فأصبحت الرسوم الجمركية المطبقة منذ ذلك التاريخ صفر \% على حديد التسليح، وصفر \% على البيليت (حديد صلب نصف المصنع)، و5\% على منتجات الصلب المسطح، مما يجعل السوق المصرية من أقل الأسواق حماية على مستوى العالم. كما هو موضح من الثكل رقم (10) تستورد مصر صلب مسطح بما قيمته 902 مليون دولار عام 2019، وذلك على الرغم من تو افر بديل محلى يكفي لاحتياجات السوق ويفيض ويتم تصديره للخارج مما يدل على وجود ميزة تنافسية للمنتجات المصرية منه بالسوق العالمية. ولكن يعد السبب الرئيسي لاستير اد الصلب المسطح هو اتخاذ قرار بفتح أسواق مصر على مصر اعيها أمام منتجات الصلب من كل دول العالم بداية من عام 2008. فأصبحت الرسوم الجمركية المطبقة منذ ذلك التاريخ صفر \% على حديد التسليح، وصفر \% على ال (حديد التسليح شبه المصنع)، و5\% على منتجات الصلب المسطح، مما 
يجعل السوق المصرية من أقل الأسواق حماية على مستوى العالم. و الأخير يعد مستوى حماية متدني للصناعة المحلية إذا ما قارنا ذلك بنحو 32.9\% وهو متوسط الحماية الجمركية وغير الجمركية المفروضة في عدد من الدول المنتجة للصلب على وارداتها من مسطحات الصلب. نضف إلى ذلك، قيام

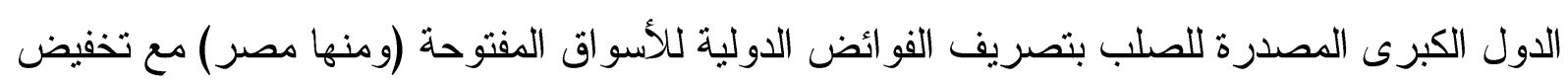
أسعار ها مما أدى إلى انخفاض تكلفة الو اردات بـ 1850 جنيه عن تكلفة الإنتاج المحلي. وهو ما سمح للواردات بالاستحواذ على حصة غالبة من السوق، حيث تصدر الشركات العالمية فوائضها للصر بأسعار تقل عن أسعار بيعها في السوق المحلي، طالما تقوم بتغطية تكاليفها المتغيرة، وجزء من التكلفة الثابتة. وهو ما أدى إلى انخفاض معدل استغلال الطاقات الوطنية إلى 40\% فقط. فالطاقات الإنتاجية الوطنية من الصلب المسطح قادرة على تغطية الاستهلاك المحلي أكثر من مرتين إذا توققت الواردات. ذلك لأن : - - الطاقات الإنتاجية لمسطحات الصلب المدرفلة على الساخن تبلغ 2.9 مليون طن، بينما يبلغ الاستهلاك السنوي 1.3 مليون طن . - الطاقات الإنتاجية لمسطحات الصلب المدرفلة على البارد تبلغ 1.1 مليون طن، سنوياً بينما يبلغ حجم الاستهلاك المحلي 500 ألف طن.

\section{هـ فرص العمل بصناعة الحديد والصلب}

شهدت الفترة (2007-2019) نراجع أعداد المشتغلين بصناعة الحديد والصلب من نحو 44.6 ألف مشتغل عام 2007 إلى 30.6 ألف مشتغل خلال الربع الرابع من عام 2019 بنسبة تراجع 31\%

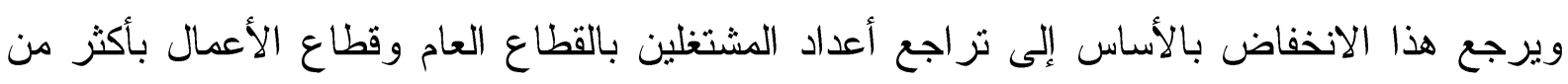
45\% كما تز اجع أعداد المشتخلين بالقطاع الخاص بنسبة 18\% خلال ذات الفترة. وذلك لعدة أسباب بجانب خصخصة شركات قطاع الأعمال العام، أهمها مواجهة صناعة الحديد و الصلب المصرية للعديد من التحديات التي أجبرتها على العمل بأقل من نصف طاقتها الإنتاجية المتاحة. بينما يبلغ عدد المشتغلين بشكل غير مباشر 198 ألف مشتغل يعملون بالقطاعات الأخرى التي تثكل الروابط الأمامية والخلفية بالصناعة كما قدرتها ودر اسة Oxford و التي قدمت للاتحاد العالمي للصلب. 


\section{شكل رقم (11): أعداد المشتظلين بصناعة الحديد والصلب \\ (الف مشتخل) (الفنان)}

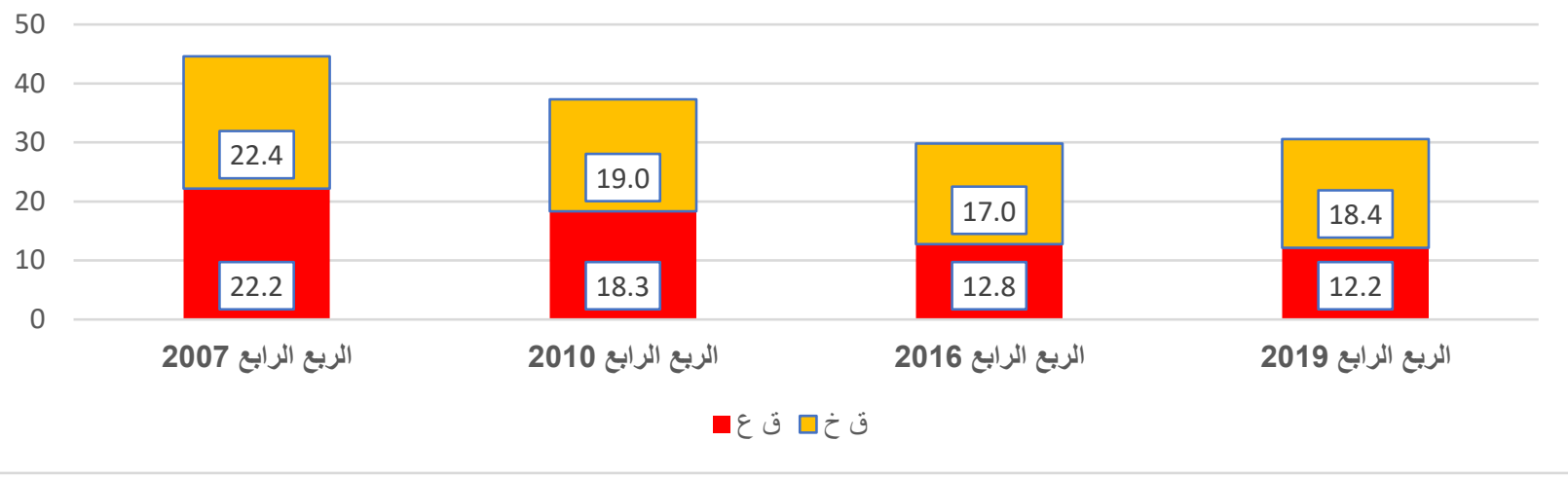

المصدر: الجهاز المركزي للتعبئة العامة والإحصاء، الإحصاء الصناعي السنوي، أعداد متفرقة.

4- التحديات التي تواجه صناعة الحديد والصلب عانت صناعة الحديد و الصلب المصرية من أزمة اقتصادية خانقة منذ نهاية عام 2018 لأسباب متعلقة بالسوق العالمي للحديد و الصلب و أخرى منعلقة بالسوق المحلى. ا- التحديات الدولية فمع بداية نشوب الحرب التجارية التي تزعمتها الولايات المتحدة الأمريكية التي فرضت حزمة من الإجر اءات الحمائية ضد الواردات من منتجات الحديد والصلب من الصين وغيرها من الدول. وردت عليها الصين بإجراءات مماثلة وانتقلت هذه الحرب لكبريات الدول المنتجة للصلب وخاصة الاتحاد الأوروبي الذي فرض رسوم وقائية على واردات الحديد والصلب مع وضع نظام حصص. كل هذه الإجر اءات سو اء تتفق مع قو اعد النظام التجاري العالمي وقو اعد منظمة التجارة العالمية أو لا كان الهدف الأول منها هو حماية الصناعة المحلية للحديد والصلب بهذه الدول. نتج عن هذه الحرب التجارية بين أقطاب التجارة العالمية والتوسع في فرض المعالجات التجارية بأشكالها المختلفة إلى تر اكم مخزون إنتاج كبير من الحديد والصلب يبحث عن أسواق تتخفض فيها الرسوم الجمركية ولا تستخدم المعالجات التجارية. وجاءت قرار ات الأغلاق العالمية (بداية 2020) لمنع تفشى وباء كورونا لتوجه ضربة قاسمة لصناعة الحديد و الصلب العالمية. فقد تراجع النمو الاقتصادي بالاتحاد الأوروبي من 1.9\% عام 2018 إلى 3.3\% عام 2020 وتز اجع النمو الاقتصادي بالو لايات المتحدة الأمريكية من 2.9\% إلى 2\%، وتر اجع النمو الاقتصادي للصين من 6.6\% عام 2018 إلى 5.7\% عام 2020 (OECD, 2020) إلى نز اجع الطلب العالمي على الصلب بنسبة 5\% عام 2020. 


\section{ب- التحديات المحلية}

تو اجه صناعة الحديد والصلب الوطنية العديد من التحديات بعضها يتعلق بجانب العرض ويؤثر على تكاليف الإنتاج ومنها ارتفاع أسعار الطاقة مقارنة بالدول الأخرى المثيلة المنتجة للصلب. وبعضها يتعلق بجانب الطلب منها جمود الطلب المحلى بسبب عدم اعتماد الأحوذة العمر انية وغياب أو ضعف الحماية الجمركية للمنتجات الوطنية أمام المنافسة الشرسة و الممارسات الضارة بالتجارة الدولية.

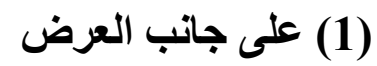
>

الغاز الطبيعي هو "مُخخَ إنتاج" في صناعة الصلب القائمة على نكنولوجيا الاختز ال المباشر، وليس "مصدراً للطاقة". وكان تو افر الغاز الطبيعي سبباً رئيسياً لتوطن صناعة الصلب المتكاملة في مصر. ذلك لعدم توفر أي مدخل إنتاج آخر في مصر لهذه الصناعة (سواء خام حديد، أو فحم، أو خردة) بالكميات أو الجودة، التي تستطيع أن ثقوم عليها صناعة الصلب. على الرغم من قيام الدولة بخفض أسعار توريد الغاز للصناعة في مارس 2020 دن 5.5 دو لار للمليون وحدة حرارية بريطانية إلى 4.5 دو لار للمليون وحدة حرارية، إلا أن صناعة الصلب المصرية كانت تدفع أكثر من ضعف سعر الغاز للصناعة في الو لايات المتحدة وأوروبا والتي ثراجعت لمستويات قياسية مع تداعيات أزمة كورونا. فقد انخفضت أسعار الغاز الطبيعي للصناعة في الولايات المتحدة وأوروبا إلى ما دون الـــ 2 دو لار للمليون وحدة منذ شهر مايو 2020. وقد بدأت الأسعار العالمية للغاز الطبيعي في التعافي خلال النصف الثاني من عام 2020 مع تخفيف حدة قرارات الأغلاق. أدى هذا الارتفاع التدريجي لأسعار الغاز الطبيعي العالمية إلى تحسن نسبي في تتافسية صناعة الصلب المحلية؛ حيث انخفضت الفجوة السعرية بين مصر و العالم الخارجي (انظر شكل رقم 12). 


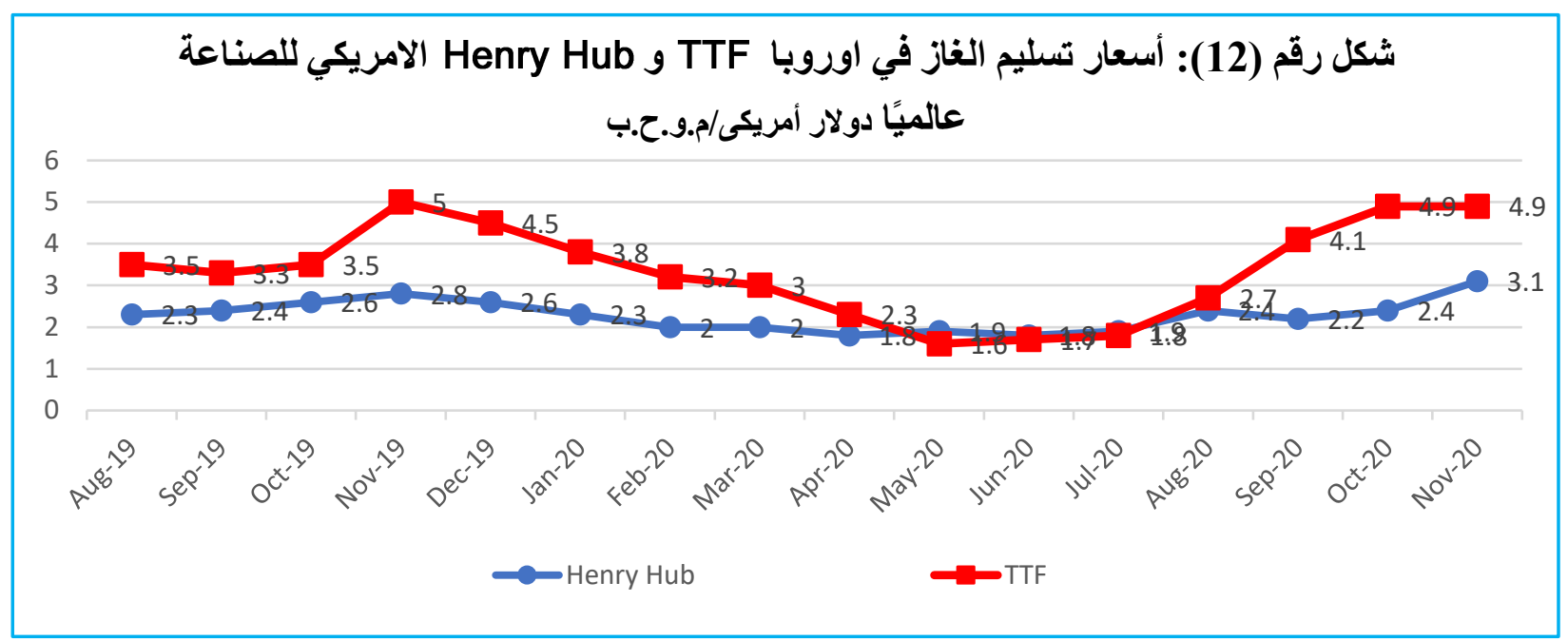

المصدر: وكالة وود ماكينزي(2020)،"تطورات أسواق الغاز العالمية و المصرية" ، الجمعية المصرية لصناعة الحديد و الصلب، ديسمبر.

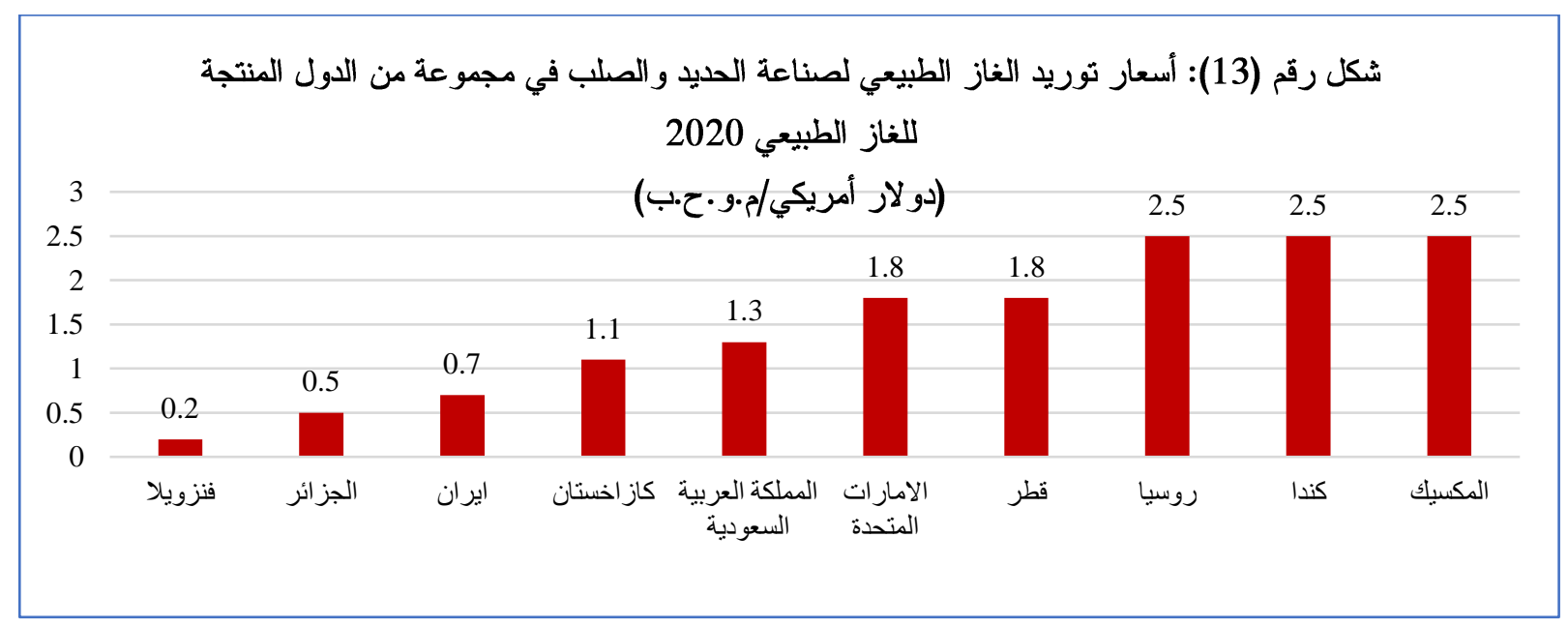

المصدر: وكالة وود ماكينزى (2020)،"تطورات أسواق الغاز العالمية والمصرية"، الجمعية المصرية لصناعة الصيد والصلب، يونية.

و التسليم بارتفاع سعر الغاز الطبيعي خلال الربع الأخير من 2020، فأن سعر بيعه لصناعة الصلب في مجموعة من الدول المتقدمة والنامية ماز ال اقل من بنسبة أكثر من 40\% من سعر الغاز لصناعة الصلب في مصر

إن الارتفاع النسبي لسعر توريد الغاز الطبيعي للصناعة في مصر قد أدى إلى تراجع تتافسية منتجات الحديد المصرية بالسوق المحلية والأسو اق العالمية بنسبة 30\% في عام واحد ليبلغ مؤشر الميزة النسبية 
الظاهرية13 لصادرات مصر من الحديد و الصلب 1.1 عام 2019 مقارنة ب6.1. عام 2018. وهو ما انعكس على الأداء التصديري للمنتجات الوطنية. لذلك طالبت الصناعة المحلية مرارا تخفيض سعر معرد توريد الغاز للصناعة إلى 2.5 دو لار أمريكي للمليون وحدة حرارية بريطانية.

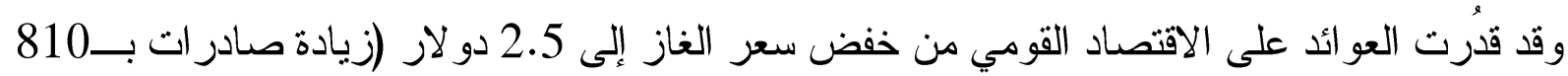
مليون دو لار - خفض الو اردات بـ1 مليار دو لار - زيادة استغلال الطاقات الإتتاجية بـ20 \%) و التي تفوق بكثير الإير ادات المخفضة لقطاع البترول بعد الخفض للسعر المستهد. يقدر الجدول أدناه النتائج المترتبة على الذفض المستهذف لسعر الغاز على معدلات تثغيل الطاقات الإنتاجية، و التصدير، والإحلال محل الواردات، حيث يتبين أن التسعير المستهدف سيوفر الظروف المناسبة لــ: ارتفاع حجم الإنتاج المحلي من الصلب من 9.3 مليون طن إلى 13.1 مليون طن (بنسبة 41\%)، كنتيجة مباشرة لزيادة التتافسية، وتخفيض تكلفة الإنتاج. سيترتب على ذلك ارتفاع قيمة الإنتاج المحلي بـ 38 مليار جنيه، تضاف للناتج المحلي الإجمالي. ارتفاع معدل استغلال الطاقات الإنتاجية من 49\% إلى 70\%. انخفاض فاتورة الواردات بما قيمته 1 مليار دولار (16 مليار جنيه) سنوياً، حيث بحل الإتناج المحلي محل نسبة مهمة من واردات مسطحات الصلب وحديد التسليح. زيادة الصادر ات بمقدار 810 مليون دو لار (13 مليار جنيه)، نتيجة لخفض تكلفة الطن بو اقع 26 دو لار (حيث يستهلك طن المنتج النهائي 13 مليون وحدة)، بالإضافة إلى خفض التكلفة الثابتة مع زيادة الإنتاج. تحول قطاع الصلب من الخسارة إلى الربح، مما يرفع من حصيلة الدولة من ضريبة الأرباح

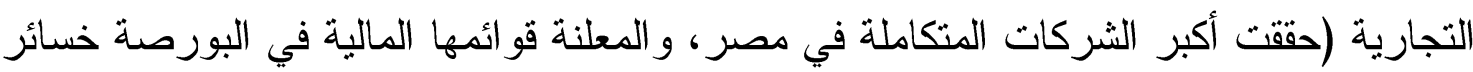
بلغت 2.2 مليار جنيه عام 2019).

13 الميزة النسبية هي مؤشر يستتد إلى مفهوم ريكاردو حول تخصص الدول في منتجات لها مميزات نسبية، ويستخدم في الاقتصاد الدولي لمعرفة

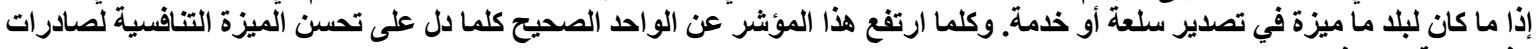
هذه الدولة من هذا المنتج. https://wits.worldbank.org/CountryProfile/en/country/bycountry/startyear/LTST/endyear/LTST/tradeFlow/Export/indicator/RCA/partner/WLD/product/Total 
جذول رقم (3): العائد الاقتصادي لتسعير الغاز عند 2.5 دولار للمليون وحدة

\begin{tabular}{|c|c|c|c|}
\hline 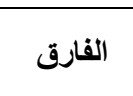 & عند سعر 2.5 & عند سعر 4.5 & \\
\hline 3.8 & 13.1 & 9.3 & إجمالي إنتاج الصلب (بالمليون طن) \\
\hline 1.5 & 9 & 7.5 & حليد تسليح \\
\hline 1.3 & 2.5 & 1.2 & مسطحات الصلب \\
\hline $\mathbf{0}$ & 0.6 & 0.6 & قطاعات \\
\hline 1 & 1 & - & إنتاج يحل محل الواردات \\
\hline $\mathbf{0}$ & 18.8 & 18.8 & إجمالي الطاقات الإنتاجية النهائية (بالمليون طن) \\
\hline$\% 21$ & $\% 70$ & $\% 49$ & معدل استغلال الطاقات الإتتاجية \\
\hline 810 & (2) 1,730 & (1) 920 & قيمة صادرات الصلب ومصنو عاتها (بالمليون دولار) \\
\hline (3) 1000- & 2900 & (1) 3900 & قيمة واردات الصلب ومصنو عاتها (بالمليون دولار) \\
\hline
\end{tabular}

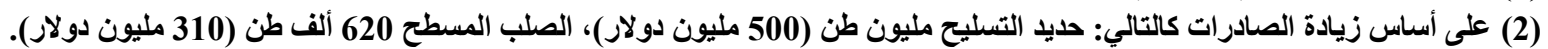

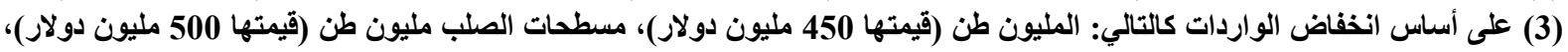
وحديد التسليح 100 ألف طن (50 ملئن التيون دولار)، بإجمالي مليار دولار.

المصدر: قدرت بمعرفة الجمعية المصرية لصناعة الحديد والصلب اعتمادا على بيانات الشركات المنتجة للحديد والصلب والبنك المركزي

المصري.

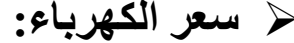

الكهرباء عنصر هام في تكلفة إنتاج الصلب. ففي المصانع شبه المتكاملة، يتم صهر الخردة في أفران القوس الكهربائي، التي تقوم على الطاقة الكهربائية. وفي المصانع المتكاملة، يتم صهر الحديد المختزل لإنتاج صلب سائل أيضاً في أفران الصهر، التي تعتمد على الطاقة الكهربائية. تحقق الصناعات الثقيلة استقر اراً للشبكة القومية للكهرباء خارج ساعات الذروة. لذا، تقوم معظم دول العالم بتقديم معاملة مالية سعرية تفضيلية للصناعات الكثيفة استخدام للطاقة وكبار المستهلكين. فقد قامت العديد من دول الاتحاد الأوروبي، منذ مطلع عام 2020، بخفض أسعار الكهرباء للصناعات الثقيلة بنسب تر اوحت ما بين من 27\%-50\% وذلك كأحد الإجر اعات المتخذة لاعم الصناعات التقيلة لمو اجهة تداعيات كورونا. فقد خفضت أسبانيا، إيطاليا، فرنسا و ألمانيا، على سبيل المثال، أسعار الكهرباء في يونيو 2020 بنسبة 49\%، 51\%، 44\% و 42\% على التو الي مقارنة بنفس الفترة من العام السابق. كما خفضت الو لايات المتحدة الأمريكية أسعار الكهرباء بنسبة 22\% خلال الفترة سالفة الذكر . أما في مصر، فقد تم تخفيض أسعار الكهرباء في مارس 2020 بمقدار 10 قروش أي حوالي واحد سنت/ يورو للكيلو و ات ساعة ليصل السعر إلى 105 قرش/ك.و .س (أي ما يعادل 5.5 سنت/يورو) ارتفعت أسعار الكهرباء للجهد الفائق لكبار المستهلكين الأوروبيين في الربع الثالث من العام 2020 مقارنة بالفترة السابقة وفقاً لتقرير مركز IHS Markit ، مع ثبات أسعار توريد الكهرباء للصناعة في مصر لتزر اوح ما بين 105 قرش - 115 قرش للكيلو وات ساعة على حسب نوعية الجهذ (فائق -عالي 
متوسط) أي ما يعادل (5.52 -6.05 سنت يورو / كيلو وات) بما أدى إلى تضيق فجوة الأسعار ما بين أسعار الكهرباء الموردة للمصانع في مصر و أسعار ها في دول الاتحاد الأوروبي؛ وان كانت أسعار الكهرباء ماز الت في صالح دول الاتحاد الأوروبي (أنظر جدول رقم 4 ). ولرفع تتافسية المنتج المصري من الحديد و الصلب يجب أن يتم خفض أسعار توريد الكهرباء للصناعة على الأقل بـ30 قرش للكيلو و ات ساعة

جدول رقم (4): أسعار الكهرباء لكبار المستهلكين بعدد من الدول الكبرى

(سنت يورو/ كيلو وات ساعة)

\begin{tabular}{|c|c|c|c|c|}
\hline الريع الرابع -2020 & الريع الثالث -2020 & الريع الثاني -2020 & الربع الأول -2020 & \\
\hline 3.1 & 2.38 & 2.03 & 2.66 & ألمانيا \\
\hline 3.13 & 2.48 & 1.8 & 2.94 & فرنسا \\
\hline 3.08 & 2.36 & 2.09 & 3.05 & هولندا \\
\hline 3.29 & 2.42 & 2.48 & 3.96 & إيطاليا \\
\hline 3.36 & 2.41 & 2.32 & 3.49 & إسبانيا \\
\hline 3.55 & 2.61 & 2.74 & 3.8 & المملكة المتحدة \\
\hline 3.11 & 2.41 & 1.85 & 3.01 & بلجيكا \\
\hline 3.37 & 2.42 & 2.32 & 3.49 & البرتغال \\
\hline 3.65 & 2.74 & 2.58 & 3.66 & إيرلندا \\
\hline 3.85 & 3.84 & 4.01 & 4.06 & بولندا \\
\hline 3.25 & 2.65 & 2.12 & 3.26 & التثيك \\
\hline 3.57 & 3.19 & 2.63 & 4.09 & المجر \\
\hline 0.84 & 1.29 & 0.56 & 1.54 & Nord Pool \\
\hline 3.2 & 2.6 & 2.3 & 3.3 & المتوسط الأوروبي \\
\hline 3.16 & 2.39 & 2.08 & 3.15 & أستراليا \\
\hline 2.69 & 1.99 & 1.67 & 1.99 & أمريكا الثمالية \\
\hline 3.1 & 2.5 & 2.2 & 3.2 & متوسط عدد من الدول المتقدمة \\
\hline 5.5 & 5.5 & 5.5 & 5.5 & مصر \\
\hline
\end{tabular}

المصدر: تقرير مؤسسة IHS Markit، مايو ·.r.r. Nord Pool نورد بو بورصة كهرباء أوربية، تثولى تجارة الكهرباء في 14

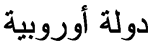

من المتوقع أن يؤدى خفض سعر توريد الغاز للصناعة من 4.5 دولار أمريكي/م.و.ح.ب إلى 2.5

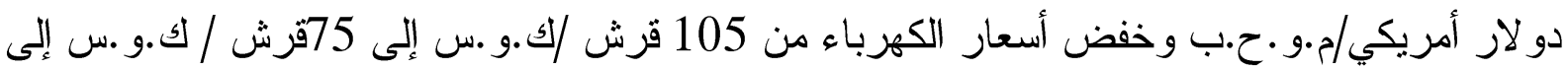
زيادة حجم الإنتاج المحلي من الصلب من 9.3 مليون طن عام2019 إلى 13.1 مليون طن بمقدار

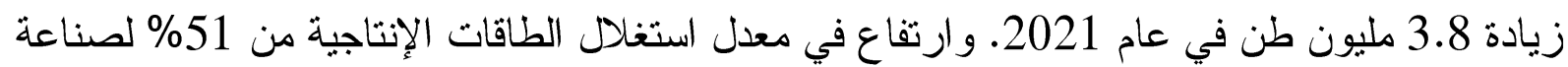
حديد التسليح و 41\% لصناعة مسطحات الصلب إلى 70\% لكل منهما (انظر جدول رقم 5) 
جدول رقم (5): تكلفة خفض أسعار الطاقة لمصانع الحديد والصلب الوطنية:

(عند التثغيل بمعدل 70\% من الطاقة الإنتاجية)

بالمليون جنيه مصري

\begin{tabular}{|c|c|c|c|c|}
\hline الإجمالي & مصانع الدرفلة & المصانع شبه المتكاملة & المصانع المتكاملة & \\
\hline 18.8 & 3.3 & 3.7 & 11.8 & الطاقة الإنتاجية للإنتاج النهائي (بالمليون طن) \\
\hline 15.1 & 3.3 & 2.9 & 8.9 & ـ حديد التسليح \\
\hline 2.9 & $\mathbf{0}$ & $\mathbf{0}$ & 2.9 & 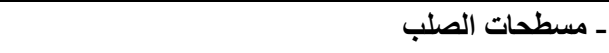 \\
\hline 0.8 & $\mathbf{0}$ & 0.8 & $\mathbf{0}$ & ـ ق قطاعات الصلب \\
\hline \multirow[t]{5}{*}{13.2} & 2.3 & 2.6 & 8.3 & حجم الإنتاج عند معدل 70\% استغلال للطاقة الإتتاجية \\
\hline & 100 & 100 & 850 & استهلاك الطن من الكهرباء(ك.و.س) \\
\hline & 105 & 105 & 893 & 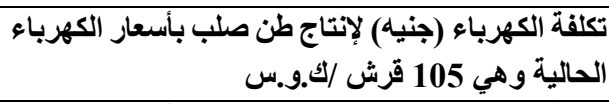 \\
\hline & 79 & 79 & 669 & 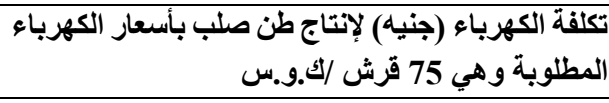 \\
\hline & 26 & 26 & 223 & الفارق في تكلفة الكهرباء اللازمة لإنتاج طن الحديد \\
\hline 1393 & 43 & 48 & 1302 & فارق الإتتاجية المستفة وصلب (الكهرباء (مليون جنيه) لإنتاج 9.3 مليونة الحالي دون تحسن الطاقة \\
\hline \multirow[t]{6}{*}{1978} & 61 & 68 & 1849 & 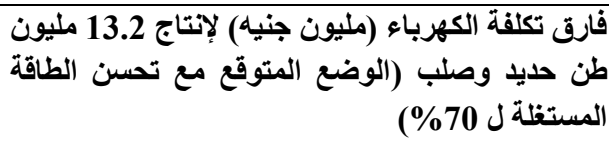 \\
\hline & 1 & 1 & 13 & استهلاك الطن من الغاز (مليون وحدة حرارية) \\
\hline & 4.5 & 4.5 & 58.5 & 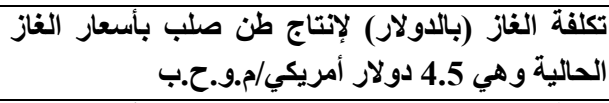 \\
\hline & 2.5 & 2.5 & 32.5 & المطلوبة وهي 2.5 دولار أمريكي/م.و.ح.ب بازب بأسعار الغاز \\
\hline & 2 & 2 & 26 & الحديد في تكلفة الغاز(بالدولار) اللازمة لإنتاج طن \\
\hline & 32 & 32 & 416 & الحديد في تكلفة الغاز(بالجنيه) اللازمة لإنتاج طن \\
\hline 2539 & 52 & 59 & 2428 & 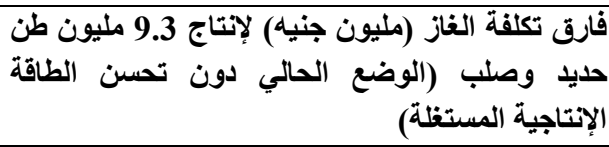 \\
\hline 3604 & 74 & 83 & 3447 & 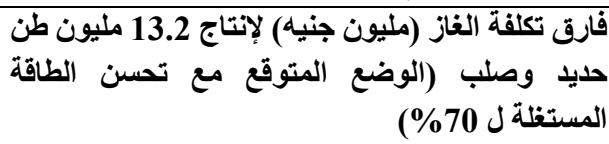 \\
\hline
\end{tabular}

المصادر : تم تقديرها بناء على:

- بيانات الشركات المنتجة للحديد والصلب الأعضاء بالجمعية

- الهيئة المصرية العامة للرقابة على الصادرات و الواردات.

> عدم توافر الحماية الكافية للصناعة المحلية

شهد عام 2018 قيام العديد من الدول بفرض إجراءات حمائية إضافية على وارداتها من الصلب. ففي مارس 2018 فرضت الولايات المتحدة رسوم جمركية بنسبة 25\% على واردات الصلب تامة الصنع، وشبه المصنعة (البيليت)، من كافة دول العالم باستثناء المكسيك وكندا. رداً على ذلك، فرضت 
الصين كل و ارداتها من الحديد و الصلب بكافة أنو اعه من الو لايات المتحدة الأمريكية 25\%. ثم توالت عدوى الإجر اءات الحمائية، فقامت دول الاتحاد الأوروبي بفرض رسوم وقائية على واردات الصلب من الخارج بنسبة 25\% بعد تجاوز حصة معينة. تلا ذلك فرض تركيا وكندا رسوم 25٪. وتختلف الرسوم الحمائية عن المعالجات التجارية. فالأولى هي رسوم تتم خارج إطار منظمة التجارة العالمية. أما رسوم المعالجات التجارية (مكافحة الإغراق، والدعم والإجر اءات الوقائية) هي علاجاً

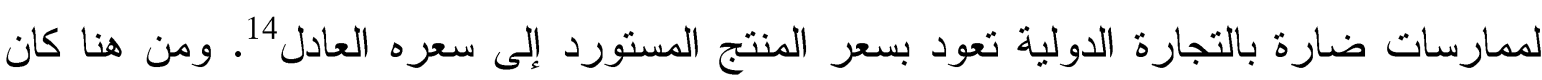
منطق تسميتها بــ "معالجات تجارية". فهذه الرسوم لا تمنع الأستير اد مثل الرسوم الحمائية، و إنما كل ما تفعله هو الوصول بسعر الواردات، التي تأتي بأسعار لا تعبر عن تكلفتها، إلى أسعار ها العادلة.

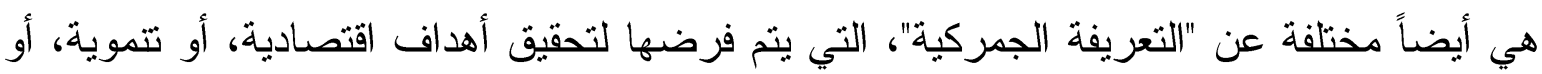
صناعية لدولة ما في فترة معينة. المعالجات التجارية تتعامل فقط مع ممارسات ضارة من منتجين دوليين، و لا ترتبط بخطط الدولة الاقتصادية و التتموية. نتج عن فرض رسوم حمائية في 2019 وجود 90 مليون طن منتجات صلب تبحث عن أسو اق بديلة. وبالتالي تم إغراق أسواق الدول الأقل حماية بواردات صلب، خاصة واردات الصلب شبه المصنعة كالبيليت. فمع عجز بعض الدول عن تصريف منتجاتها تامة الصنع، يقوم المنتِج الأجنبي بوقف الإنتاج في المرحلة الرابعة (مرحلة الدرفلة الأقل كلفة وقيمة مضافة)، ويصدر المنتَج شبه المُصنَّع، تجنباً لاعاوى إغراق ضد المنتجات تامة الصنع. أما في مصر فمنذ عام 2008، أصبحت الرسوم الجمركية المطبقة على واردات مصر من حديد التسليح وال(حديد التسليح شبه المصنع) صفر \%، و5\% على منتجات الصلب المسطح، مما جعل السوق المصرية من أقل الأسواق حماية على مسنوى العالم وبالتالي أصبحت أحد أهم الأسواق المستهدفة من الدول الكبرى المصدرة لمنتجات الحديد والصلب. وهو ما نتج عنه زيادة هائلة في و اردات مصر من الصلب، من 917 ألف طن عام 2017 إلى حوالي 1.6 مليون طن عام 2018. بنسبة زيادة 74\% في عام واحد، جعلت مصر خامس أكبر مستورد للبليت في العالم، وهو ما دعا وزارة التجارة والصناعة إلى فرض رسوم وقائية على البيليت وحديد النسليح في أكتوبر 2019. 
حيث و افقت الحكومة على فرض رسوم بنسبة 16 \% على ال المستورد في الفترة من 12 أكتوبر 2019 حتى أبريل 2020 بحد أدنى 74 دو لار اللطن، على أن تتخفض الرسوم المفروضة إلى 13 \% خلا الفترة من 12 أبريل 2020 إلى 11 أبريل 2021 بحد أدنى 60 دو لار ا للطن، ومن 12 أبريل 2021 إلى 11 أبريل 2022 تتخفض الرسوم إلى 10 \% بحد أدنى 46 دو لار ا للطن، كما نم فرض رسوم على حديد التسليح المستورد لأغر اض البناء 》عيدان وقضبان من حديد أو من صلب من غير الخلائط مشكلة بالأسطو انات مدرفلة بالدرارة في شكل لفائف أو قضبانه، بنسبة 25 \% خلال الفترة من 12 أكتوبر 2019 إلى 11 أبريل 2020 بحد أدنى 125 دو لار ا للطن، على أن تتخفض الرسوم إلى 21 \% بالفترة من 12 أبريل 2020 إلى 11 أبريل 2021 بحد أدنى 105 دو لارات للطن، وتتخفض إلى 17 \% من 12 أبريل 2021 إلى 12 أبريل 2022 بحد أدنى 85

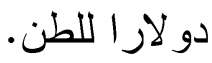

(بند جمركي 7207)

\begin{tabular}{|c|c|c|c|c|}
\hline إجمالي الرسوم الجمركية & الرسوم الوقائية & رسوم الإغراق & الرسوم الجمركية & الاولة \\
\hline$\% 25.00$ & $\% 25.00$ & $\% 0.00$ & $\% 0.00$ & الولايات المتحدة \\
\hline$\% 13.90$ & $\% 0.00$ & $\% 0.00$ & $\% 13.90$ & تركيا \\
\hline$\% 35.00$ & $\% 0.00$ & $\% 24.00$ & $\% 11.00$ & باكستان \\
\hline$\% 23.80$ & $\% 15.30$ & $\% 0.00$ & $\% 8.50$ & فيتنام \\
\hline$\% 20.00$ & $\% 0.00$ & $\% 0.00$ & $\% 20.00$ & تونس \\
\hline$\% 11.10$ & $\% 0.00$ & $\% 0.00$ & $\% 11.10$ & الجزائر \\
\hline$\% 12.00$ & $\% 0.00$ & $\% 0.00$ & $\% 12.00$ & السعودية \\
\hline$\% 20.00$ & $\% 0.00$ & $\% 0.00$ & $\% 20.00$ & أنجولا \\
\hline$\% 13.10$ & $\% 0.00$ & $\% 0.00$ & $\% 13.10$ & زيمبابوي \\
\hline$\% 26.00$ & $\% 0.00$ & $\% 0.00$ & $\% 26.00$ & جيبوتي \\
\hline$\% 15.00$ & $\% 0.00$ & $\% 0.00$ & $\% 15.00$ & الهند \\
\hline$\% 10.00$ & $\% 0.00$ & $\% 0.00$ & $\% 10.00$ & جنوب أفريقيا \\
\hline$\% 18.74$ & \multicolumn{4}{|c|}{ المتوسط } \\
\hline$\% 13.00$ & $\% 13.00$ & $\% 0.00$ & $\% 0.00$ & مصر \\
\hline
\end{tabular}

جدول رقم (6) الرسوم الجمركية المفروضة على واردات البيليت

المصدر: منظمة التجارة العالمية (WWw.Wto.org) 
جدول رقم (7) متوسط الرسوم الجمركية المطبقة في عينة من دول العالم على مسطحات الصلب

\begin{tabular}{|c|c|c|c|c|}
\hline إجمالي الرسوم الجمركية & الرسوم الوقائية & رسوم الإغراق & الرسوم الجمركية الثابتة & الدولة \\
\hline$\% 71.00$ & $\% 25.00$ & $\% 46.00$ & $\% 0.00$ & الولايات المتحدة \\
\hline$\% 57.00$ & $\% 25.00$ & $\% 32.00$ & $\% 0.00$ & الاتحاد الأوروبي \\
\hline$\% 43.30$ & $\% 0.00$ & $\% 20.00$ & $\% 23.30$ & تركيا \\
\hline$\% 53.80$ & $\% 0.00$ & $\% 42.00$ & $\% 11.80$ & البرازيل \\
\hline$\% 77.00$ & $\% 0.00$ & $\% 77.00$ & $\% 0.00$ & كندا كنا \\
\hline$\% 55.00$ & $\% 0.00$ & $\% 40.00$ & $\% 15.00$ & المكسيك \\
\hline$\% 47.40$ & $\% 0.00$ & $\% 42.00$ & $\% 5.40$ & الصين \\
\hline$\% 18.00$ & $\% 0.00$ & $\% 0.00$ & $\% 10.00$ & جنوب أفريقيا \\
\hline$\% 10.00$ & $\% 0.00$ & $\% 0.00$ & $\% 10.00$ & الهند \\
\hline$\% 26.00$ & $\% 0.00$ & $\% 21.00$ & $\% 5.00$ & ت تايلاند \\
\hline$\% 15.00$ & $\% 0.00$ & $\% 0.00$ & $\% 15.00$ & إندونيسيا \\
\hline$\% 15.50$ & $\% 0.00$ & $\% 0.00$ & $\% 15.50$ & باكستان \\
\hline$\% 15.00$ & $\% 0.00$ & $\% 0.00$ & $\% 15.00$ & الجزائر \\
\hline$\% 15.00$ & $\% 0.00$ & $\% 0.00$ & $\% 15.00$ & ماليزيا \\
\hline$\% 11.80$ & $\% 0.00$ & $\% 0.00$ & $\% 11.80$ & فنزويلا \\
\hline$\% 35.00$ & $\% 25.00$ & $\% 0.00$ & $\% 10.00$ & المغرب \\
\hline$\% 15.00$ & $\% 0.00$ & $\% 0.00$ & $\% 15.00$ & السعودية \\
\hline$\% 11.60$ & $\% 0.00$ & $\% 0.00$ & $\% 11.60$ & الأرجنتين \\
\hline$\% 32.91$ & \multicolumn{4}{|c|}{ المتوسط } \\
\hline$\% 5.00$ & $\% 0.00$ & $\% 0.00$ & $\% 5.00$ & مصر \\
\hline
\end{tabular}

(www.wto.org) المصدر: منظمة التجارة العالمية

أن الرسوم الجمركية على الصلب المسطح في مصر (5\%) تتضاءل أمام الرسوم المطبقة في الدول الأخرى جدول (7)، فهي تبلغ في المتوسط 71\% في أمريكا، و57\% في دول الاتحاد الأوروبي (27 دولة)، و 35\% في المغرب، و43.3\% في نركيا، و 15\% في السعودية و الجزائر • يبلغ المنوسط العام لتلك الرسوم، وفقاً لمنظمة التجارة العالمية 32.9\%. يتضح مما سبق ضعف الحماية الجمركية للصناعة المحلية التي أدت إلى ارتفاع فاتورة الواردات المصرية ونزاجع حصة المصانع الوطنية من السوق المصري. لذلك ثتطلع الصناعة الوطنية للحديد والصلب إلى فرض 20\% رسوم جمركية ثابتة على واردات المسطحات و 15\% على واردات وحديد التسليح. فحين فرضت مصر رسوم وقائية متتاقصة في أكتوبر 2019 على واردات البيليت قدرها 16\%؛ استبعدت وز ارة الصناعة واردات الصلب المسطح من فرض الرسوم الوقائية رغم أنها أهم منتج بالتجارة الدولية للصلب. فقد نتج عن ضعف الحماية الجمركية لصناعة الحديد و الصلب الوطنية وخاصة مسطحات الصلب، إن تتامت واردات الصلب المسطح بصورة كبيرة، لتصل في النصف الأول من عام 2020 إلى 296 ألف طن مقارنة ب 165.8 ألف طن في نفس الفترة من عام 2019، ذلك بنسبة زيادة 56\%. وبالتالي 
أصبحت واردات الصلب المسطح تستحوذ على حصة سوقية وصلت إلى 56\% من إجمالي الاستهلاك المحلي. وذللك على الرغم من نو افر طاقات إنتاجية وطنية قادرة على تغطية احتياجات السوق المحلى مرتين وتفيض. الأمر الذي وصل بمعدل استغلال الطاقات الوطنبة للصلب المسطح إلى ما لا يتجاوز 40 فقط. فالوضع القائم يعرض الصناعة الوطنية لمخاطر جمة وخسارة أسواقها المحلية لصالح المنتجات الأجنبية.

و السؤال الذي بطرح نفسه حالياً: هو كيف تثبنى الدولة سياسات التعميق الصناعي وهدف مضاعفة الصادرات والحد من الواردات لمواجهة العجز المزمن في الميزان التجاري ونترك السوق المحلية مكشوفة بدون حماية كافيه أمام تدفق واردات الصلب وذلك بالرغم من تو افر الطاقات الإتتاجية الوطنية القادرة على تغطية الطلب المحلى والتصدير؟

\section{> رسوم مرور في قناة السويس كعنصر تكلفة إضافي}

كانت دعوة الحكومات المتتالية منذ نسعينات القرن السابق لإعادة توطين الأنشطة الصناعية وتوجيهها نحو مناطق جديدة سببا في نشأة عدة مصانع للصلب بمنطقة شمال غرب خليج السويس. تحقيقاً للاستر اتيجية العامة للاولة. ولكن التوطن في هذه المنطقة كان له أثار سلبية على هيكل تكاليف الإنتاج

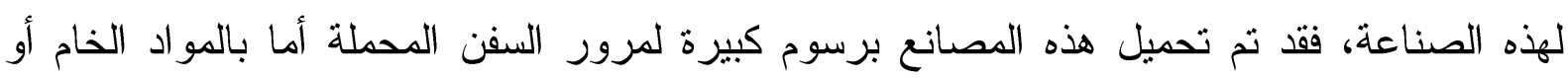

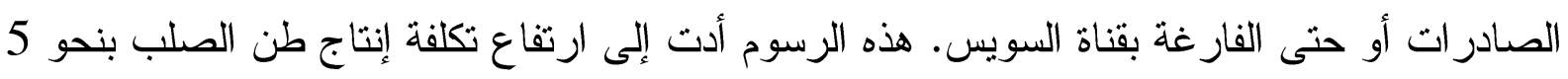

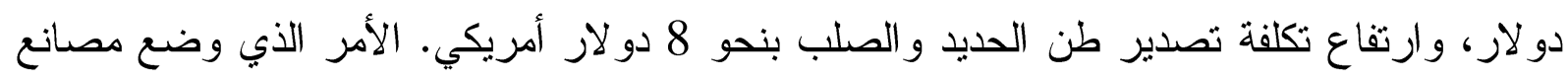
الحديد والصلب المنوطنة بمنطقة شمال وغرب خليج السويس في موقف غير تتافسي سواء مقارنة

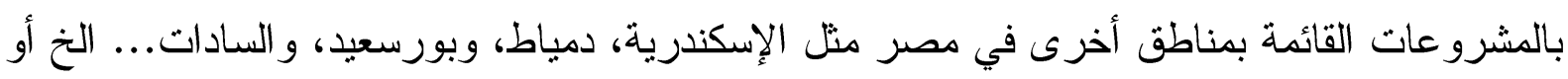
على المسنوى الإقليمي مع دول مثل تركيا، الأمارات، السعودية، قطر، و الجزائر. وهو ما أضطر

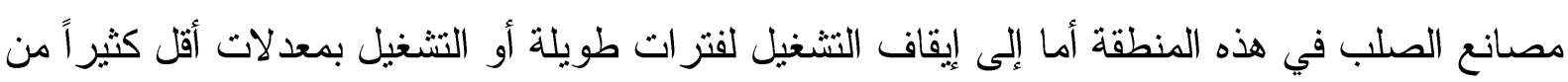
الطاقة الإنتاجية.

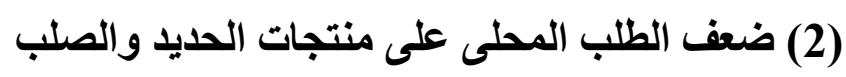
منذ عام 2009، هناك شبه ثبات، بل و انخفاض، في حجم سوق حديد التسليح في مصر • بلغ إجمالي الاستهلاك عام 2009 وفقاً للبيانات الرسمية الصادرة عن الهيئة العامة للرقابة على الصادر ات و الواردات 8.572 مليون طن، في حين بلغ عام 2019 إجمالي 7.433 مليون طن. بلغ متوسط معدل الانكماش 
في هذه الفترة (-1.4\%) سنوياً، وهو معدل حنماً سيتز ايد عام 2020، بفعل الانكماش الحادث بالفعل في النصف الأول من عام 2020 (شكل 14).

\section{شكل رقم (14): الاستهلاك السنوي لحديد التسليح (بالألف طن)}

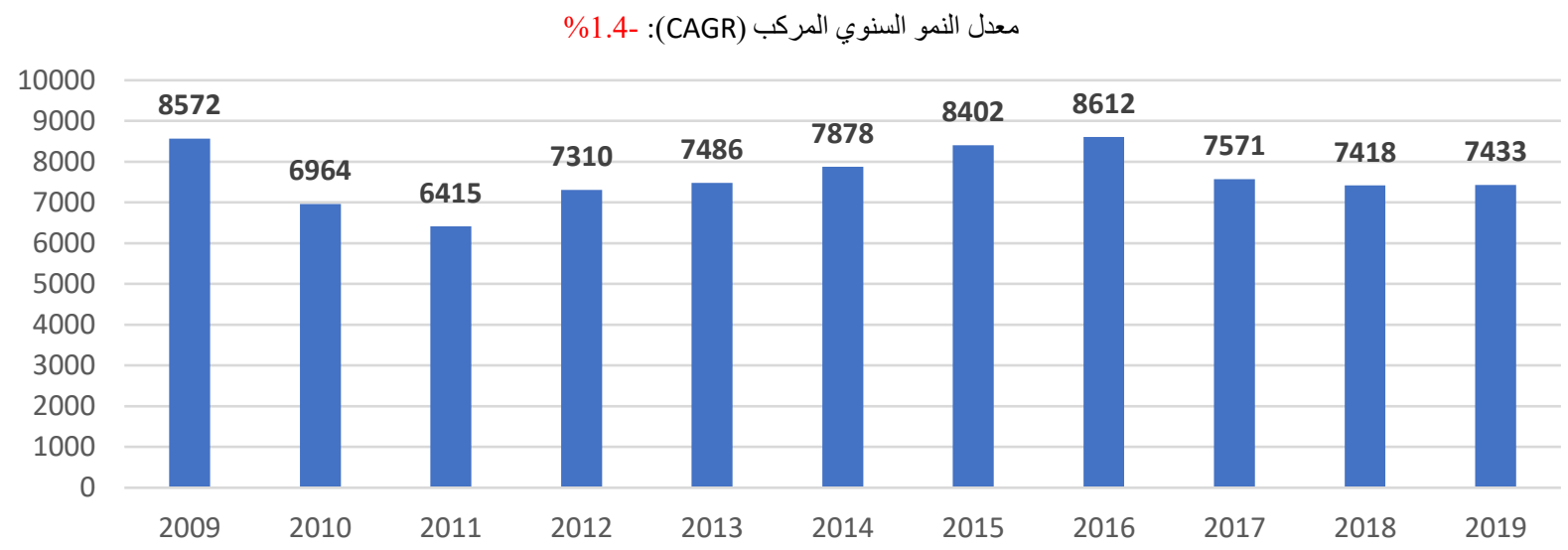

المصدر: وزارة التموين والتجارة الاخلية، الهيئة العامة للرقابة على الصادرات والواردات.

شكل رقم (15): الاستهلاك السنوي لمسطحات الصلب المدرفلة على الساخن

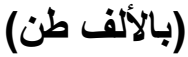

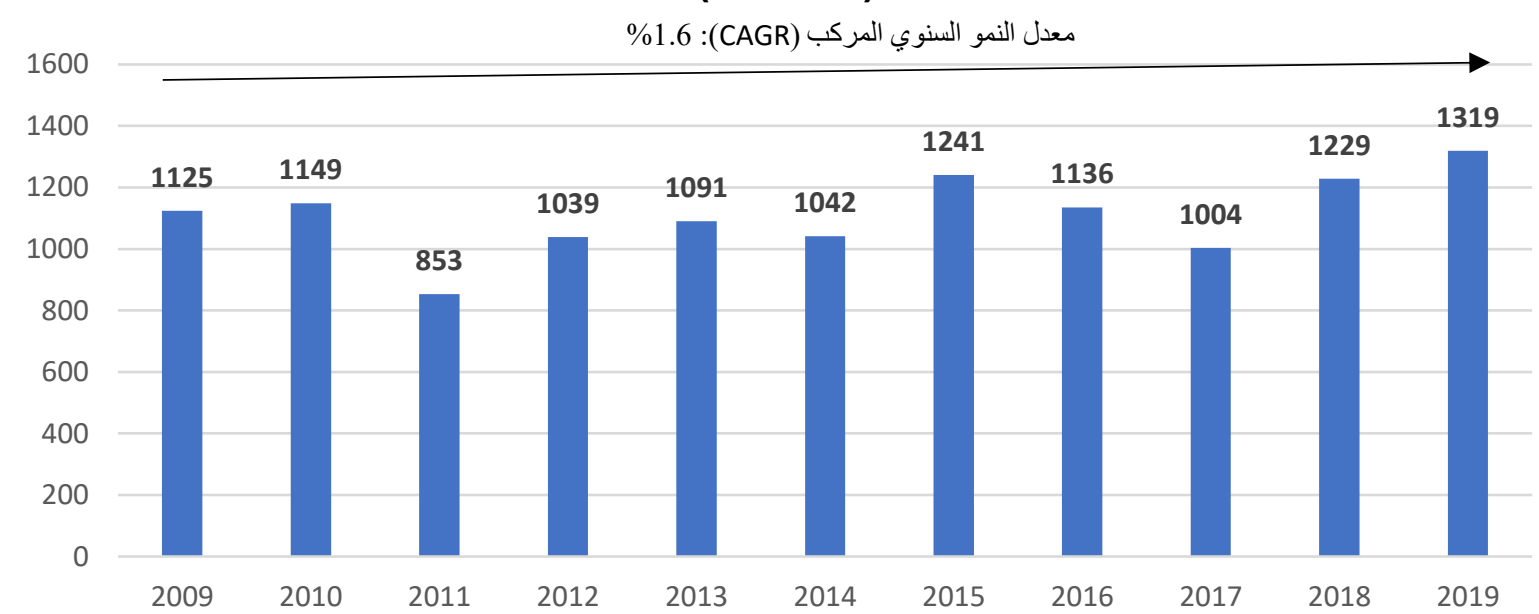

المصدر: وزارة التموين والتجارة الاخلية، الهيئة العامة للرقابة على الصادرات والواردات.

فاذا كان استهلاك حديد التسليح ينمو بالمعدلات الطبيعية (5\% سنوياً) لكان حجم السوق الآن 14 مليون طن. ولكن الواقع هو أن النمو في استهلالك حديد التسليح ومسطحات الصلب في العشر سنوات الماضية كان بأقل من معدلات النمو في الناتج المحلي الإجمالي (شكل 15)، في وضع غريب على أي اقتصاد

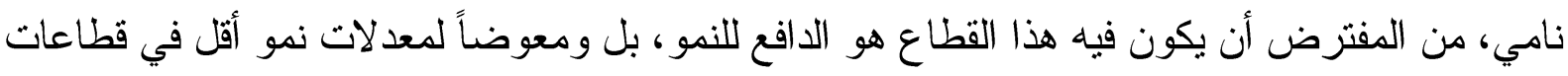
أخرى. أحد الأسباب الرئيسية ور اء هذا الانكماش هو انخفاض استثمار ات القطاع الخاص نتيجة تباطؤ 
عملية البناء داخل الحيز العمر اني الكثيف في المر اكز و الأقسام على مستوى الجمهورية، انتظار اً لتحديث و إصدار الأحوزة العمرانية و الكردونات الجديدة، بالمدن وعواصم المر اكز و القرى و التو ابع. هذا التباطؤ كان له أكبر الأثر على انكماش البناء، على الرغم من الجهود الحثيثة التي قامت بها الدولة لتحفيز المشروعات، وزيادة الاستثمار في المشروعات القومية. هذا بالإضافة إلى تحول طلب الصناعات الأخرى المصرية التي تستخدم مسطحات الصلب كمدخل إنتاجي -مثل الأجزةة المنزلية والسياراتإلى المنتجات المستوردة التي تأتى إلى مصر محملة بأسعار منخفضة للطاقة و لا توجد أسوار حماية جمركية مناسبة توقف تدفقها .

\section{شركة الحديد والصلب المصرية (مثال على شركات الحديد والصلب المتعثرة)}

شركة الحديد و الصلب المصرية هي شركة مساهمة مصرية. وهي أول شركة في الشرق الأوسط لإتتاج الحديد و الصلب، تأسست عام 1954 بقرار من الرئيس الر احل جمال عبد الناصر برأسمال 2.1 مليون

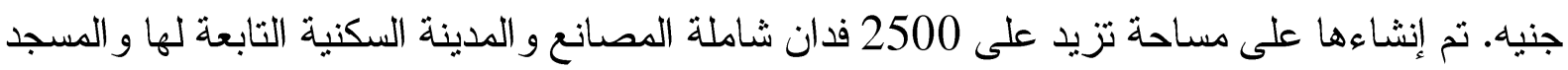
الملحق بها. مقر ها الرئيسي في مدينة التبين بحلوان. و انضمت الثركة في عام 1991 للشركة القابضة للصناعات المعدنية، حيث أصبحت تخضع لأحكام قانون قطاع الأعمال العام رقم 203 لسنة 1991. يبلغ رأس مالها المرخص به نحو 2 مليار جنيه ورأس المال المدفوع 976.8 مليون جنيه. بينما يبلغ حجم استثمار اتها 650.7 مليون جنيه مصري وتعد شركة الحديد والصلب المصرية أول مصنع متكامل يستخدم تكنولوجيا الأفران العالية ومعدات ألمانية الصنع لصهر خامات حديد منخفضة الجودة و عالية الشو ائب مستخرجة من أسوان هذا بالإضافة إلى فحم الكوك المسنورد وتحويلها إلى زهر سائل ومن ثم صبها يدويا وتشغيلها إلى منتجات صلب نهائي. وقد شهدت الثركة العديد من مراحل الإضافة والنطوير أهمها إنثاء مجمع الصلب الذي بدأ إنتاجه عام 1972 باستخدام نفس تكنولوجيا الأفران العالية بمعدات روسية حيث بلغت الطاقة الإنتاجية مليون طن سنويا من كافة الأشكال الطولية والمسطحة للصلب16. لذلك تعد شركة الحديد والصلب المصرية أحد مصانع الصلب المتكاملة17 تتنج كافة أثكال منتجات الصلب وخاصة مسطحات الصلب

/http://www.hadisolb.com شركة العديد والصلب المصرية(2021) 16 غرفة الصناعات المعدنية (2021). 17 الشركات المتكاملة هي التي تتتج منتجات الحديد والصلب من الخامات الاستخراجية وحتى المنتج النهائي. 
كما تتتج كمية محدودة من حديد التسليح هذا بالإضافة لكميات من مربعات الصلب لمصانع الدرفلة. وفقاً

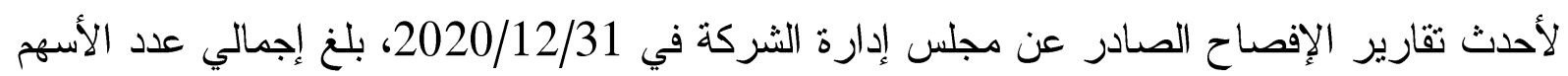
المقيدة بالبورصة نحو 977 مليون سهر. نملك الشركة القابضة للصناعات المعدنية 82.5\% من أسهر الشركة.

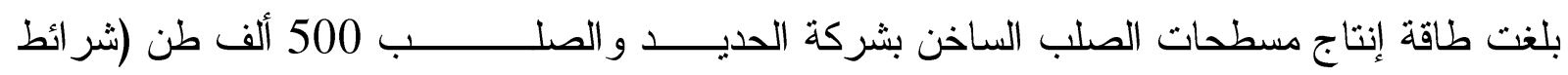
ولفائف) سمك من2 إلى 8 مم عرض حتى 1000 مم. كما ثقوم الثركة بإنتاج مسطحات الصلب الباردة. وبلغت الطاقة الإنتاجية للشركة لارفلة الألو اح 90 ألف طن سمك 8 -100 مم عرض حتى 1500 مم. استهدفت الثركة إنتاج ما يقرب من 450ألف طن من منتجات الحديد و الصلب بمشروع موازنة عام 2019/2018، وهو ما يفوق ضعفي إنتاجها الفعلي عام 2018/2017 و البالغ نحو 133 الف طن. ولكن في حقيقة الأمر بلغ إنتاج الثركة الفعلي خلال عام 2019/2018 نحو 112 ألف طن فقط وهو ما يقل عن مسنوى الإنتاج خلال عام 2018/017 بنحو 16\%، بسبب ثقادم الآلات و المعدات.

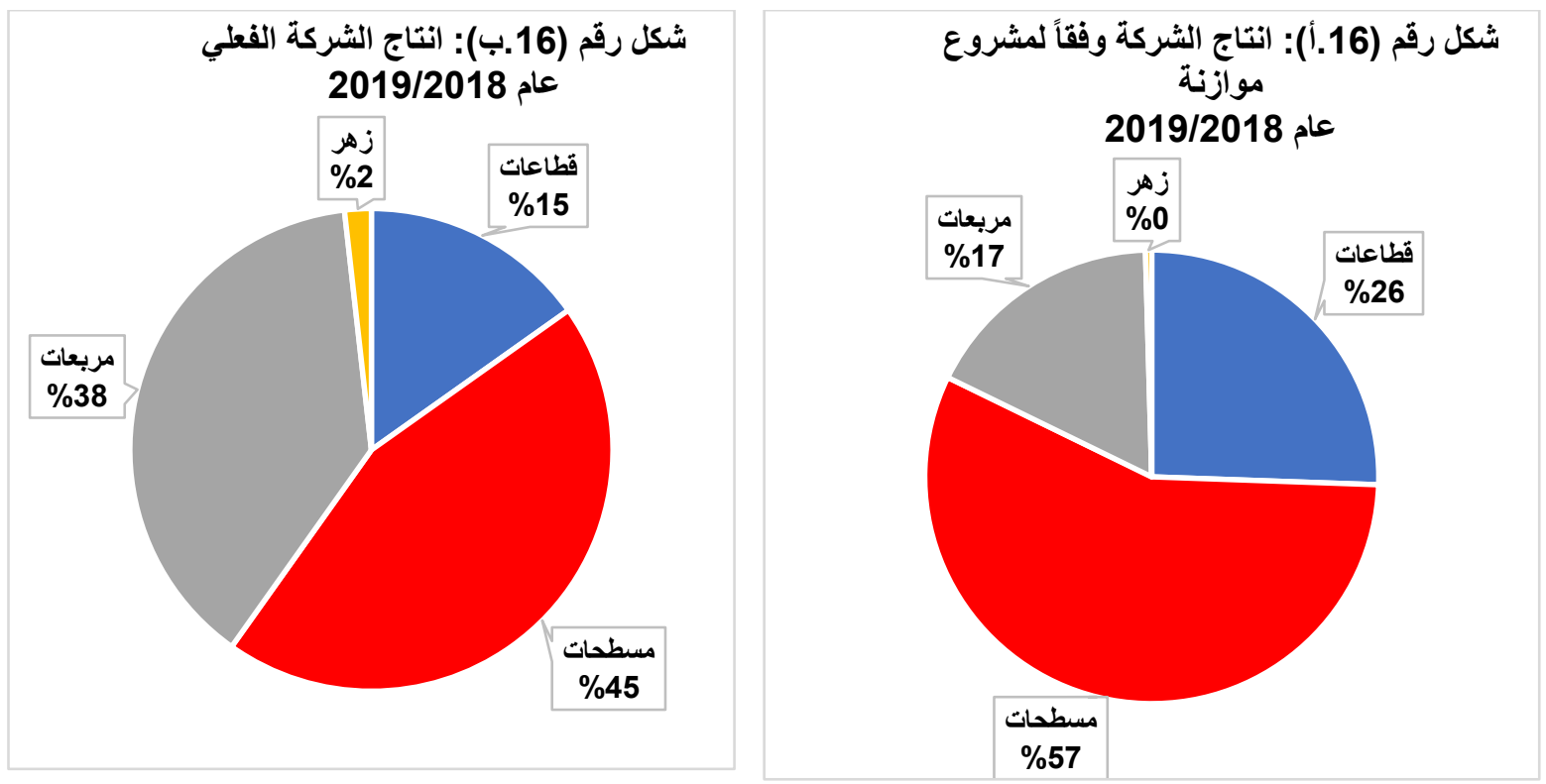

المصدر : شركة الحديد و الصلب المصرية. الموازنة الثقيرية لعام 2018/2019. 
جدول رقم (8): تطور إنتاج شركة الحديد والصلب المصرية

\begin{tabular}{|c|c|c|c|c|}
\hline 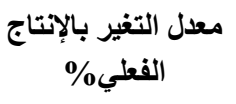 & فعلى 2019/2018 & موازنة 2019/2018 & فعلى2017/2016 & المنتج \\
\hline 45- & 17 & 115 & 31 & قطاعات \\
\hline 58- & 50 & 255 & 119 & مسطحات \\
\hline $10-$ & 43 & 78 & 48 & مربعات \\
\hline 100 & 2 & 2 & 1 & زهر \\
\hline 44- & 112 & 450 & 199 & الإجمالي \\
\hline
\end{tabular}

المصدر : شركة الحديد و الصلب المصرية. الموازنة الثقديرية لعام 2021/2020.

أما فيما يخص الموقف المالي للشركة، فقد أظهرت نتائج أعمال الشركة خلال الربع الأول من العام المالي 2020 /2021 تحقيق خسائر بلغت 274 مليون جنيه. وفي السنة المالية 2019 /2020، تكبدت الشركة خسائر بلغت 982.8 مليون جنيه مقابل خسارة قدر ها 1.5 مليار عام 2019/2018، ولم نستطع الشركة الإنتاج بكميات اقتصادية للوصول إلى نقطة التعادل

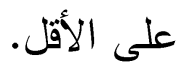
ويبلغ عدد العاملين بالشركة خلال السنة المالية 2019 / 2020 نحو 7114 عاملاً. بلغت أجورهم 827 مليون جنيه في هذا العام. هذا وقد توقف الإنتاج بمصانع الشركة بشكل منكرر بسبب ثقادم الآلات و المعدات وعدم تو افر الخامات اللازمة. وبلغت الالتزامات المالية على الثركة للغير نحو 6 مليار ات جنيه في عام 2019 / 2020 مقارنة بنحو 5.3 مليار جنيه بالعام المالي السابق. ليصدر في يناير 2021، بيان رسمي باتخاذ قرار تصفية شركة الحديد والصلب المصرية من قبل الجمعية العمومية غير العادية و تأسيس شركة مساهمة جديدة لنشاط المحاجر ، وذلك لوقف نزيف الخسائر المستمرة وذللك بعد محاو لات

كثيرة لإصلاحها.

لقد اختارت الجمعية العمومية القرار الأسهل وليس الأصوب اقتصادياً مضحية بالعمالة المدربة ذات الخبرات الكبيرة ومجمع صناعي يفوق عمره نصف القرن ويقدم للاقتصاد المصري طاقة إنتاجية من المنتجات المختلفة من الصلب تصل ل1.2 مليون طن سنويا. ولكن السؤال الذي يطرح نفسه: ما هي السياسات الاقتصادية البديلة التي كان من الممكن اتخاذها تجنبا لقرار فصل المحاجر عن الشركة بشركة منفصلة ثم اتخاذ قرار بتصفية الشركة؟ تدهور الأداء المالي و التشغيلي للثركة بسبب تو الي إدار ات لا تتميز بالكفاءة وعدم وجود در اسات جدوى حقيقية لنطوير ها لمو اكبة أحدث التكنولوجيا. لذلك اقترح الخبر اء إسناد أمر تطوير الشركة لشريك 
استر اتيجي لإعادة هيكلة الثركة وجدولة مديونيتها. فقد كان من الممكن بيع جزء من أراضي الثركة و استخدام عائدات البيع في سداد مديونيتها. فعلى سبيل المثال، يمكن استخدام جزء من الأرض في بناء مشروع إسكان متوسط وشعبي أو بيع جزء من هذه الأصول واستغلال العائد من البيع في تحديث

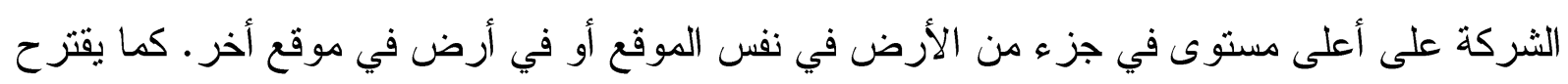
زيادة رأسمال الشركة عن طريق طرح أسهم جديدة بالبورصة و الاكتتاب عليها و استخدام هذه الأموال

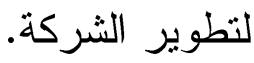
5- مسنقبل صناعة الحديد و الصلب في العالم

كان لسياسات الحماية الدولية التي اتبعتها الو لايات المتحدة الأمريكية والاتحاد الأوروبي و الصين وتلاها الكثير من الدول المتقدمة والنامية إن تأثر الطلب العالمي للصلب سلبا. ثم كلن لجائحة فيروس كورونا وقرارات الإغلاق أثر كبير على إنتاج القطاعات التي تستخدم الصلب كمخل أساسي، وخاصة خلا فترات إغلاق المصانع وتعطيل سلاسل التوريد بشكل كبير .و على الرغم من إزالة تدابير الإغلاق و واستئناف النشاط الصناعي، فلا تزال حالة عدم اليقين مرتفعة للغاية لأن الوباء لم ينته بعد ولا يزال

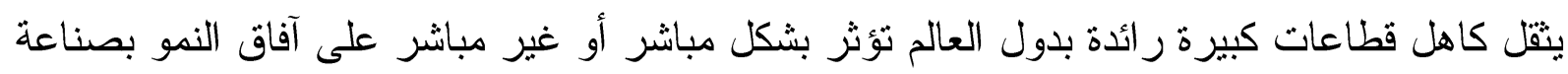

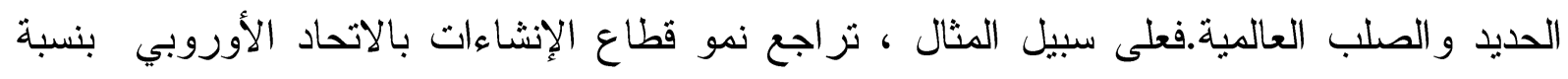

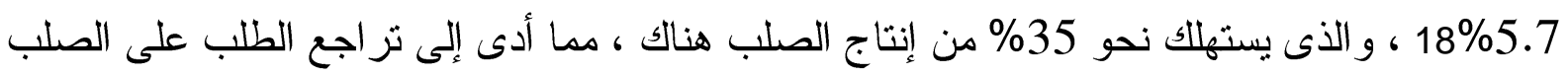

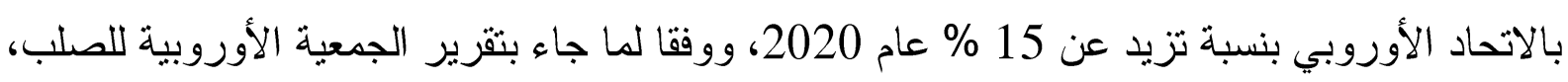
فانه مع توقع نمو قطاع الإنشاءات بنسبة 4.3\% خلال عام 2021 ، و كذلك نمو الطلب على الصلب بنحو 11\%.

وأن يرتفع الطلب العالمي على الصلب بنسبة 4.1\% خلال عام 2021، في حين انه من المتوقع أن ينمو الطلب العالمي -باستبعاد الصين - بنسبة 9.4\% خلال هذا العام. وسوف يعزز الطلب على الصلب: (ا) نمو القطاع الصناعي في جميع أنحاء العالم و (ب) الحوافز المالية العالمية التي تدعم مشاريع البنية التحتية. في غضون ذلك، سوف يتباطأ نمو الطلب على الصلب في الصين بنسبة 2.2\% مقابل معدل نمو 8.5\% خلال عام 2020 وذلك بسبب قرار الحكومة الصبنية بخفض إنتاج الصلب الخام في عام 2021. حيث

\footnotetext{
${ }^{18}$ https://www.eurofer.eu/assets/publications/economic-market-outlook
} 
أعلنت وزارة الصناعة وتكنولوجيا المعلومات الصينية أن قطاع الصلب في البلاد يجب أن يخفض إنتاج الصلب الخام في عام 2021، بما ينماشى مع المبادرات منخفضة الكربون في إطار الخطة الخمية

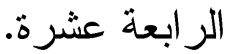

\begin{tabular}{|c|c|c|c|c|c|c|}
\hline \multicolumn{3}{|c|}{$\%$} & \multicolumn{3}{|c|}{ مليون طن } & \\
\hline \multicolumn{2}{|c|}{ معدل نمو متوقع } & \multirow{2}{*}{ معدل نمو فعلى 2019} & \multicolumn{2}{|c|}{ متوقع } & \multirow{2}{*}{ فطلى } & \\
\hline 2021 & 2020 & & 2021 & 22020 & & \\
\hline 11.0 & $15.2-$ & $5.5-$ & 149 & 134 & 158 & الاتحاد الأوروبي \\
\hline 11.9 & 4.0 & $10-$ & 39 & 35 & 34 & دول أوروبية أخرى \\
\hline 5.5 & $8.5-$ & 5.9 & 57 & 54 & 59 & دول الكومنولث \\
\hline 6.7 & $15.3-$ & $4-$ & 122 & 115 & 135 & النافتا \\
\hline 8.2 & $10.1-$ & $3-$ & 40 & 37 & 42 & وسط وجنوب أمريكا \\
\hline 9.3 & $16.0-$ & 0.4 & 33 & 31 & 36 & أفريقيا \\
\hline 6.2 & $19.5-$ & $3.5-$ & 41 & 39 & 48 & الثرق الأوسط \\
\hline 2.5 & 2.1 & 6.6 & 1313 & 1281 & 1255 & أسيا \\
\hline 4.1 & $2.4-$ & 3.5 & 1795 & 1725 & 1767 & 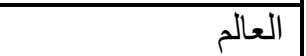 \\
\hline 9.4 & $13.3-$ & $1.4-$ & 815 & 745 & 859 & العالم باستثناء الصين \\
\hline 7.7 & $14.4-$ & $3.8-$ & 363 & 337 & 393 & الاقتصاديات المتقدمة \\
\hline 0.0 & 7.9 & 8.5 & 980 & 980 & 908 & الصين \\
\hline
\end{tabular}

Source: World Steel Association, DBS Bank

ففي النصف الأول من عام 2020، انخفضت أرباح الصلب بشكل ملحوظ حيث انخفضت أسعاره بسبب اضطر ابات الطلب الناتجة عن الوباء وتزامن مع ذلك الزيادات غير المتوقعة في أسعار خام الحديد. لذلك بدأت شركات الصلب في زيادة أسعار البيع لتجاوز عبء النكلفة وتجنب الخسائر. بدأت معظم أسواق الصلب الإقليمية تشعر بتر اجع العرض في الربع الرابع من عام 2020 وخاصة مع

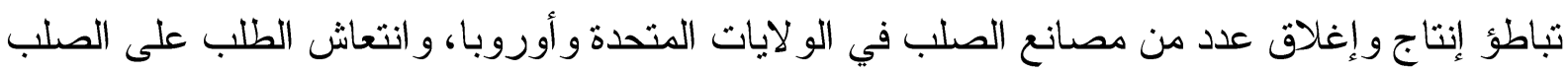
في الصين ليبلغ نحو 8.5\% عام 2020. ولذلك فمن المتوقع أن ترتفع أسعار الصلب خلال عام 2021.

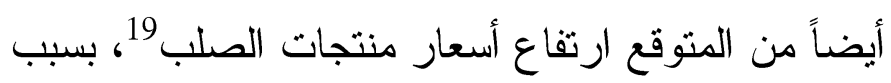
(1) توقع ارتفاع أسعار خام الحديد إلى 120 دو لار للطن خلال عام 2021 مقابل 109 دو لار أمريكي

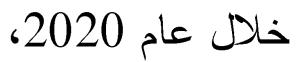


(2) توقع ارتفاع أسعار فحم الكوك لتبلغ 141 دولار أمريكي للطن مقابل 126 دولار خلال العام السابق،

(3) التأثير الإيجابي لخطط التحفيز، (4) تحسن الثقة في الأعمال التجارية من طرح اللقاحات وبالتالي انتعاش الطلب على الصلب مما يرفع أسعاره.

6- مستقبل صناعة الحديد و الصلب في مصر

تملك مصر طاقات إنتاجية كبيرة بهذه الصناعة حيث تجاوزت نسبة الطاقات العاطلة منها 50\%. كما أن المنتج المصري يتمتع بجودة عالية مكنته من التو اجد بالعديد من الأسواق الأوروبية و الو لايات المتحدة الأمريكية و الدول العربية، فضلا عن أن المنتجات الوطنية قادرة على فتح أسو اق جديدة في أسيا و أفريقيا، وخاصة مسطحات الصلب و الذي تعتمد عليه أكبر الثركات الصناعية العالمية. و المصانع المحلية يمكن أن تتمكن من رفع نسبة الطاقات الإنتاجية المستغلة حال استجابة الدولة لمطالب الصناعة في خفض تكاليف الطاقة، رسوم المرور بقناة السويس للمصانع القائمة بمنطقة شمال غرب القناة، وفرض الحماية الجمركية و المعالجات التجارية التي تكفل تجارة عادلة وحماية للمنتجات الوطنية من الممارسات الضارة بالتجارة الدولية، هذا فيما يخص جانب مستقبل المعروض من الصناعة المصرية. أما فيما يخص مستقبل الطلب على صناعة الصلب المصرية، فحتى بعد تعافي إجر اءات كورونا سوف يظل الطلب على الحديد والصلب اقل من مستوى الطلب عام 2009 على الرغم من النمو السكاني الكبير و المشروعات القومية العملاقة. وذلك لسببين رئيسين، عدم اعتماد أحوزه عمر انية جديدة تضمن التوسع العمر اني المنظم بالمناطق الريفية، و صدور قرار رئيس مجلس الوزر اء بإيقاف إصدار تر اخيص بناء جديدة لمدة 6 شهور في جميع الأحياء السكنية.." في أبريل 2020. وهو ما انعكس على استهلاك حديد التسليح خلال عام 2020، علما بأن قطاع الأهالي يمثل 65\%-70\% من إجمالي الاستهلاك المحلي لحديد التسليح، فأي قرارات تحد من البناء من الطبيعي أن تؤثر على حجم استهلاك حديد التسليح وغيره من مواد البناء على مستوى الجمهورية. ويظهر من شكل رقم (17) نراجع الطلب على حديد النسليح خلال عام 2020 مقارنة بالعام السابق بنسبة 17.6\%، أي أن الاستهلاك المحلي لحديد النسليح قد انخفض من 7.4 مليون طن في عام 2019 
إلى 6.1 مليون طن في عام 2020. مما ترتب عليه زيادة في الطاقات الإنتاجية العاطلة، وتر اكم ضخم في المخزون. شكل رقم (17) توقعات الطلب على منتجات الحديد و الصلب فى مصر

$$
\text { (مليون طن) }
$$

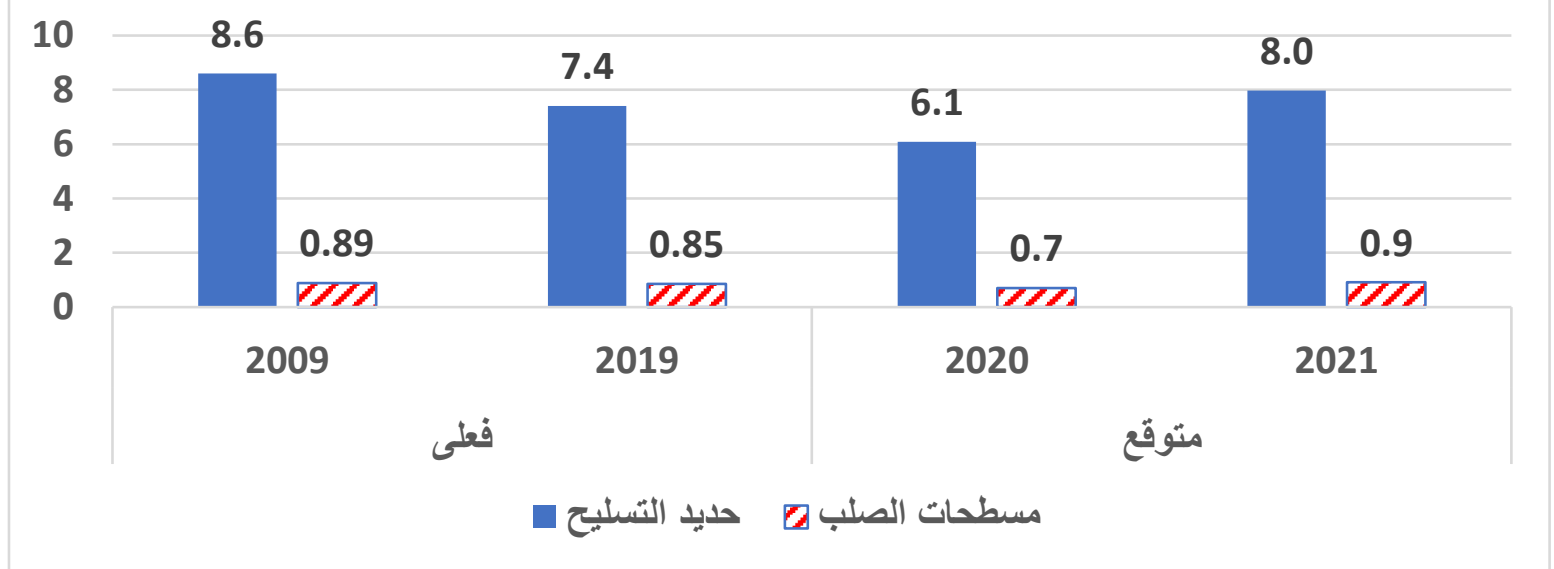

المصدر: قدرت بواسطة الباحثين اعتمادا على بيانات وزارة التموين التجارة الداخلية والشركات المنتجة ومتوسط معدل نمو الطلب المتوقع بمنطقتي أفريقيا و الشرق الأوسط. إن صناعة مو اد البناء بوجه عام وصناعة الحديد و الصلب الوطنية بوجه خاص أصبحت نو اجه حالة تعثر شديدة وتحقق خسائر غير مسبوقة، بسبب انخفاض الاستهلاك المحلي بشدة مقارنة بكل الأعوام السابقة. فقد حقق معدل نمو استهلاك حديد التسليح في الفترة من 2009-2020 معدلاً سالباً ليصل وفقاً لأفضل التقدير ات إلى -33 سنوياً. ولكن هذا الوضع قابل للتحسن والتعافي إذا وصل الطلب خلال عام 2021 إلى 8 مليون طن وخاصة بعد انتشار النطعيمات ضد كورونا وصدور قرار باستئناف أعمال البناء والتشطيب لمن سبق لهخ الحصول على رخصة بناء، حتى 4 أدو ار فقط، لحين إصدار اثتر اطات البناء الجديدة. ومع ذلك فان مستوى الطلب المتوقع لعام 2021 ماز ال بحاجة لدفعة قوية تعوض نقص معدل نموه منذ عام 2009. فإذا كان الاستهلاك المحلي لحديد التسليح في مصر ينمو بمعل طبيعي منوسط 5\% سنوياً خلال السنوات العشر الماضية لكان حجم الاستهلاك المحلي حالباً 14 مليون طن. ومعدل نمو 5\% سنوياً ليس معدلاً مبالغاً فيه، فعلى سبيل المثال شهد السوق الأوكراني خلال نفس الفترة معدل نمو منوسط 8\% و السوق الصيني 6\% ...الخ. ولكن في الحالة المصرية كان معدل نمو استهلاك حديد التسليح خلال السنوات العشر السابقة منخفض للغاية حتى أنه كان أقل من معدلات نمو الناتج المحلي الإجمالي. وهذا وضع 
غريب مقارنة بأي اقتصاد نامي أخر، يفترض أن يكون قطاع التثييد و البناء به من القطاعات الأساسية الدافعة و المحركة للنمو.

هذا الوضع يجعل من الضروري النظر في سياسات البناء و التثييد لإعادتها لمعدلات النمو الطبيعية التي تضمن استقرار الإنتاج في هذا القطاع الحيوي. لذلك المطلوب هو دفع حركة التثييد و البناء بما بحقق معدل نمو استهلاك حديد نسليح لا يقل عن 5\% سنوياً.

الخلاصة

اتضح مما سبق التحديات المختلفة التي تو اجه صناعة الحديد و الصلب الوطنية. و المطالب التي طالما

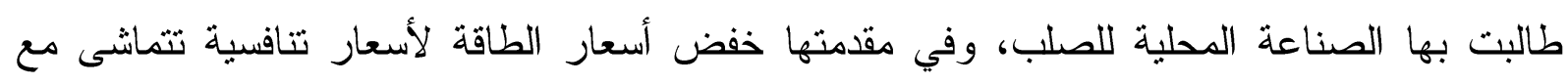

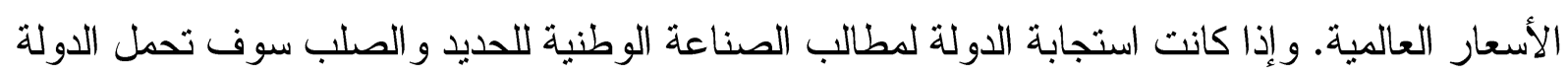
نحو 6.2 مليار جنيه ولكن تحقيق هذه المطالب سوف يدر على الدولة ما يفوق 38 مليار جنيه مصري، هذا بالإضافة إلى العائد من الأرباح التجارية والإير ادات الضريبية ونوفير النقد الأجنبي. كذلك فإن ضعف تطبيق سياسات الحماية الجمركية الفعالة و المعالجات التجارية التي كفلها النظام التجاري العالمي لكل دول العالم، أدى إلى هجمة واردات شرسة على أسو اقنا المحلية أضرت بالصناعة المتكاملة وشبه المتكاملة وز اد من تفاقم الوضع تباطؤ الاستهلاك المحلى وارتفاع أسعار الطاقة. ولذلك لم تعد الصناعة المحلية قادرة على المنافسة بالسوق المحلى و العالمي وسط كل هذا الكم من التحديات. لذا فأن مر اجعة السياسة الصناعية بوجه عام ولقطاع الصلب بوجه خاص يعد أمر اً مطلوباً سريعاً. 


\section{المراجع}

- شبكة الحديد والصلب. (2015). صناعة الحديد والصلب في مصر. تم الاسترجاع من الرابط https://steel-network.com/index.php?go=news\&more=2207

- القابضة للصناعات المعدنية. شركة مصانع الالتا للصلب. تم الاسترجاع من الرابط https://ar.mih.eg/myservice/delta-steel-mill-company/

$$
\text { - }
$$
http://egyptiancopperworks.com/\%D8\%B9\%D9\%86\%D8\%A7\%D9\%84\%D8\%B4\%D8\%B1\%D9\%83\% D8\%A9/

https://aisusteel.org/archives/members/ezz-steel

$$
\text { - الاتحاد العربي للصلب. حديد عز. تم الاسترجاع من الرابط }
$$

- - مديد عز. نبذة عن شركة العز الدخيلة للصلب - الإسكندرية. تم الاسترجاع من الرابط https://www.ezzsteel.com/ar/\%D8\%B9\%D9\%84\%D8\%A7\%D9\%82\%D8\%A7\%D8\%AA-

\%D8\%A7\%D9\%84\%D9\%85\%D8\%B3\%D8\%AA\%D8\%AB\%D9\%85\%D8\%B1\%D9\%8A\%D9\%86/\%D8\%B4 \%D8\%B1\%D9\%83\%D8\%A9-\%D8\%A7\%D9\%84\%D8\%B9\%D8\%B2-

\%D8\%A7\%D9\%84\%D8\%AF\%D8\%AE\%D9\%8A\%D9\%84\%D8\%A9\%D9\%84\%D9\%84\%D8\%B5\%D9\%84\%D8\%A8-

\%D8\%A7\%D9\%84\%D8\%A5\%D8\%B3\%D9\%83\%D9\%86\%D8\%AF\%D8\%B1\%D9\%8A\%D8\%A9

- غرفة الصناعات المعدنية. صناعة الصلب بمصر تاريخ وتصنيف. تم الاسترجاع من الرابط https://steel-network.com/index.php?go=news\&more=2207

https://www.cmiegypt.org/News/138/Default.aspx

$$
\text { - غرفة الصناعات المعدنية (2021). صناعة الصلب في مصر: }
$$

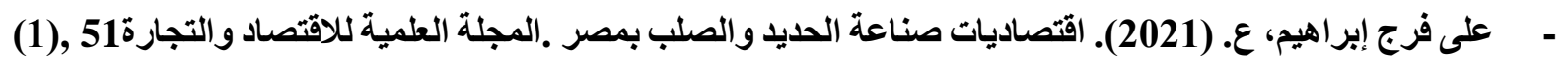

13-82.,

- الاتحاد العربي للحديد والصلب (2019). تقرير حول صناعة الحديد والصلب في الوطن العربي.

- World steel association. (2019). Top steelmakers in 2019. Retrieved from World Steel Association website: https://www.worldsteel.org/en/dam/jcr:21ca3ee7-4e2b-4c4e-b07d47b139553ee1/2019\%2520Top\%2520Steel\%2520Producers\%2520and\%2520tonnage\% 25 20of\%2520worldsteel\%2520members_28May2020.pdf

- KONAK,A.,\& KAMACI,A. (2019). Effects Of Iron-Steel Sector On Global Competition, Economic Growth And Unemployment. Manisa Celal Bayar Üniversitesi..

- Dubey, S., Singh, A., \& Kushwah, S. S. (2019). Utilization of iron and steel slag in building construction. In AIP Conference Proceedings (Vol. 2158, No. 1, p. 020032). AIP Publishing LLC. September.

- OECD (2020), Steel Capacity. Retrieved from World Steel Association website: https://stats.oecd.org/Index.aspx?datasetcode=STI_STEEL_MAKINGCAPACITY

- OECD(2020). Steel Market Developments. June.

- DBS Group Research(2021). Industry Outlook: Steel. February. Asian Insights Office.

- Eurofer(2021). Economic and steel market outlook 2021-2022. February 


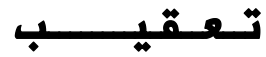

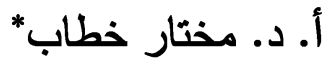

جاءت هذه الورقة البحثية في وقتها تماما، فصناعة الحديد و الصلب العالمية نو اجه مشكلات معقّه في كل من جانب العرض و الطلب، أثزت عليها سلبياً خلال عام 2020. كما أن صناعة الحديد والصلب المصرية تو اجه تحديات أكثر حدة مما تو اجهه الصناعة العالمية، وهي تحديات تكاد تهدّد وجودها، وهي الأخرى تحديات في كل من جانبي العرض و الطلب. كما أن هناك متغير اً جديداً فرض نفسه على الرأي العام في مصر ، ألا وهو القرار الذي اتخذته الجمعية العامة غير العادية للشركة القابضة المعدنية بتصفية شركة الحديد و الصلب المصرية، التي هي أم صناعة الحديد والصلب في مصر و البلاد العربية ودول القارة الأفريقية. وتتصدى الورقة لهذه التحديات المطروحة بإلحاح الآن. درست الباحثات موضوعهن الرئيسي و هو، مستقبل صناعة الحديد والصلب في مصر ، من خلال عدد من النقاط الرئيسية على النحو الآتي: 1- عرض أهمية صناعة الحديد والصلب، حيث عرضت الباحثات جو انب هذه الأهمية في الاقتصاديات المعاصرة، بالرجوع لدراسة Oxford economics. ووفقت الباحثات في دق أجراس الإنذار ونو اقيس الخطر لتتبيه الأجهزة المسئولة عن صناعة الحديد و الصلب في مصر إلى المخاطر التي تحيق بها، وبالأزمة التي أطُبقت عليها، والتي أصبحت تهدد وجودها. ويلقى البحث الضوء على دلائل ومؤشرات الخطر و المخاطر التي انزلت فيها الصناعة المغذية لكل الصناعات والأنشطة بصورة مطلقة. وأوضح البحث أن أهم الدلائل و المؤشرات على الأزمة، هو انخفاض الطلب على حديد التسليح بنسبة 4. 1. سنوياً في المتوسط خلال السنوات العشر الماضية، ويشكل حديد التسليح في مصر من 65 إلى 70\% من الطلب على الحديد و الصلب، وكذلك كثف البحث عن أن الإنتاج الفعلي لصناعة الحديد و الصلب في مصر يعادل أقل من 50\% من الطاقة المناحة في الصناعة، أي أن هناك أكثر من 50\% من الطاقة الإنتاجية لصناعة الصلب في مصر معطلة. ونظر اً لارثفاع أثمان المدخلات المفروضة على الصناعة (غاز ، كهرباء)، وارتفاع رسوم عبور القناة على المصانع المقامة بشمال غرب خليج السويس، ولنق الحماية الجمركية على هذه الصناعة في مصر بالمقارنة بجميع 
دول العالم، دفعت مصر ثمناً فادحاً، فقد زادت وارداتها من الحديد والصلب من الخارج لتصل إلى 3.6 مليار دو لار عام 2019، بعدما كانت هذه الواردات 446 مليون دو لار عام 2001، بمعدل نمو

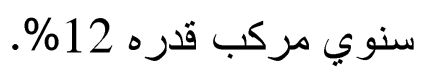

عملت الدراسة على إلقاء الضوء على هذا الواقع المر والخطير، والذي يثير حفيظة أي مواطن مصري، ويجعله يتساعل ماذا ينتظر المسئولون عن صناعة الحديد والصلب. ومتى يتحركون؟ مع الأمل أن يسنو عب متخذ القرار نتائج هذه الدراسة، و العمل على اتخاذ القرارات و السياسات اللازمة

بشأنها.

2- توضيح تشابكات أمامية وخلفية لصناعة الصديد والصلب مع كافة الصناعات والأنشطة الاقتصادية، لكي تصل الدراسة إلى غايتها في بيان ما يحيق بهذه الصناعة في مصر من أخطار حقيقية، أوضحت الورقة أن الحديد و الصلب هو أهم المواد الأساسية Basic materials التي تعتمد عليها جميع الصناعات و القطاعات و الأنشطة الاقتصادية. فحتى الصناعة أو النشاط الذى لا يدخل الصلب في مكونات المنتج النهائي له، يدخل في صناعة الآلات التي تتتج هذا المنتج النهائي. فعلى سبيل المثال، فان المنتجات الغذائية المصنعة أو حتى الخام (المنتجات الزراعية)، بعتبر الصلب المادة الرئيسية لصناعة الآلات التي تنتجها. كما تساهم صناعة الصلب في خلق فرص عمل ضخمه في الاقتصاد، فكل فرصه عمل واحدة، يتم خلقها في صناعة الحديد والصلب، يتبعها خلق 6.5 فرصة عمل في

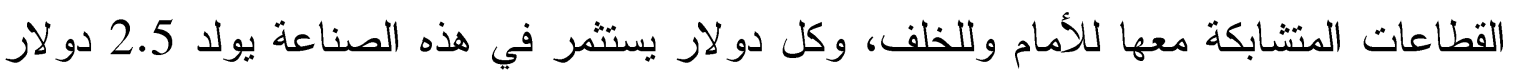
قيمة مضافة في القطاعات الأخرى، وان إنتاجية العامل في هذه الصناعة تصل إلى 80000 دو لار ، و هى ثلاثة أضعاف الإتتاجية المتوسطة للعامل في كافة الأنشطة الصناعية الأخرى، وأن هناك ارنباطا طردياً وثيقاً بين نمو الناتج المحلى الإجمالي ونمو صناعة الحديد والصلب، أوضحته الباحثات بجلاء ووضوح. 3- توضيح المفاهيم الأساسية المرتبطة بصناعة الحديد والصلب، حتى يستطيع القارئ العادي متابعة وتفسير الإحصائيات و البيانات المنشورة عن الحديد والصلب، كان لابد للار اسة أن توضح الفرق بين الصلب الخام و المدرفلات. فالصلب الخام هو ما تتتجه المصانع المتكاملة، التي تستخدم خامات الحديد وتحوّلها إلى صلب وبعد ذلك تحوّلها إلى مدرفلات (منتجات نهائية)، و المصانع شبه المتكاملة

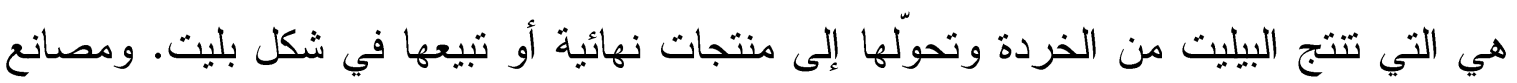
الدرفلة هي التي تحوّل البيليت، الذي تشتريه من الداخل أو الخارج، إلى مدرفلات (أسياخ، قطاعات، 
مسطحات ...)، وبدون هذا التوضيح لا يسنطيع قارئ الدر اسة أن يفهر دلالة الإحصاءات و البيانات الو اردة فيها، أو المنشورة. 4- ملامح هامة في النطور الاقتصادي لصناعة الحديد والصلب، حيث تم عرض النطور الاقتصادي لصناعة الحديد و الصلب في مصر • وهو ما يمهد لدر اسة التحديات و المشكلات التي تعاني منها هذه الصناعة. وقد أوضحت الدر اسة أن مصر تملك طاقة إنتاجية من الصلب قدر ها 15.6 مليون طن تعادل 36\% من الطاقات الإنتاجية في دول قارة أفريقيا مجتمعه، و26\% من طاقات الإنتاج في

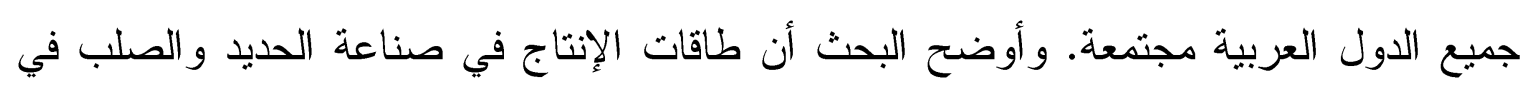

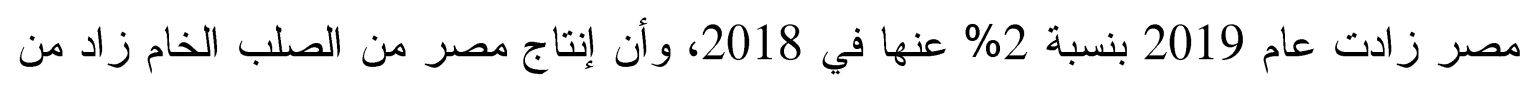
7 مليون طن عام 2010 إلى 7.3 مليون طن فقط عام 2019. وأوضحت الدراسة أن إنتاج الصلب في مصر يقل عن 50\% من الطاقة الإنتاجية المتاحة، أي أن أكثر من 50\% من ون الطاقة الإنتاجية غير مستغل أي معطل. كما زادت الو اردات لتصل إلى 3.6 مليار دو لار عام 2019 بمعدل نمو الإنه

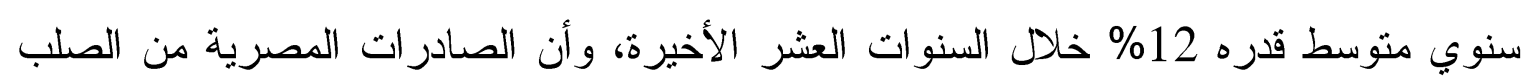

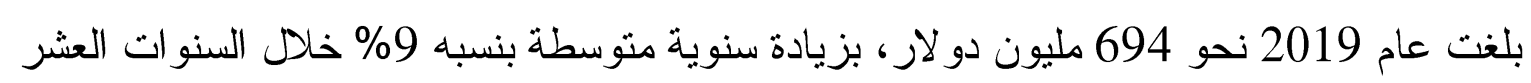

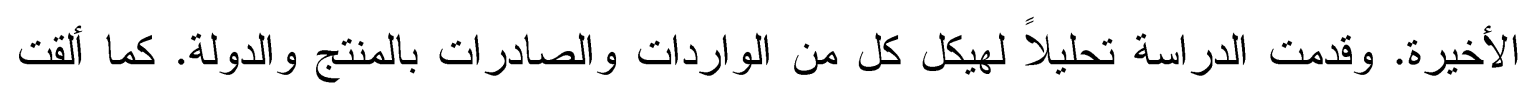
الدراسة الضوء على ثقاعس أجهزة التجارة الخارجية عن حماية صناعة الحديد و الصلب الدصرية. ففي الوقت الذي تبلغ فيه درجة الحماية الجمركية وغير الجمركية على مسطحات الصلب على المستوى العالمي 32.9\%، فإنها في مصر تبلغ 5\% فقط، مما جعل مصر تستورد ما قيمته 649

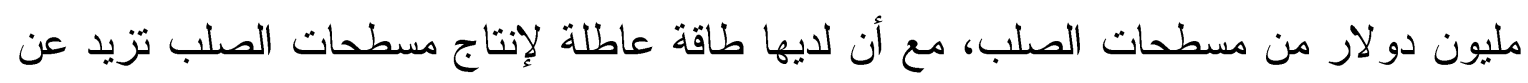

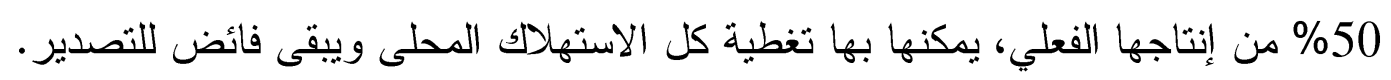

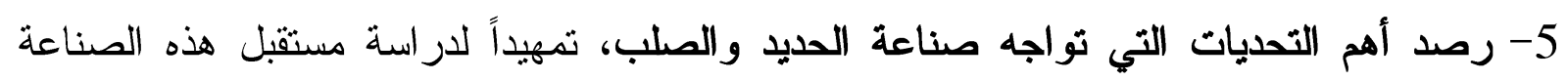
الأساسية، وقد تم العرض لهذه التحديات على المستوى العالمي، وتم التركيز على التحديات الجسيمة

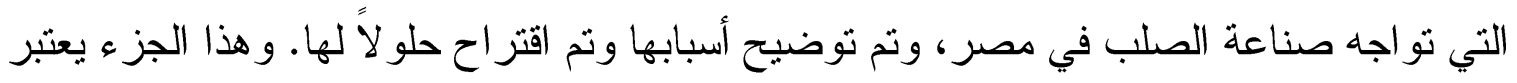
نقطة قوة كبيرة في هذا البحث. فالتحديات العالمية نكمن في الحرب التجارية التي نثأت في العام

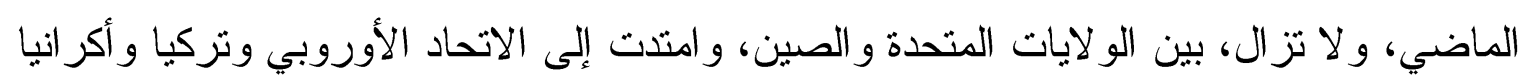

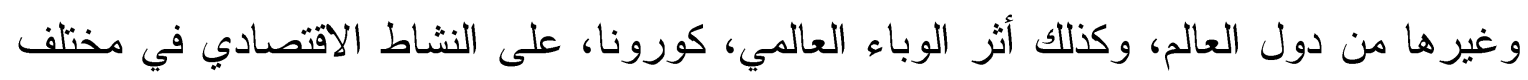
دول العالم، وما أدى إليه من انخفاض الطلب على الصلب، وتسبب في تكوين فائض رفع المخزون 
العالمي بمقدار 90 مليون طن، هذا الفائض غَزا أسواق الصلب في الدول الأقل من حيث معدلات الحماية ومنها مصر .

انتقلت الدراسة إلى توضيح النحديات التي تو اجه صناعة الصلب في مصر، فأوضحت أن هناك تحديات تواجه الصناعة في جانب العرض أهمها، ارتفاع سعر الغاز الطبيعي المورد لمصانع الصلب المتكاملة لاستخدامه في عملية الاختز ال المباشر . فمتوسط السعر لكل مليون وحدة حرارية من الغاز على المستوى العالمي في عامي 2019، 2020 هو 2.5 دو لار، في حين يبلغ سعر الغاز الطبيعي المورد للمصانع المصرية للصلب 4.5 دو لار ـ و أن الكيلووات من الكهرباء يورد لمصانع الصلب في الاتحاد الأوروبي في المنتسط بمبلغ 3.2 سنت، وفي أمريكا الثمالية بمبلغ 2.69 سنت، وفي عدد من الدول المتقدمة (متوسط) 3.1 سنت، وفي مصر 5.5 سنت، بعد تخفيضه بعشرة قروش للكيلو وات. و اقترحت الباحثات تخفيض سعر المليون وحدة حرارية بريطانية إلى 2.5

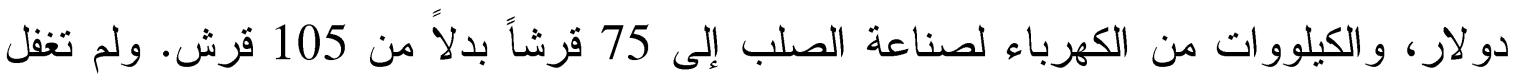
الدراسة أثز رسوم عبور قناة السويس على تكلفة الإنتاج للمصانع المنشأة في منطقة شمال غرب لهرب خليج السويس، واقترحت تخفيض هذه الرسوم لهذه المصانع حتى تتمكن صناعة الصلب المصرية

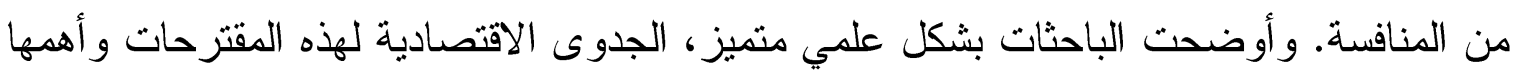
تشغيل 41 \% من الطاقة المُعطّة لصناعة الصلب، ليصل المستخدم من الطاقة الإنتاجية للصلب إلى 70\% (بدلاً من 49\% حالياً)، و إلى زيادة الصادرات بمقدار 810 مليون دولار في السنة وتخفيض الواردات بمقدار 1000 مليون دو لار . وقدمت الدراسة جداول محسوبة بمنهجية علميه جيدة، لجدوى هذه السياسات. و اقترحت الدراسة رفع الحماية الجمركية الثابتة على منتجات الصلب في مصر بنسبه 20\%.

6- شركة الحديد والصلب المصرية - إنكاليات دور الشركة في إطار دور الصناعة، نعتقد أن هذا الجزء ربما يمثل نقطة الضعف الني يمكن أن نأخذها على البحث. فهو من ناحية المنهج و الثنكل، يخرج عن نطاق در اسة قطاع من قطاعات الاقتصاد الوطني، ولذلك جاء هذا الموضوع من الدراسة

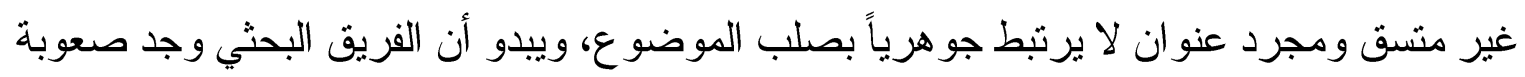
في دمجه هيكلياً في البحث. ورغم الإقرار بأن قرار تصفية شركة الحديد والصلب في مصر هو

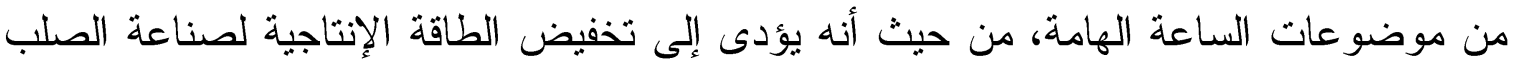
في مصر، وكذلك الإنتاج المتاح. لكن هذا الأثر ينحصر في نقص 200 ألف طن من الطاقة 
الإنتاجية، و109 ألف طن في الإنتاج، أي 1.3 \% من كل من الإنتاج و الطاقة الإنتاجية، وهو تأثير

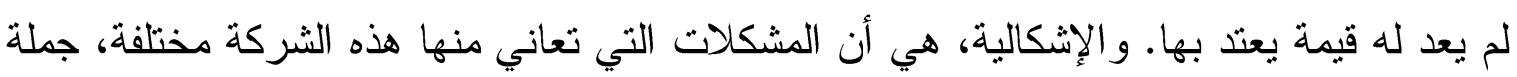

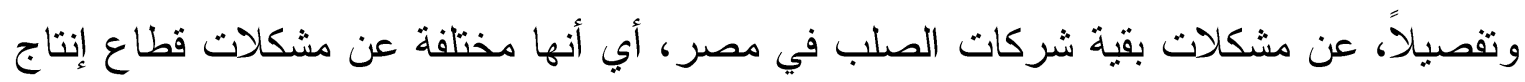
الصلب في مصر • فهي لا تستخدم الغاز الطبيعي المُنتج في مصر، وهى تستخدم خامات محلية مليئة بالثو ائب، وقليلة المحتوى من الحديد، وتستخدم في عملية الاختز ال الفحم الحجري المستورد، الذي يتحول إلى كوك، فهي مشكلة على مستوى الاقتصاد الوحدى (الجزئي) بامنياز وليست مشكلة

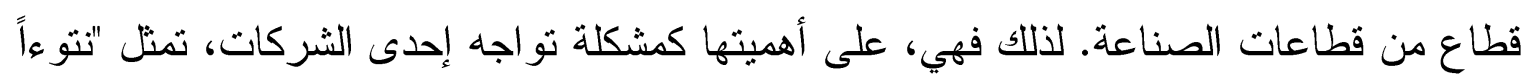

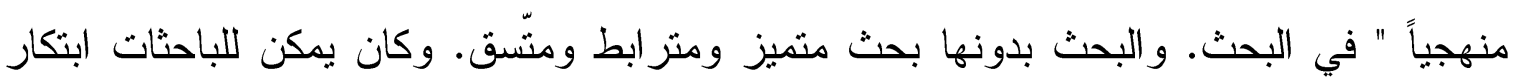

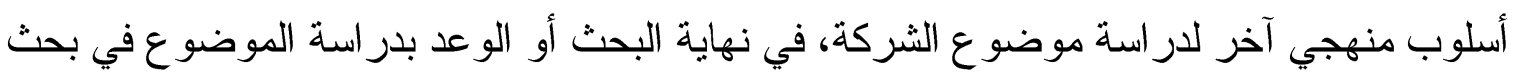
مستقل.

ومن ناحية الموضوع، تطرق البحث إلى أهم المشكلات التي عانت منها الثركة، وهي أنها تقوم بصهر

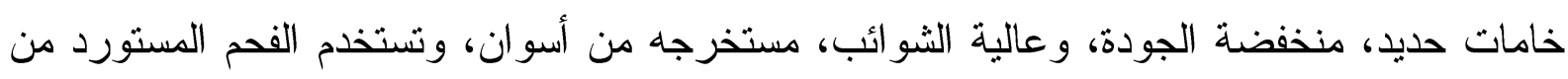
الخارج في عملية الاختز ال. كما ذكر البحث أن الشركة خسرت 982.8 مليون جنيه عام 2020/2019، وبلغ إنتاجها الفعلي من الصلب 112 ألف طن (108 ألف طن في تقرير الجهاز المركزي للمحاسبات 2020/19 ص2) في حين أن طاقتها الإنتاجية الأصلية 1.2 مليون طن. كما بلغت الالتز امات المستحقة على الثركة للغير نحو 6 مليار ات جنيه، بدون خسائر أخر سنه. وأن أفران ومعدات وآلات الثركة متهالكة ومتقادمة. وعَزَت الباحثات تدهور الأداء المالي و التشغيلي للشركة إلى تو إلى إدار ات لا تثميز بالكفاءة، و إلى عدم وجود در اسات جدوى حقيقية لنطوير ها لمو اكبة أحدث التكنولوجيات. وتري الباحثات، أن الجمعية العمومية غير العادية للثركة قد اتخذت القرار السهل، وهو تصفية الثركة، وليس القرار الصواب اقتصادياً، مضحية بالعمالة الددربة ذات الخبرات الكبيرة. وترى الباحثات، أنه لذلك اقترح الخبر اء إسناد أمر تطوير الثركة لشريك استراتيجي لإعادة هيكلة الثركة وجدولة هديونياتها. وتسنطرد الباحثات أنه كان من المكن بيع جزء من أر اضي الشركة، واستخدام عائدات البيع في سداد

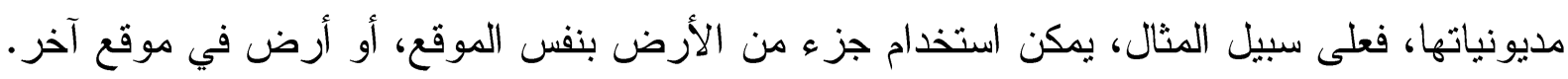

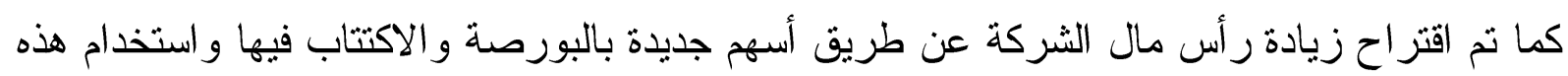
الأمو ال لتطوير الثركة. 
على عكس المنهج الذي اتبعته الباحثات، في بحثهن، من التزام المنهج العلمي وتعزيز النقاط المعروضة

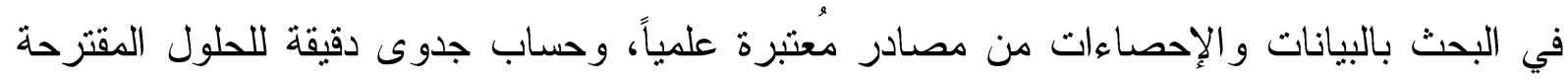
منهن، فإن ما ورد في البحث في شأن شركة الحديد والصلب المصرية جاء مرسلاً، ومقدماته متتاقضة

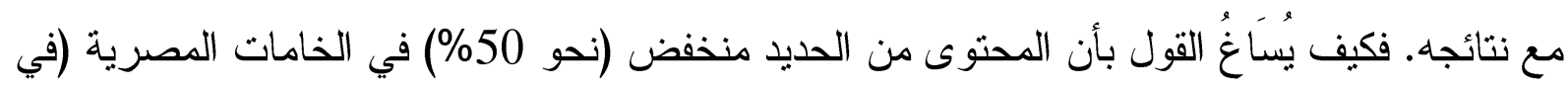

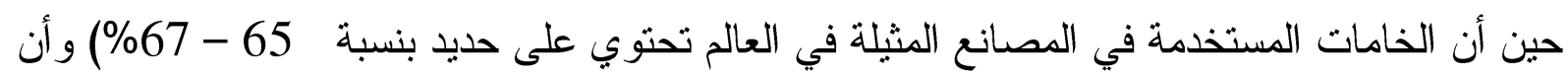
فحم الكوك مسنورد كله من الخارج (والحقيقة أن المستورد هو الفحم الحجري وينم تحويله في شركة الكوك) ويقال إنه لا نوجد كفاءات إدارية، وأن الحجر الجيري ينقل من المنيا، وأن الدولمايت بنقل من أن السويس، وأن إنتاج الثركة في عام 2020/19 وصل إلى 108 ألف طن، بنسبة 9 \% من بن الطاقة الإنتاجية، وتكون النتيجة الني نوصلت إليها الدراسة هي: 1- الاعتر اض على قرار الجمعية العامة غير العادية للشركة بتصفية الثركة.

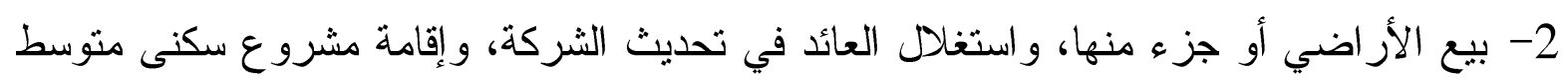

$$
\text { وشعبي }
$$

و الملاحظة الجديرة بالتسجيل في هذا الجزء من الدراسة ليست متعلقة بخيارات الفريق البحثي الذي استقر على خيار معين، لكن النقد هنا مرتبط بالحياد عن المنهجية العلمية الرصينة المتميزة التي التزم بها البحث. فقد كان من الواجب إمّا مناقثة موضوع الثركة مناقشة علمية موضوعية، بعد معالجة "

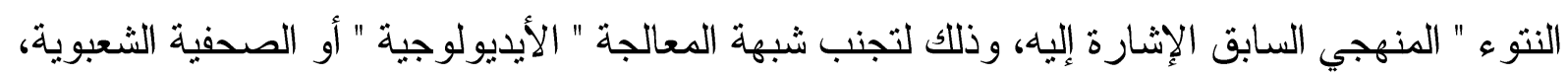
أو استبعاد موضوع شركة الحديد و الصلب المصرية على أهميته، من هذا البحث.

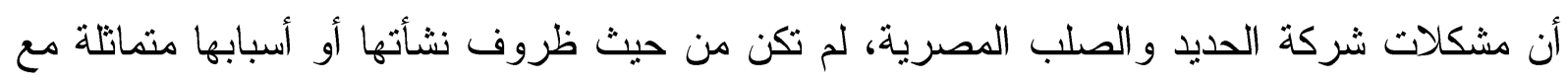
ظروف وأسباب مشكلات بقية قطاع الحديد و الصلب في مصر، كما سبق وأن أوضحنا. فمشكلات صناعة الحديد والصلب في مصر محددة في ارتفاع أسعار الغاز، و الكهرباء، ورسوم قناة السويس وليس

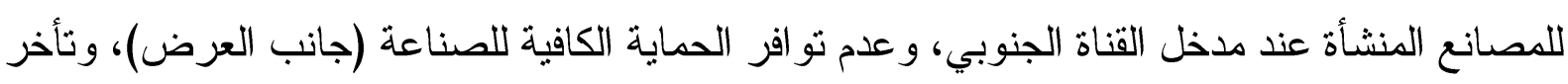
إصدار قرارات الأحوزة العمر انية، ووقف إصدار نر اخيص البناء لفترة طويلة، (مما أثر سلباً على حجم الطلب على الصلب). أما مشكلات شركة الحديد والصلب المصرية، فهي مشكلات نشأت منذ نشأة الثركة في منتصف الخمسينيات من القرن الماضي، وهو ما كان على البحث إلقاء الأضواء عليه، وفي ضوء نتائجه يقتر ح البحث ما ينسق مع هذه النتائج من حلول وخيار ات. 
وفي هذا الصدد نجد من اللازم لمن يريد أن يتخذ موقفاً من التصفية، أو الاستمرار والإصلاح، أن يقوم بدراسة موضوعيه تأخذ النقاط الآثية وغير ها، بعين الاعنبار: 1-6. إنشالية إنشاء الشركة كشركة حكومية لا تركز على الربح، فقد أنشئت شركة الحديد والصلب المصرية في عام 1954 بر أس مال حكومي، ثم زيد رأسمالها عام 1955 بطرح أسهم للجمهور. وجاء في مرسوم زيادة رأس المال، أن الحكومة المصرية تضمن، للمكتتبين في الأسهم من الأفراد،

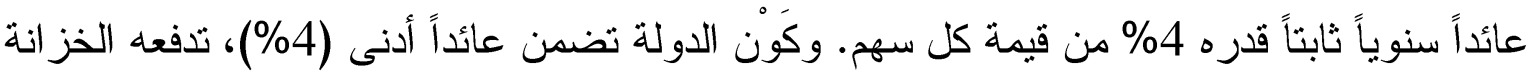
العامة، فهو دليل على أنها تعلم أن هدف الثركة ليس تحقيق الربح المالي وإنما كان هدفها في هذا الوقت أبعد من ذلك.

2-6. إشكاليات تغير مقاصد وأدوار الشركة، فقد تأسست شركة الحديد والصلب المصرية في بداية المشروع الناصري لتصنيع مصر وتتميتها، كان الهذف الرئبسي لها هو تزويد الصناعة المصرية وبقية القطاعات الاقتصادية بالحديد و الصلب. وقد أدت دورها المكلفة به بامتياز ، بصرف النظر عن هدف الربحية المالية لها، ولم يعد لوجود الثركة الآن، أو غيابها، تأثثر يذكر على سوق الصلب في

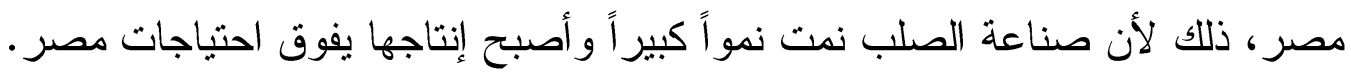

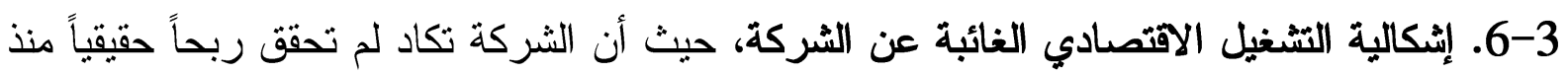
نشأتها، سوى خلال عامين ارتفعت فيهما الأسعار العالمية للصلب فوق عشرة آلاف جنيه للطن، وكانت التكلفة وقتها لا تزيد عن 6 آلاف جنيه. وبالرجوع لتقارير تقييم الأداء الصادرة عن الجهاز المركزي للمحاسبات منذ نثأتها، يجد أنه حتى عام 1995، كان يتم تغطبة الخسائر السنوية عن طريق إعادة تقييم الأصول خصوصاً الأراضي التي كانت قيمتها في أول ميزانيات الثركة مئات الآلاف القليلة من الجنيهات، ثم أصبحت في عام 2020/2019 نحو 181 مليون جنيه (وفق تقرير الجهاز المركزي للدحاسبات 2019 / 2020). 4-6. نوعية الخامات المستخدمة وأثره على جودة وتكلفة المنتج النهائي، تستخدم الثركة خامات محلية قليلة المحتوى من الحديد (خامات مناجم أسوان 44.8 - 47.2\%) ثم بعد ذلك استخدمت خامات الواحات البحرية (52.9\%). و هذه الخامات المحلية تحتوي على شوائب من عناصر الفسفور و السيليكا و الهنجنيز بنسب عالية (من 121إلى 15\%) ويؤدى ذللك إلى أن نسبة خبث الحديد من ناتج الأفران العالية يتراوح ما بين 22إلى25 \% من المنتج النهائي، وتستخدم الثركة الحجر الجيري الذي يُنقل من محافظة المنيا، والدالميث الذي يُنقل من السويس، لذلك فإن تكلفة إنتاج الصلب المنتج 
في الثركة كان، دائماً، أعلى من ثن البيع، حتى حين كانت الثركة تتنج بكامل الطاقة. وفي عام

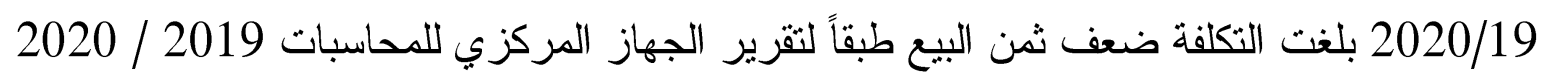
5-6. إنكالية عمر الاحتياجات المساندة، تبلغ الاحتياطيات من الحديد الخام في مناجم الجديدة 62 مليون طن، يفترض أنها لا تكفي الثركة أكثر من 15 عاماً وتتنهي. ومعروف أن عمر شركات الصلب في العالم يزيد عن 80 عاما، وقد يصل إلى أكثر من مائة عام، طالما يتم صيانة الأفران و المعدات وتجديدها، فكأن الخامات المحلية، فوق أنها رديئة بسبب الثو ائب ومنخفضة المحتوى من الحديد، فهي ليست كافية ولا تشجع على ضخخ استثمار ات كبيرة للمدى الطويل. 6-6. استخدام الفحم - أكثر من إنكالية، حيث تستخدم الثركة فحم الكوك في عملية اختز ال الخامات لأن الخامات المصرية وهي من فصيلة "الهيماتيت" " غنية " بالثو ائب، " وفقيرة " في المحتوى من الحديد، ويستورد الفحم ذو الأحجام والصلابة الخاصة، ليتحول إلى فحم كوك في شركة النصر

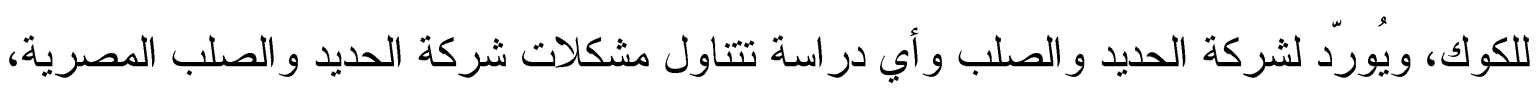
لابد أن تتناول مشكلات شركة الكوك لارتباطهما بعضهما البعض. من جهة أخرى، فإن المحتوى المنخفض للحديد في أفضل الخامات المحلية جودة (الواحات)، و الشو ائب العالية من السيلكا و الفسفور والمنجنيز، ينسبب في زيادة استهلاك فحم الكوك لكل طن صلب منتج بالقياس للمصانع التي تستخدم نفس التكنولوجيا خارج مصر، فقد كانت شركة الحديد و الصلب المصرية تستهلك 900 كيلو جر ام من فحم الكوك لإنتاج طن صلب (في التلبيد وفي الأفران العالية)، في حين أن المصانع المنافسة في العالم تستهلك 500 كيلو جر ام من فحم الكوك لإنتاج نفس القدر (طن صلب).

7-6. مشكلة المواصفات في المنتج النهائي، أن منتجات الشركة من الصلب غير مطابقة للمواصفات بسبب الثوائب وتقادم الآلات والمعدات. وجاء بثقرير الجهاز المركزي للدحاسبات لعام 2019 /2020، صفحة (2)، أن نسبة غير المطابق و المسلم للصب بلغ نحو 81\% من إنتاج الأفران. 8-6. إنكالية الجدوى الاقتصادية في معالجة الخامات، فقد درس المستثرون، الذين أر ادو زيادة طاقة إنتاج شركة السويس للصلب مؤخر اً، معالجة الخامات المحلية، لزيادة تركيز الحديد فيها، وتخليصها من الثوائب، فوجدوا أن ذلك غير مجدي اقتصادياً. فاستثروا أموالهم في زيادة الطاقة الإنتاجية للشركة بتكنولوجيا الاختز ال المباشر باستخدام خامات مستوردة عالية المحتوى وقليلة الثو ائب (أقل من 4\%) تُخْنَل بالغاز الطبيعي. 
9-6. هل هناك بدائل أخرى أكثر جدوى للمحافظة على الشركة، إذا كانت المحافظة على الملكية العامة لشركة الحديد و الصلب، هدفاً عند البعض، فيمكن لهؤلاء أن يقترحوا بقاء شركة الحديد والصلب المصرية ككيان قانوني حكومي. وتقوم الحكومة بوقف إنتاج الصلب من الخامات المحلية التي تُختزل بالفحم لأن أي استثمارات تضخ فيها فهي خاسرة. وتقوم الحكومة بضخ الاستثمار ات، في شركة الحديد والصلب، في إنشاء طاقة جديدة ملك الشركة وداخلها لإنتاج 3 مليون طن صلب، باستخدام خامات عالية المتوى من الحديد (67\%) نظيفة من الثو ائب (أقل من 4\%) وتستخدم الغاز الطبيعي المصري في الاختزال. ويحتاج إنشاء طاقة إنتاج قدرها 3 مليون طن بالاختز ال المباشر بالغاز إلى منى

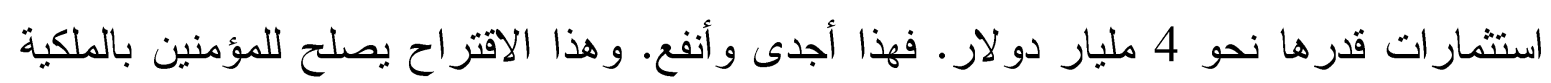
العامة ولغير المؤمنين بالملكية العامة، وفي كل الحالات فإن إنشاء شركة جديدة تتتج 3 مليون طن

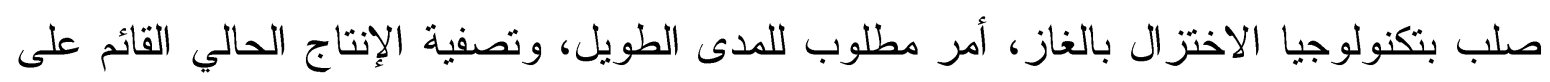
خامات رديئة وقليلة المحتوى يجب أن يكون هو السبب الحقيقي للتصفية وليس السبب هو الملكية

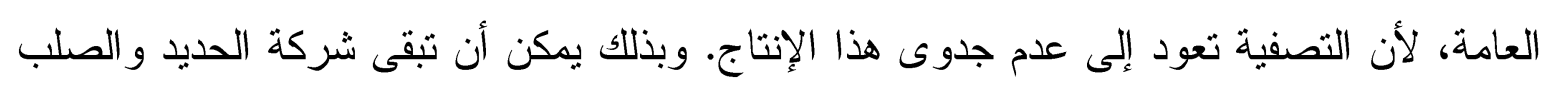

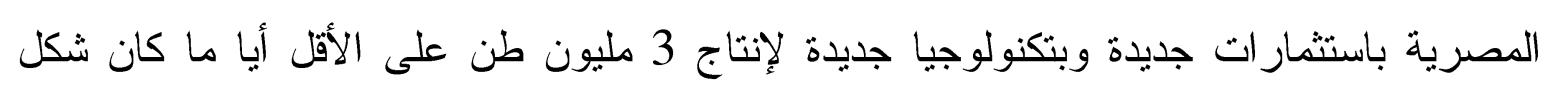
الملكية.

7- ملاحظات حول مستقبل صناعة الصلب في العالم، عرضت الباحثات التوقعات الواردة بتقرير

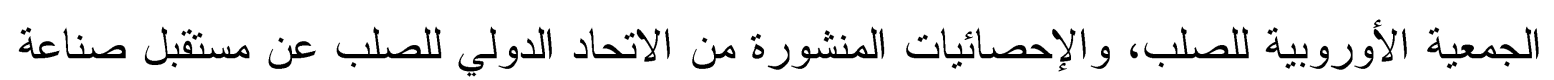
الحديد و الصلب في العالم. و الحقيقة أن هذه التقاريز والإحصاءات تتحدث عن توقعات لعام 2021 أكثر مما تتحدث عن المستقبل على المدى البعيد، أو حتى المتوسط، وتوضح هذه التقارير أن الطلب العالمي على الصلب سينخفض من 1767 مليون طن عام 2019 إلى 1725 مليون طن عام 2020، بنسبة (-) 2.4\%، وذلك بسبب الحرب التجارية التي نشبت بين الدول الكبرى في إنتاج الصلب،

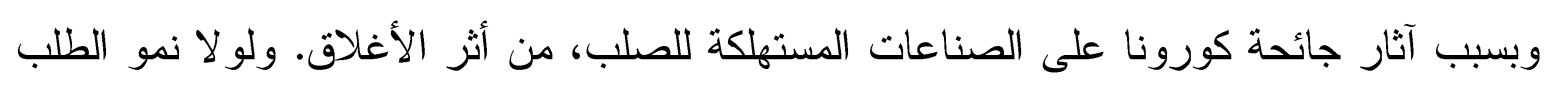
في الصين بنسبة 8.5\% عام 2020 بالقياس لعام 2019، لكان معدل نقص الطلب على الصلب في العالم بدون الصين (-) 13.3\%، وفي الدول المتقدمة (-) 14.4\%. وتتوقع هذه المنظمات الدولية أن الطلب سينمو في عام 2021، في العالم ككل، بنسبة 4.1\%، وفي العالم بدون الصين سينمو بنسبة 9.4 \% في نفس العام (2021). وتثتوقع هذه المنظمات ارتفاع أسعار الصلب عام 2021 تحت تأثير ارتفاع أسعار خام الحديد، وارتفاع أسعار فحم الكوك، وارتفاع أسعار الثحن البحري، 
ومع ذلك، سيرتفع الطلب بسبب التفاؤل الذي يغديه اكتشاف و إنتاج العديد من أنواع التّطعيمات ضد

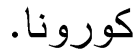

8 - التميز في طرح قضية صناعة الحديد والصلب ، فقد نجحت الباحثات في در اسة الموضو عات التي تمكنهن من استثر اف مستقبل صناعة الحديد و الصلب في مصر ، وذلك رغم تحفظي على إقحام موضوع شركة الحديد و الصلب المصرية، وتحفظي على أن مستقبل صناعة الحديد و الصلب قصد به العام الحالي 2021 بالنسبة لعام 2019 و 2020، ويمكن أن نقبل أن الحلول المطروحة لحل المشكلات التي تعانى منها هذه الصناعة الهامة في مصر، إذا ما نفذت و أدت إلى نمو جيد في الطلب (من 4-5\% عام 2021، ستقتح آفاق نمو مستقبلي للصناعة بهذا المعدل على المدى المتوسط والمدى الطويل، وهذا ما نعتقد أن البحث يرمى إليه. وقد رصدت الباحثات زيادة الطلب على حديد التسليح زيادة طفيفة جداً من نحو 6.6 مليون طن عام 2010 إلى 6.9 مليون طن عام 2020، أي بعد 10 سنوات، وأرجعن ذلك بصفة رئيسية إلى تأخّر إصدار القرار ات الخاصة بالأحوزة العمر انية، و الوقَفْ المؤقّت لتر اخيص البناء الجديدة، ماعدا الرخص القائمة حتى 4 طو ابق. ولو نم تخفيض سعر الغاز، وسعر الكهرباء، ورسوم العبور في قناة السويس للمصانع المقامة في شمال غرب خليج السويس، كما تقترح الباحثات. و إذا صدرت قرارات تحديد الأحوزة العمر انية، وقرارات تتظيم البناء، و إنفك بذلك عقال تر اخيص البناء، فسوف يرتفع كل من العرض من الصلب بنسبة 41\% من الطاقة العاطلة، ويزيد الطلب على حديد التسليح ليصل إلى 8 مليون طن، ويتحقق بذلك معدل نمو يبلغ 5\% في السنة وتتنعش الصناعة. وبغير تتفيذ السياسة التي تقترحها الباحثات فلا مستقبل لصناعة الحديد والصلب المصرية. وسوف يحدث لها ما حدث لصناعات أخرى (كالغزل و النسيج و الملابس و غيرها...) غير أنه إذا انتكست صناعة الحديد والصلب في مصر، فسينخفض معدل نمو الاقتصاد المصري، نظر اً لعلاقة الارتباط الوثيقة بين التتمية الاقتصادية ونمو صناعة الحديد والصلب وهو ما أوضحته الدر اسة بشكل جيد. أخيراً أثثى على الباحثات، وأهنئهن على ما بذلنه من جها عظيم في هذا البحث، تحت إثراف وتوجيه أستاذتهن، عالية القدر، أ.د. عالية المهدي، وأتمنى لو شرعوا في إعداد بحث علمي مستقل عن شركة الحديد والصلب المصرية، للوصول إلى تقييم لقر ار تصفية الثركة يستتد إلى تحليل دقيق للواقع، وتتسق

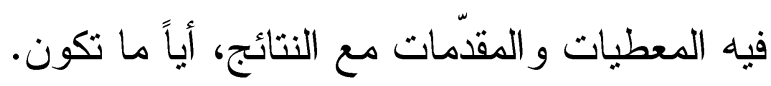
و الله الموفق ،"، 


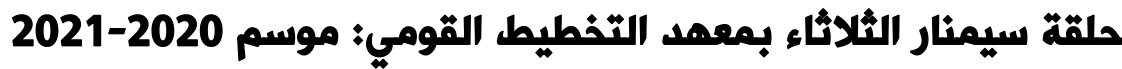 (صناعة الصديد والصلب في مصراء)}

\section{المتحدث: م. محمد سيد حنفي}

\section{إدارة الجلسة: أ.د. مصطفي أحمد مصطفى}

عقد معهد التخطيط القومي يوم الثلاثاء المو افق 16 مارس 2021 سادس حلقات نشاط سيمنار الثلاثاء لمعهد التخطيط القومي للعام الأكاديمي 2020-2021 تحت عنوان (صناعة الحديد و الصلب في مصر)، ويأتي اللقاء في إطار تبنى المعهد لمشروع بحثى شامل ومتعدد المر احل حول: توطين وتعميق التصنيع

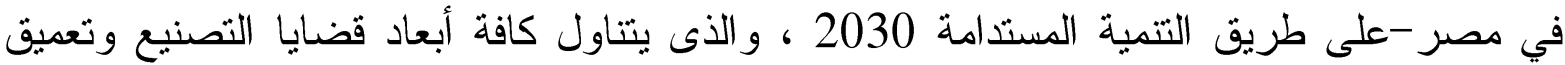
التصنيع في مصر - م وتتاول العرض عدداً من الدحاور الرئيسية، على النحو التالي:

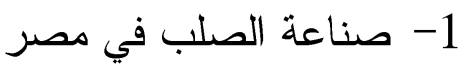

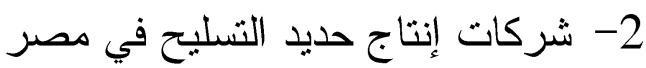
3- العو امل المؤثرة على سعر المنتج 4- نقاط القوة و الضعف في صناعة الصلب المصرية

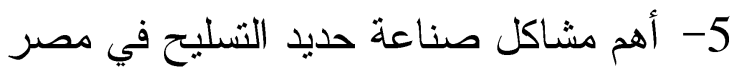
1 1. 1. 1.اعة الصلب في مصر

بدأت صناعة الحديد و الصلب في مصر في الأربعينيات من خلال شركات خاصة بهدف استغلال

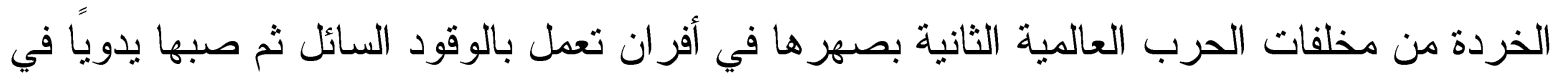
قو الب ودرفلتها إلي حديد تسليح؛ وكان ذلك بشركات الدلتا و الأهلية و النحاس. و التي شهدت فيما بعد بلان

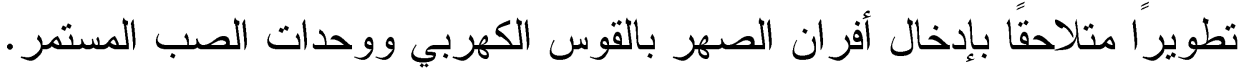

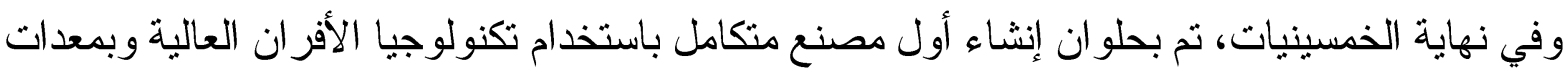
من ألمانية لصهر خامات الحديد المستخرجة من أسوان (منخفضة الجودة وعالية الثوائب) مع فحم بلئاه الكوك المستورد إلى زهر سائل ومن ثم صبها بدويا وتثغيلها إلى منتجات صلب نهائي. وقد شهدت

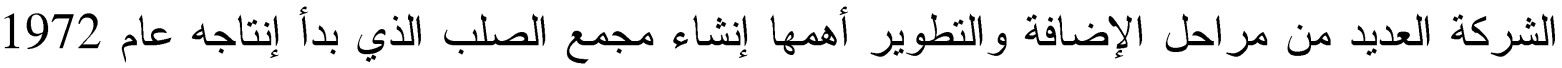
باستخدام نفس تكنولوجيا الأفران العالية بمعدات روسية حيث بلغت الطاقة الإنتاجية مليون طن سنويًا من كافة الأشكال الطولية و المسطحة للصلب. وفي بداية الثمانينيات أسست شركة أخرى بالاخيلة بالإسكندرية مشاركة مع اليابان تعتمد على تكنولوجيا جديدة لإنتاج الصلب من اختزال نوعيات عالية الجودة من خامات الحديد الاستخراجية المستوردة بالئان 
وباستخدام الغاز الطبيعي (بدلاً من الفحم)، وتحويلها إلي حديد إسفنجي (تصل نسبة الحديد به إلى >

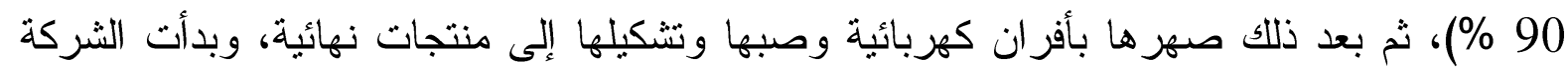

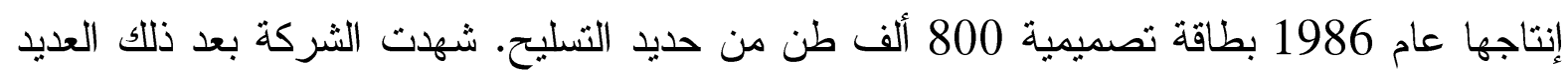
من خطو ات ومر احل التطوير بإضافة خطوط جديدة ورفع طاقات حتى بلغت الطاقة الحالية من حديد التسليح إلى 1.8 مليون طن و إنتاج مسطحات بتقنية البلاطات الرقيقة بطاقة 1.1 مليون طن.

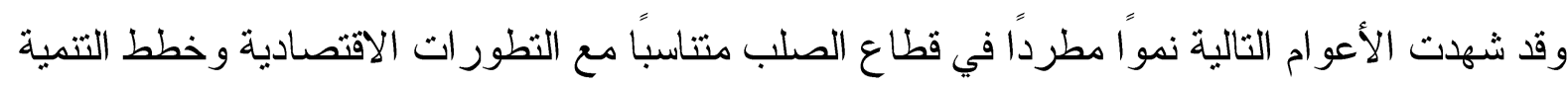

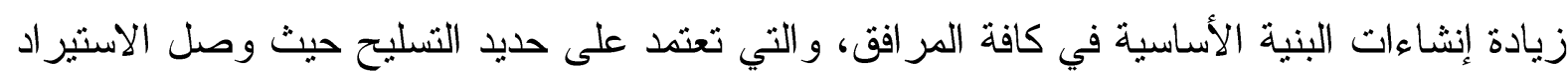

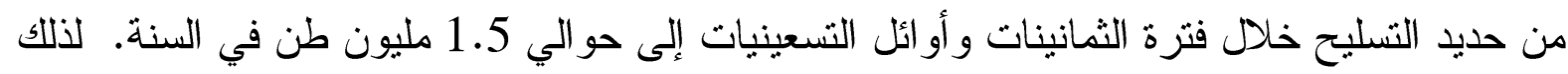

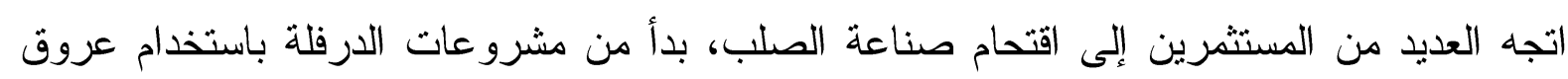

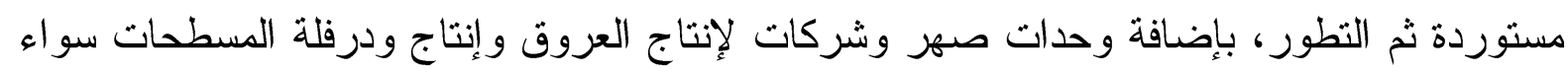

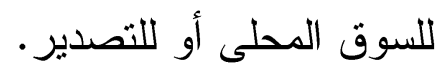

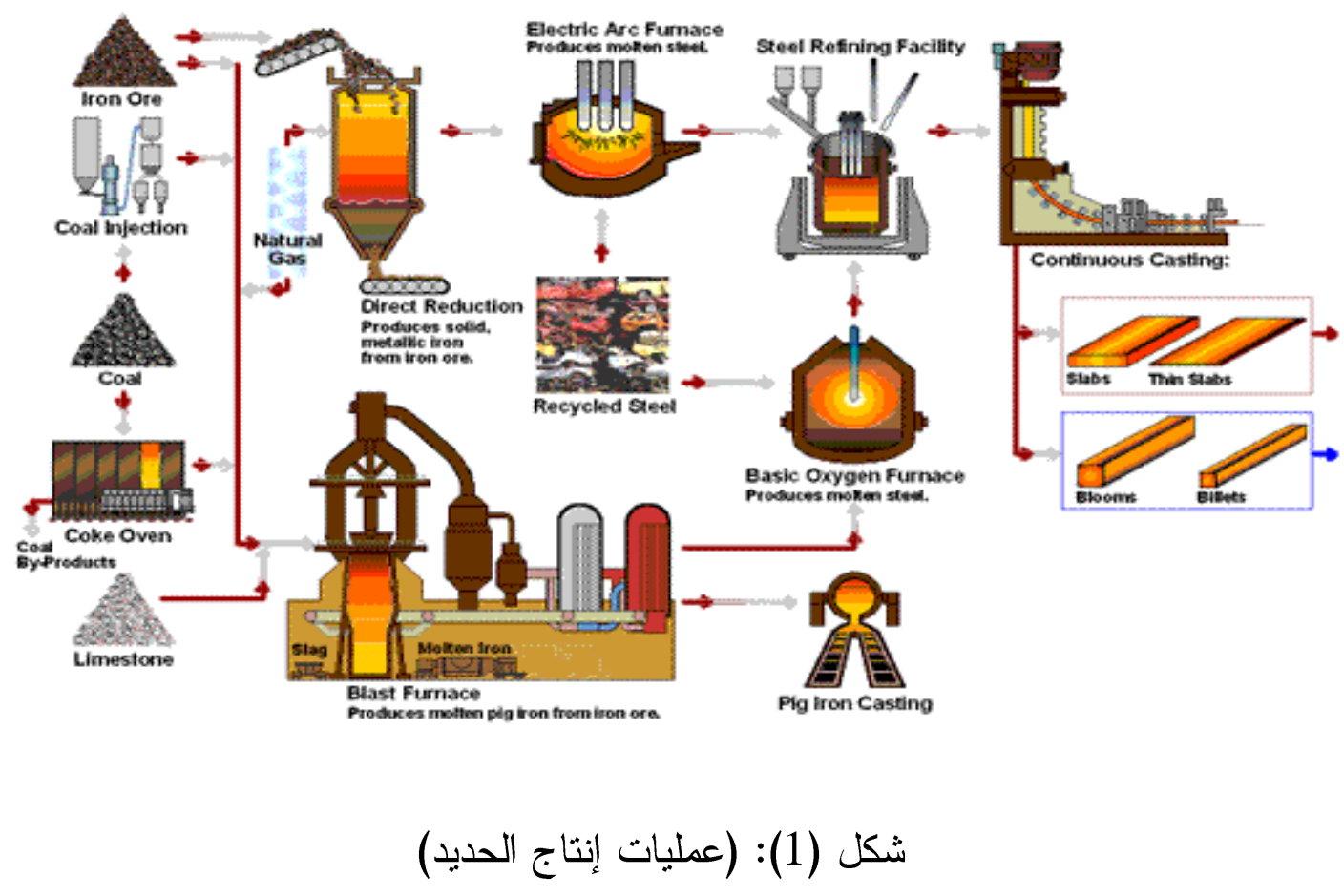


2.شركات إنتاج حديد التسليح في مصر 2-1 شركات منكاملة: وتتنج من الخامات الاستخر اجية وحتى المنتج النهائي

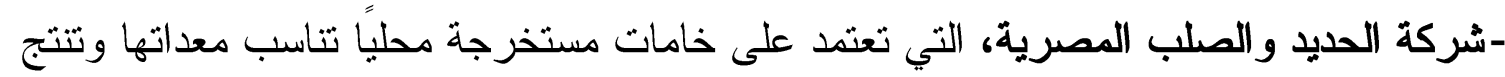

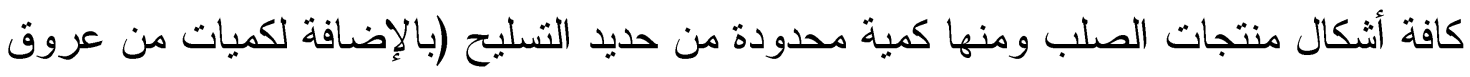

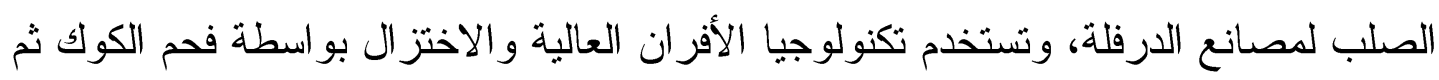
تحويل الزهر إلى صلب بمحو لات). - شركة عز -الدخيلة، التي تعتمد على خامات مستوردة ذات مو اصفات عالية. وتتتج (بالإضافة لخط

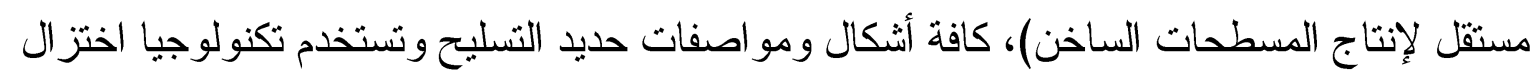
الحديد الإسفنجي باستخدام الغاز الطبيعي و الصهر بأفران الأقطاب الكهربية. - المصرية الأمريكية للصلب بالسادات، التي تعتمد على خامات مستوردة ذات مو اصفات عالية. وتتتج كافة أثكال ومو اصفات حديد التسليح ونستخدم تكنولوجيا اختزال الحديد الإسفنجي باستخدام الغاز الطبيعي و الصهر بأفران الأقطاب الكهربية

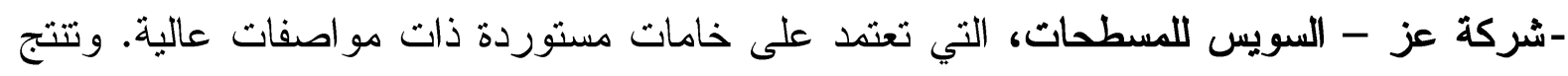

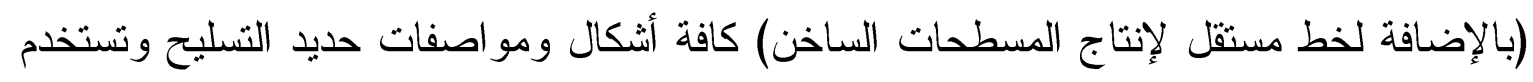
تكنولوجيا اختزال الحديد الإسفنجي باستخدام الغاز الطبيعي والصهر بأفران الأقطاب الكهربية. -السويس للصلب، التي تعتمد على خامات مستوردة ذات مواصفات عالية. وتتنج كافة أثنكال

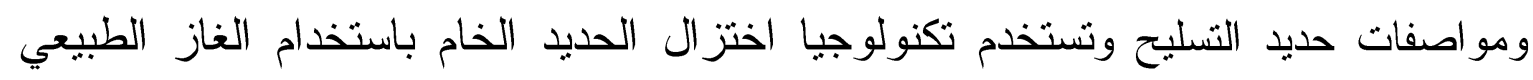
و الصهر بأفران الأقطاب الكهربية. وتبلغ طاقة إنتاج حديد التسليح لهذه المجمو عة حو الي 8 مليون طن. 2-2. شركات نصف متكاملة: وتتنج المنتج النهائي من صهر الخردة (أو الحديد الإسفنجي): - مصر للصلب (العاشر) و المر اكبي للصلب ومجموعة حديد المصريين (بني سويف و السخنة) وحديد

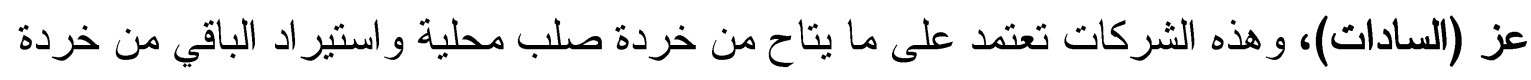

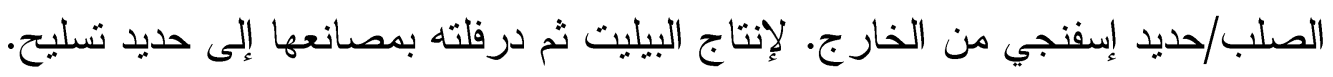
(تبلغ الطاقات المتاحة لتلك المصانع من التبارج 3.5 مليون طن من حديد تسليح)

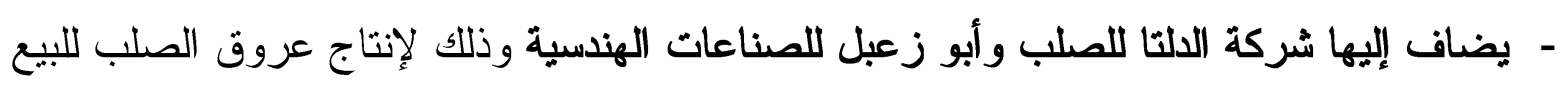
بطاقــة 300 ألف طن. وليس لديها مصانع للارفلة. - مصانع الدرفلة، والتي تقوم بشر اء عروق الصلب من مصدر محلى أو مستورد ودرفلتها إلى حديد لإنها التسليح. 
و عددها كبير يصل إلى 28 شركة و أكبر ها العز للصلب بالعاشر، الدولية للصلب بالسادات مجموعة

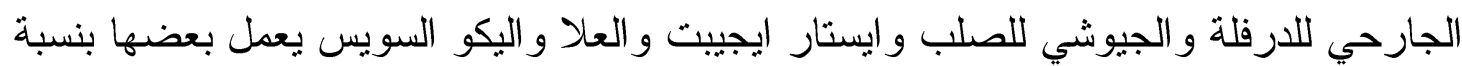
استغلال محدودة للطاقة لأسباب اقتصادية وتمويلية.

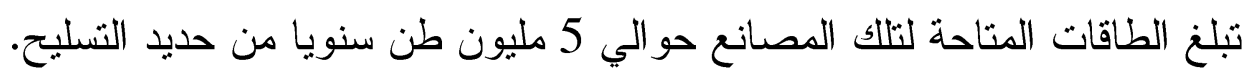
2-3-3.3ركات تعمل في منتجات حديدية متنوعة - قطاعات خفيفة ومنوسطة وثقيلة، بالإضافة للمصانع العاملة في مجال حديد التسليح و التي بمكن لبعضها التحول لإنتاج القطاعات الخفيفة، فان هنالك العديد من الثركات تعمل في إنتاج القطاعات

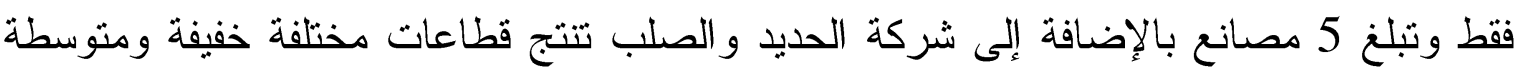

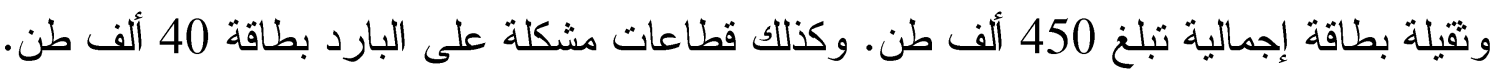
- مسطحات الصلب الساخن. نوجد عدة مصانع لإنتاج مسطحات الصلب الساخن: شركة الحديد والصلب، بطاقة 500 ألف طن (شر ائط ولفائف) سمك من2 إلى 8 مم عرض لألى حتى 1000 مم.

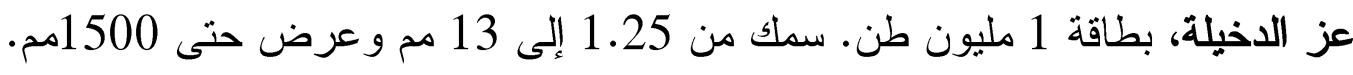

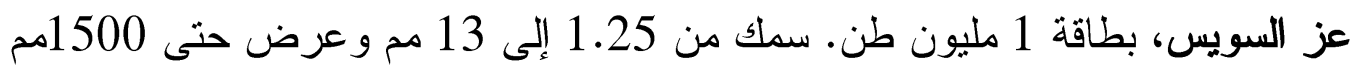

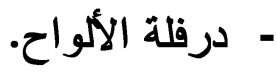
شركة الحديد والصلب بطاقة 90 ألف طن سمك 8 -100 مم عرض حتى 1500 مم. أبو زعبل للصناعات الهندسية بطاقة 30 ألف طن وسمك وعرض سن هن هنى 3500 مم. - درفلة مسطحات على البارد، ويلغ عددها خمسة خطوط بعضها مزود بطاقة جلفنه وطلاء، وهي: مجمع قنديل بالعاشــر جلفاميتال للجلفنة و الطلاء بالعبور الحديد و الصلب المصرية

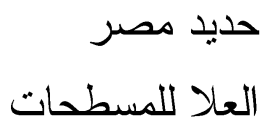

وتبلغ الطاقة الإجمالية لإنتاج الصاج بأنو اعه المطلي و المجلفن حو الي 1.4 مليون طن.

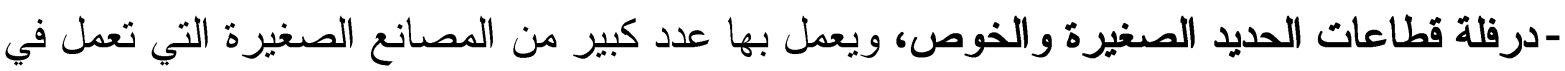
درفلة قطاعات الحديد الصغيرة والخوص و التي يستخدم اغلبها في المنشآت الخفيفة، مثل: الأسوار و البو ابات و النو افذ المعدنية، وبعض الهياكل المعدنية للأجهزة و المعدات الميكانيكية و اللوحات الكهربية.

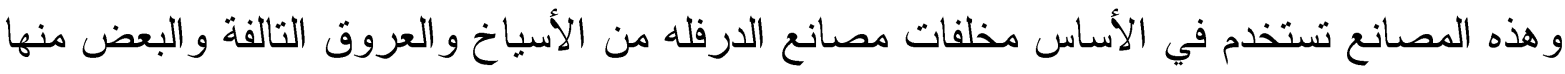

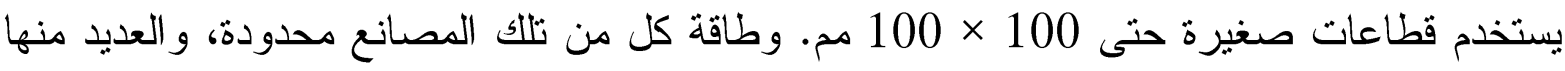


يستخدم وحدات يدوية من أفران أو در افيل، إلا إنها عديدة وتغطي كافة الاحتباجات المحلية ومنتشرة في مجال و اسع جغر افياً. - تشكيل الحديد، يوجد العديد من المصانع التي تعمل في مجال نشكيل المعادن الحديدية من سحب أسلاك تقشير الأعمدة وصناعة الجو ايط ومواسير و هياكل معدنية و أعمدة ومسامير ونشكيل وتعريج الصاج ومساحيق الفلزات و السبائك و تشكيل الواح الصلب الذي لا يصدأ. الصلب المخصوص، يوجد في مصر مصنعين لإنتاج أنواع الصلب عالي الجودة و الصلب السبائكي من الخردة وهو الشركة العربية للصلب المخصوص. وكذلك توجد وحدة لإنتاج الصلب المخصوص أو السبائكي بشركة أبو زعبل للصناعات الهندسية. بالألف طن

\begin{tabular}{|c|c|c|c|c|c|c|}
\hline ق إرفلة & مسطحات & سرطدات & ترليح & 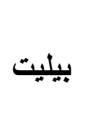 & الإسفنجي & 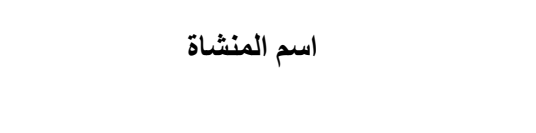 \\
\hline & & 1100 & 2100 & 2000 & 3000 & شركة عز - الدخيلة(*) \\
\hline & & & 1500 & 850 & & شركة العز للصلب بالسادات و العاشر \\
\hline & & 1200 & 1100 & 1300 & 2000 & عز السويس ع \\
\hline & & & 810 & 2050 & 2000 & السويس للصلب \\
\hline & & & 1400 & & & شركة رفيق بالسويس \\
\hline & & & 120 & & & شركة اليكو بورسعيد \\
\hline & & & 180 & & & المصرية لننتجات الحليد والصلب بالسويس \\
\hline & & & 180 & & & شركة المصرية للصلب بالعبور \\
\hline & & & 320 & & & شركة مصر الوطنية للصلب "عتاقه" \\
\hline & & & 750 & & & الثركة الدولية لارفلة الصلب بثاي \\
\hline & & & 450 & 2000 & 2000 & المصرية للحديد الإسفنجي و الصلب بثاي \\
\hline & & & 850 & 850 & & بثايرية الأمريكية للارفلة الصلب (بها صهر) \\
\hline 120 & & & & & & بثاي للقطاعات و الهياكل \\
\hline \multirow[t]{13}{*}{400} & 100 & 300 & 20 & 600 & 1200 & شركة الحديد والصلب المصرية خام محلي \\
\hline & & & & 250 & & مصانع الالتا للصلب تحت الإنثاء \\
\hline & & & 300 & & & شركة الالتا للاستثمارات البحرية (بالعاشر) \\
\hline & & & & 80 & & مجموعة مصر للصلب (بالعاشر) \\
\hline & & & 500 & 800 & & شركة المصريين ببني سويف \\
\hline & & & 350 & & & حديد المصريين ببورسعيد الوطنية للصلب \\
\hline & & & 500 & 800 & & حديد المصريين بالعين السختة \\
\hline & & & 180 & & & حديد المصريين (مرغم الإسكندرية) \\
\hline & & & 80 & & & شركة ابرايجيب (العامرية) \\
\hline & & & 80 & & & سرحان للصلب \\
\hline & & & 240 & & & شركة السويس للصناعات الحديدية (الكومي) \\
\hline & & & 150 & & & شركة المعادي للصلب (السادات) \\
\hline & & & 120 & & & شركة مياى ستيل طنطا \\
\hline 192 & & & 160 & & & شركة ايستار 6 أكتوبر (قطاعات وحديد تسليح) \\
\hline
\end{tabular}




\begin{tabular}{|c|c|c|c|c|c|c|}
\hline قطاعات & مسطحات & سطظحات & تدليد & 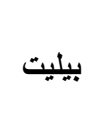 & الإسفنجي & 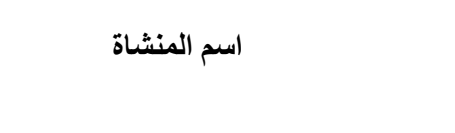 \\
\hline & & & 180 & & & المراكبي للصناعات المعدنية ب 6 أكتوبر \\
\hline & & & 250 & 350 & & المر اكبي للصناعات المعدنية ب 6 أكتوبر \\
\hline & & & 100 & & & مصر ستيل أبو رواش \\
\hline & & & 100 & & & الجيوشي للصلب أكتوبر \\
\hline & & & 450 & 450 & & طيبة للصلب تحت الإنشاء بجمصة \\
\hline & & & 780 & & & ميتاد حلوان \\
\hline & & & 150 & & & نور عنتر بالعامرية \\
\hline 130 & & & & & & العلا بالعامرية \\
\hline 60 & & & & & & التمساح \\
\hline \multirow[t]{6}{*}{207} & & & & & & العلا أكتوبر للقطاعات \\
\hline & 80 & & & & & العلا أكتوبر للصاج البارد \\
\hline & 700 & & & & & مجموعة قنديل للصاج البارد و الجلفنة \\
\hline & 70 & & & & & شركة حديد مصر بالعاشر \\
\hline & 120 & & & 70 & & شركة أبو زعبل (100 ح) \\
\hline & & & 265 & 150 & & أخري \\
\hline 1109 & 1070 & 2600 & 14715 & 12600 & 10200 & الإجمالي \\
\hline
\end{tabular}

ومن الملاحظ من خلال الجدول السابق، إن هذه المصانع ينتج فيها أكثر من الاحتياجات المحلية، ومثال على ذلك، طاقات درفلة حديد وتسليح تصل إلى 15\%، رغم أن الاستهلاك المحلي لعام 2020 وصل الإل إلى 7.5\%، وقد وضعت نلك المصانع خطة إنشاءها لتصدير المنتجات. وقد بينت اقتصاديات تلك المصانع في الأساس أن الجزء الأكبر يتجه مباشرة لأنداير للتصدير ، ولكن تبدّل

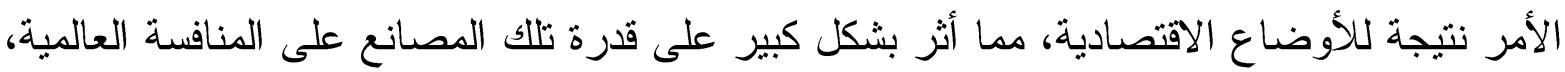
بل تفاقم الأمر سوءاً حينما نم استير اد بعض المعدات من الخارج بتكلفة أقل من تكاليف إنتاجها محليًا. مما جعل قطاع الحديد و الصلب بشكل خاص يو اجه قضايا الإغر اق، و المطالبة برسوم وقائية و الحماية و غيره، من الأمور التي أثرت بشكل كبير على القطاع في مصر .

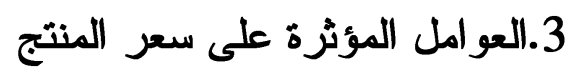
- ق قيمة الخامات الداخلة في الإنتاج - الخامات المستوردة وتنثمل الخردة / مكور ات الحديد الخام و العروق و الفحم. (بالإضافة إلى تغير سعر الصرف). - الخامـات المساعدة مـن سبائك حديدية وحجر جيري أخرى. - تكاليف الثحن البحري و النقل الداخلي.

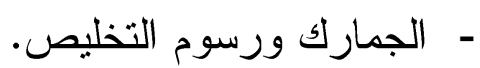

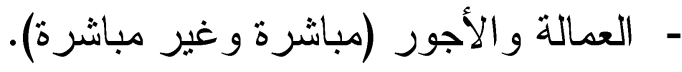


- مستلزمات الإنتاج من أقطاب الجر افيت وقطع الغيار و الدر افيل و الثنحوم و الزيوت. - - أسعار وتوفر الطاقة الكهربية. - الأعباء التمويلية (فو ائد البنوك و أمو ال محبوسهة) - الرسوم السيادية و الضر ائب بأنو اعها - التكاليف الاستثمارية و الإنشائية. جدول (2): بيان الاستهلاك الظاهري لمنتجات الحديد والصلب بمصر

بالألف طن

\begin{tabular}{|c|c|c|c|c|c|c|}
\hline 2020 & 2019 & 2018 & 2017 & 2016 & 2015 & البند \\
\hline \multicolumn{7}{|c|}{ الإنتاج الكلي للمصانع } \\
\hline \multirow[t]{5}{*}{6894} & 7453 & 7448.8 & 7418 & 7031 & 7151 & إجمالي حديد التسليح \\
\hline & 1695 & 1470 & 1806.6 & 1421 & 873.7 & إجمالي مسطحات ساخن للبيع \\
\hline & 175 & 190 & 219 & 207.9 & 100 & إجمالي قطاعات للبيع \\
\hline & 280 & 605 & 833 & 33 & $\mathbf{0}$ & إجمالي عروق للبيع ل \\
\hline & 630 & 657 & 1050 & 776 & 548 & إجمالي مسطحات بارد ومطلي ومجلفن \\
\hline \multicolumn{7}{|c|}{ الإنتاج المباع محلياً } \\
\hline \multirow[t]{5}{*}{6724} & 7230 & 7207 & 7178 & 6904 & 7094 & إجمالي حديد التسليح \\
\hline & 1160 & 1050 & 1151.6 & 1044 & 616.7 & إجمالي مسطحات ساخن للبيع \\
\hline & 145 & 155 & 170 & 189 & 95 & إجمالي قطاعات للبيع \\
\hline & 100 & 438 & 750 & 17 & $\mathbf{0}$ & إجمالي عروق للبيع \\
\hline & 470 & 450 & 600 & 530 & 470 & إجمالي مسطحات بارد ومطلي ومجلفن \\
\hline \multicolumn{7}{|c|}{ الصادرات } \\
\hline 300 & 223 & 241.8 & 240 & 127 & 57 & إجمالي حديد التسليح \\
\hline 592 & 535 & 420 & 655 & 377 & 257 & إجمالي مسطحات ساخن للبيع \\
\hline 26 & 30 & 35 & 49 & 18.9 & 5 & إجمالي قظاعات للبيع \\
\hline 5 & 180 & 167 & 83 & 16 & $\mathbf{0}$ & إجمالي عروق للبيع \\
\hline 230 & 160 & 207 & 450 & 246 & 78 & إجمالي مسطحات بارد ومطلي ومجلفن \\
\hline \multicolumn{7}{|c|}{ الواردات } \\
\hline 1 & 123 & 138 & 270 & 1317.6 & 1500 & إجمالي حليد التسليح \\
\hline 1276 & 1270 & 780 & 1171 & 772 & 1035 & إجمالي مسطحات ساخن للبيع \\
\hline 233 & 296 & 191 & 185 & 183.9 & 255 & إجمالي قطاعات للبيع \\
\hline 520 & 2293 & 3400 & 2340 & 2722 & 3970 & إجمالي عروق للبيع إن \\
\hline 537 & 580 & 497 & 720 & 647.1 & 680 & إجمالي مسطحات بارد ومطلي ومجلفن \\
\hline \multicolumn{7}{|c|}{ الاستهلاك الظاهري } \\
\hline & 7353 & 7345 & 7448 & 8221.6 & 8594 & إجمالي حليد التسليح \\
\hline & 2430 & 1830 & 2322.6 & 1816 & 1651.7 & إجمالي مسطحات ساخن للبيع \\
\hline & 441 & 346 & 355 & 372.9 & 350 & إجمالي قطاعات للبيع \\
\hline & 2393 & 3838 & 3090 & 2739 & 3970 & إجمالي عروق للبيع \\
\hline & 1050 & 947 & 1320 & 1177.1 & 1150 & إجمالي مسطحات بارد ومطلي ومجلفن \\
\hline
\end{tabular}

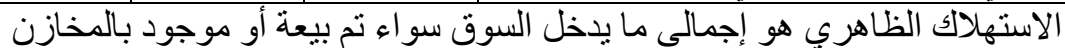

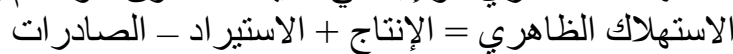
هناك مصانع تتتج أحتياجاتها من العروق ذاتياً 
أسباب اختلاف أسعار البيع بين المنتجين

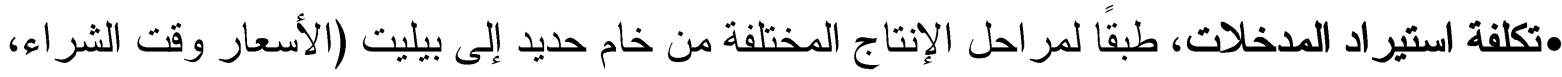
تكلفة النقل، أسعار الصرف ووسيلة التمويل). •عدد المر احل الإتتاجية، فكلما ز ادت المر احل (مصانع متكاملة) قلت تكلفة المنتج النهائي بسبب تحقيق قيمة مضافة في كل مرحله. •المستوى التقني للوحدات الإنتاجية، من حيث أنها وحدات حديثة أم مستعمله بالخار ج وتم إعادة تأهيلها

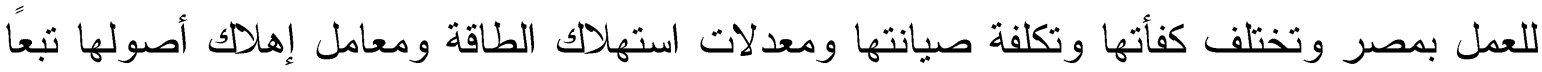
لذلك. • حجم تشكيلة الإنتاج من الأقطار و الإثكال ونوعية الصلب ومدى تغطيتها لكافة احتياجات العميل من موز ع واحد. • • حجم و إنتاجية العمالة، ومدى مناسبتها لمر احل الإنتاج. • كمية الإنتاج للسوق المحلى، فكلما زادت الصادرات (كضرورة لتدبير عملات لشراء الخامات

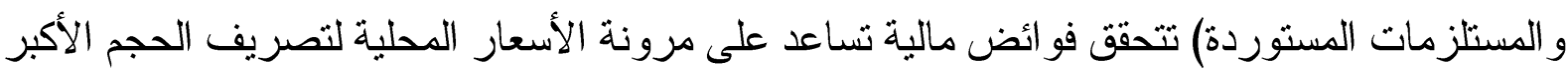
من الإنتاج و الذي يصعب تصديره. و والعكس بالعكس.

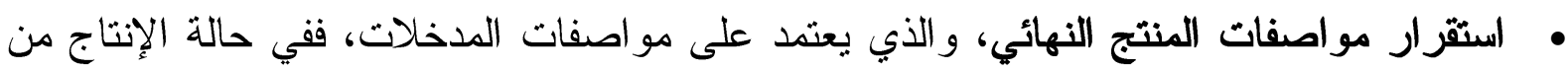

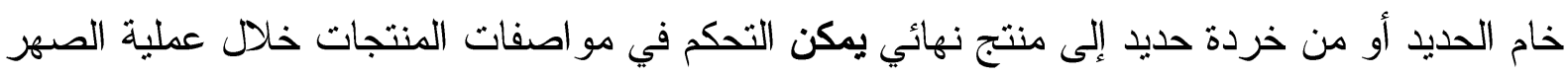

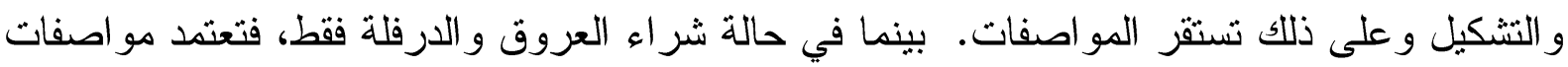

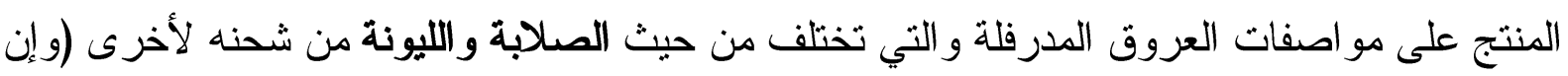

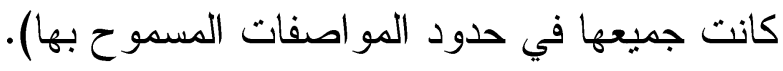

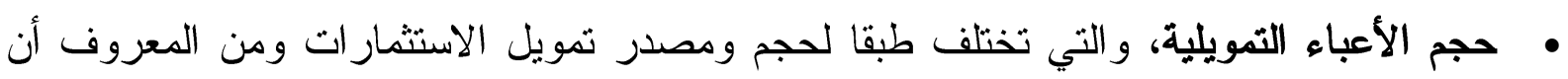

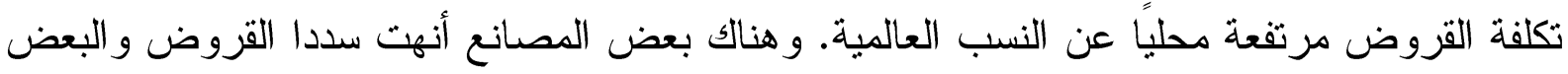

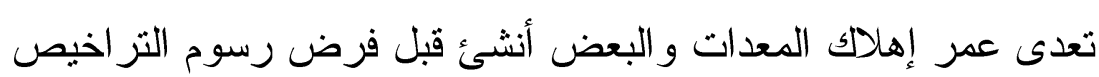

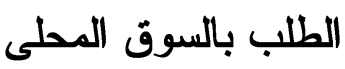

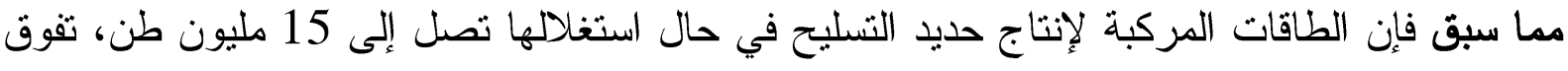

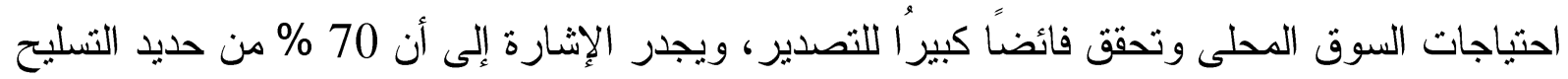

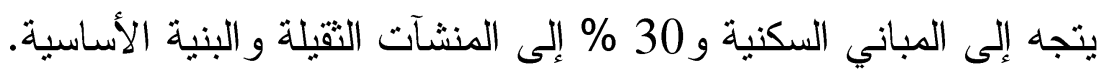

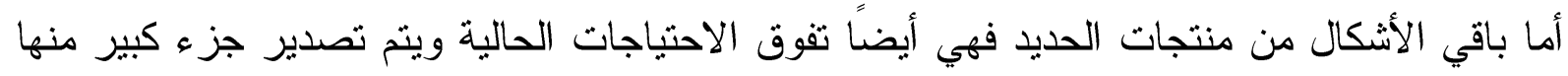

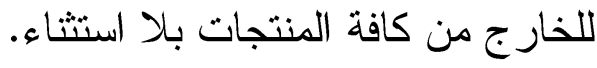


كما أن هناك العديد من الصناعات القائمة على تلك المنتجات (غير حديد النسليح) نشهد نموًا مطرداً مثل: صناعة الهياكل المعدنية والآلات و المعدات و الأجهزة المنزلية وصناعة المواسير وسحب السلك و المسمار و ....الخ.

وتتوز ع مصانع الصلب في السويس وبورسعيد والإسكندرية و المنوفية والقاهرة والقليوبية و الجيزة وبني سويف و العين السخنة (وبكل المدن الصناعية). جدول (3): البنود الجمركية لمنتجات قطاع الحديد والصلب

\begin{tabular}{|c|c|c|}
\hline 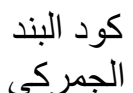 & \multicolumn{2}{|l|}{ وصف البند } \\
\hline 72.01 & $\begin{array}{l}\text { Pig iron and spiegeleisen in pigs, blocks or } \\
\text { other primary forms. }\end{array}$ & سبيجل"، بشكل كتل أو بأثنكال أولية أخر. صد " \\
\hline 72.02 & Ferro-alloys. & \\
\hline 72.03 & $\begin{array}{l}\text { Ferrous products obtained by direct reduction } \\
\text { and other spongy ferrous products, in lumps, } \\
\text { pellets }\end{array}$ & 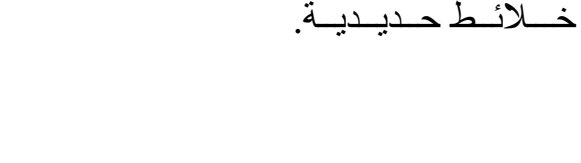 \\
\hline 72.04 & $\begin{array}{l}\text { Ferrous waste and scrap; remelting scrap } \\
\text { ingots of iron or steel. }\end{array}$ & 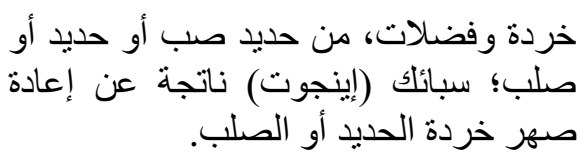 \\
\hline 72.05 & $\begin{array}{l}\text { Granules and powders, of pig iron, } \\
\text { spiegeleisen, iron or steel. }\end{array}$ & حديبيات صب " سبيجل " أو من حديد صب أو خلب أو \\
\hline 72.06 & Iron and Non-Alloy Steel & حديد وصلب من غير الخلائط \\
\hline 72.07 & $\begin{array}{l}\text { Semi-finished products of iron or non-alloy } \\
\text { steel. }\end{array}$ & من غير الخلائط. جاهزة من حديد، أو من صلب \\
\hline 72.08 & $\begin{array}{l}\text { Flat-rolled products of iron or non-alloy steel, } \\
\text { of a width of } 600 \mathrm{~mm} \text { or more, hot-rolled, not } \\
\text { clad, plated or coated. }\end{array}$ & 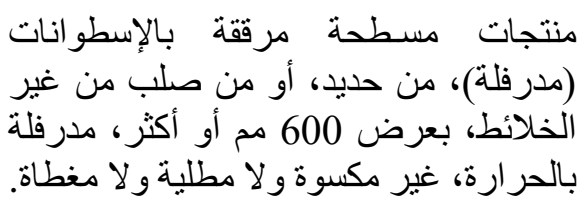 \\
\hline 72.09 & $\begin{array}{l}\text { Flat-rolled products of iron or non-alloy steel, } \\
\text { of a width of } 600 \mathrm{~mm} \text { or more, cold-rolled } \\
\text { (cold-reduced), not clad, plated or coated. }\end{array}$ & 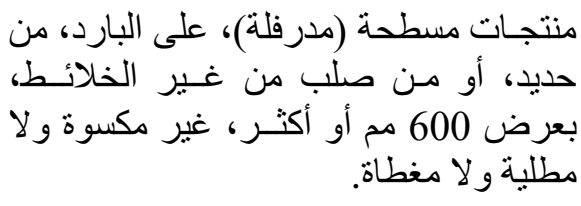 \\
\hline 72.10 & $\begin{array}{l}\text { Flat-rolled products of iron or non- } \\
\text { alloy steel, of a width of } 600 \mathrm{~mm} \text { or more, clad, } \\
\text { plated or coated. }\end{array}$ & 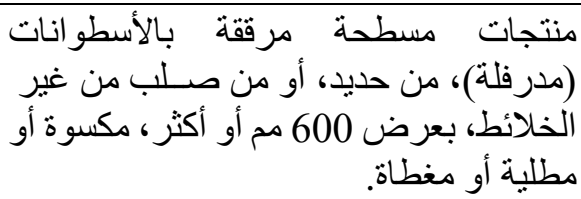 \\
\hline
\end{tabular}




\begin{tabular}{|c|c|c|}
\hline 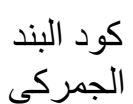 & \multicolumn{2}{|c|}{ وصف البند } \\
\hline 72.11 & $\begin{array}{l}\text { Flat-rolled products of iron or non-alloy } \\
\text { steel, of a width of less than } 600 \mathrm{~mm} \text {, not } \\
\text { clad, plated or coated. }\end{array}$ & 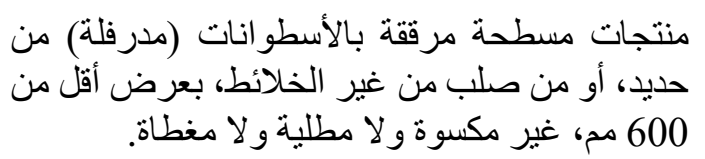 \\
\hline 72.12 & $\begin{array}{l}\text { Flat-rolled products of iron or non-alloy } \\
\text { steel, of a width of less than } 600 \mathrm{~mm} \text {, clad, } \\
\text { plated or coated. }\end{array}$ & 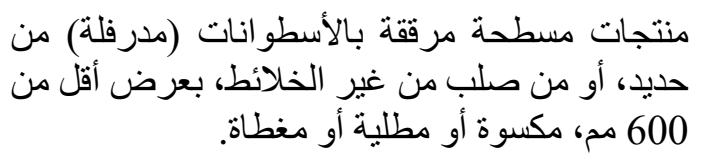 \\
\hline 72.13 & $\begin{array}{l}\text { Bars and rods, hot-rolled, in irregularly } \\
\text { wound coils, of iron or non-alloy steel. }\end{array}$ & 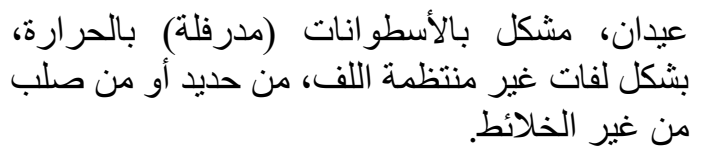 \\
\hline 72.14 & $\begin{array}{l}\text { Other bars and rods of iron or non-alloy } \\
\text { steel, not further worked than forged, hot- } \\
\text { rolled, hot-drawn or hot-extruded, but } \\
\text { including those twisted after rolling. }\end{array}$ & 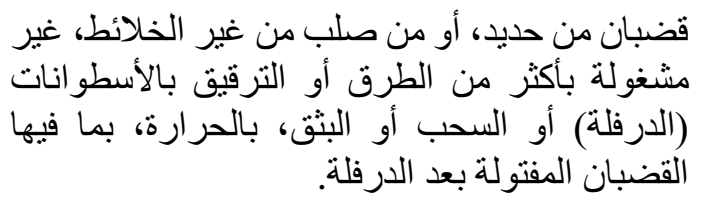 \\
\hline 72.15 & $\begin{array}{l}\text { Other bars and rods of iron or non-alloy } \\
\text { steel. }\end{array}$ & قضبان أخر من حديد أو من صلب من غير الخلائط. \\
\hline 72.16 & $\begin{array}{l}\text { Angles, shapes and sections of iron or non- } \\
\text { alloy steel. }\end{array}$ & 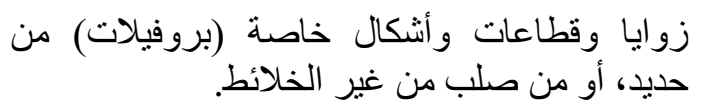 \\
\hline 72.17 & Wire of iron or non-alloy steel. & أسلاك من حديد، أو من صلب من غير الخلائط. \\
\hline 72.18 & III. STAINLESS STEEL & - 3صلب مقاوم للصدأ ( ستانلس سنيل ) \\
\hline 72.19 & $\begin{array}{l}\text { Flat-rolled products of stainless steel, of a } \\
\text { width of } 600 \mathrm{~mm} \text { or more. }\end{array}$ & صنب مقات مسطحة مرقة للصدا، بعرض بالإسطو انات (مدر أوفلة) من 600 من \\
\hline 72.20 & $\begin{array}{l}\text { Flat-rolled products of stainless steel, of a } \\
\text { width of less than } 600 \mathrm{~mm} \text {. }\end{array}$ & 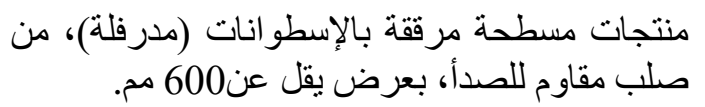 \\
\hline 72.21 & $\begin{array}{l}\text { Bars and rods, hot-rolled, in irregularly } \\
\text { wound coils, of stainless steel. }\end{array}$ & لفات غيدان، مرققة بالإسطو انات من صدرفلة) بالحر ارة، بشكل \\
\hline 72.22 & $\begin{array}{l}\text { Stainless steel; angles, shapes and } \\
\text { sections of stainless steel. }\end{array}$ & زلصدأ. وقطاعات و أثنكال خاصة، من صلب مقاوم \\
\hline
\end{tabular}




\begin{tabular}{|c|c|c|}
\hline 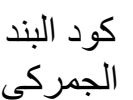 & \multicolumn{2}{|c|}{ وصف البند } \\
\hline 72.23 & Wire of stainless steel. & أسلاك من صلب مقاو م للصدأ. \\
\hline 72.24 & $\begin{array}{l}\text { IV. OTHER ALLOY STEEL; HOLLOW } \\
\text { DRILL BARS AND RODS, OF ALLOY } \\
\text { OR NON-ALLOY STEEL }\end{array}$ & صلب من غير الخلائط أخر؛ من خلانئ مجوفة للب صفر من \\
\hline 72.25 & $\begin{array}{l}\text { Flat-rolled products of other alloy steel, of } \\
\text { a width of } 600 \mathrm{~mm} \text { or more. }\end{array}$ & خلائجات صلب أخر، مسرة مرقة بالأسطو انات (مدرفلة)، من 600 مم أو أكثر. \\
\hline 72.26 & $\begin{array}{l}\text { Flat-rolled products of other alloy steel, of } \\
\text { a width of less than } 600 \mathrm{~mm} \text {. }\end{array}$ & منترض أقل مسطحة (مدرفلة)، من خلانط صلب أخر ، \\
\hline 72.27 & $\begin{array}{l}\text { Bars and rods, hot-rolled, in irregularly } \\
\text { wound coils, of other alloy steel. }\end{array}$ & 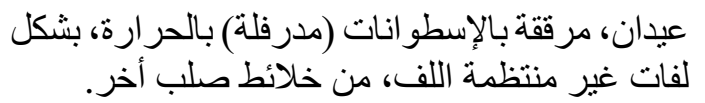 \\
\hline 72.28 & $\begin{array}{l}\text { Other bars and rods of other alloy steel; } \\
\text { angles, shapes and sections, of other alloy } \\
\text { steel; hollow drill bars and rods, of alloy or } \\
\text { non-alloy steel. }\end{array}$ & 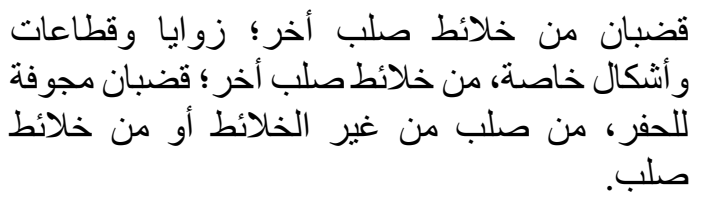 \\
\hline 72.29 & Wire of other alloy steel. & أسلاك من خلائط صلب أخر. \\
\hline 73.01 & $\begin{array}{l}\text { Sheet piling of iron or steel, made from } \\
\text { assembled elements; welded angles, } \\
\text { shapes and sections }\end{array}$ & دصنعة من عناصر مجيضة من حديدة أو صلب، وايات وقطاعات. كانت \\
\hline 73.02 & $\begin{array}{l}\text { Railway or tramway track construction } \\
\text { material : rails, switch blades, and other } \\
\text { crossing pieces, sleepers (cross-ties), fish- } \\
\text { plates, }\end{array}$ & 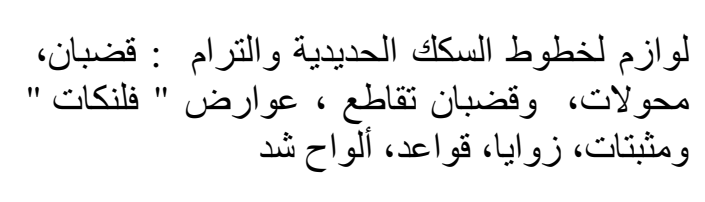 \\
\hline 73.03 & $\begin{array}{l}\text { Tubes, pipes and hollow profiles, of cast } \\
\text { iron. }\end{array}$ & من حديد صلبب. مو أنابيب و أشكال خاصة (بروفيلات) مجوفة، \\
\hline 73.04 & $\begin{array}{l}\text { Tubes, pipes and hollow profiles, } \\
\text { seamless, of iron (other than cast iron) or } \\
\text { steel. }\end{array}$ & غير ملحومة، من حديد أو صلبيب و أنثكال خاصة (بروفيلات)، مجوفة، \\
\hline
\end{tabular}




\begin{tabular}{|c|c|c|}
\hline 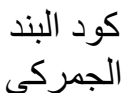 & \multicolumn{2}{|c|}{ وصف البند } \\
\hline 73.05 & $\begin{array}{l}\text { tubes and pipes welded, riveted or } \\
\text { similarly closed), }\end{array}$ & بطريقة ممانلكة. \\
\hline 73.06 & $\begin{array}{l}\text { Other tubes, pipes and hollow profiles (for } \\
\text { example, open seam or welded, riveted or } \\
\text { similarly closed), of iron or steel. }\end{array}$ & 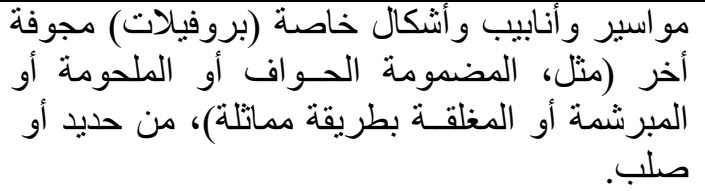 \\
\hline 73.07 & $\begin{array}{l}\text { Tube or pipe fittings (for example, } \\
\text { couplings, elbows, sleeves), of iron or } \\
\text { steel. }\end{array}$ & الأكمام ..إلخ) من حديد أو أنابيب (مثل، أو حديد أو صلات، الأكواع، \\
\hline 73.08 & $\begin{array}{l}\text {--- Rolled and stranded rods for concrete } \\
\text { reinforcement }\end{array}$ & --- عيدان مدرفلة ومجدولة لتقوية الخرسانة \\
\hline 73.24 & $\begin{array}{l}\text { Sanitary ware and parts thereof, of iron or } \\
\text { steel. }\end{array}$ & صلب . كات صحية وأجز اؤها، من حديد صب أو حديد أو \\
\hline 73.25 & Other cast articles of iron or steel. & صلب. مصنو عات أخر مصبوبة، من حديد صب أو حديد أو \\
\hline 73.26 & Other articles of iron or steel. & مصنو عات أخر من حديد أو صلب. \\
\hline
\end{tabular}

4. نقاط القوة و الضعف في صناعة الصلب المصرية

4-1-4 نقاط القوة

- مت - توفر العمالة القابلة للتدريب.

- توفر نسبة مرتفعة من طاقة ومياه ووقود محليًا.

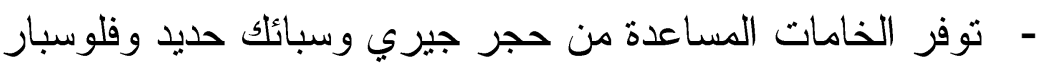

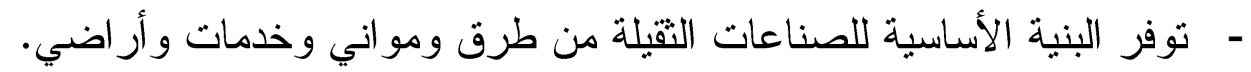

- مستوى التلوث البيئي أقل من المعدلات العالمية والقيود البيئية المحلية أفضل.

- - حجم السوق المحلى مناسب ووجود العديد من الاتفاقيات مع دول أفريقيا وأوروبا.

- - إقبال الاستثمار ات المحلية و الإقليمية و الدولية.

- توسط الموقع الجغر افي بالنسبة للأسواق العالمية (للمدخلات و المنتجات). 
4-2. نقاط الضعف

- ت تفاوتات التكلفة بين مصر والخارج، حيث أن تكلفة إنثاء مصنع صلب منكامل بالخار ج بطاقة مليون طن على أرض فضاء كاملة المر افق تقدر بمليار دو لار أي أن تكلفة الإهلاك تبلغ 50 دو لار للطن. أما في مصر فإن هنالك العديد من عناصر التكلفة ضريبة مبيعات على المعدات 5\% تسدد بالمو انئ قبل الإنشاء وتسترد من عائد بيع المنتجات بعد

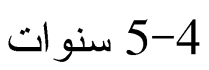

رسوم توليد لدعم الكهرباء 3 مليون جنيه لكل ميجاو ات تسدد عند التعاقد مع وزارة الكهرباء

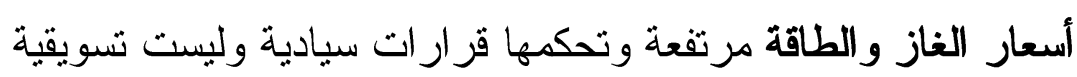
عقود الغاز و الكهرباء تضع شروط إزعان مرهقة (تأمين استهلاك و أسعار للكميات الأقل و الأكثر

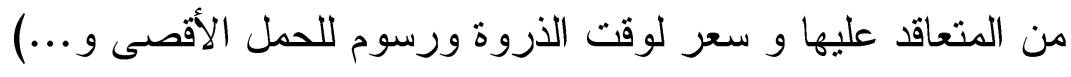
ارتفاعات المنشآت محددة ب 15 مثر وضرورة سداد رسوم مقابل التصريح بارتفاعات.

رسوم باهظة الحصول على الترخيص من الهيئة العامة للتنمية الصناعية.

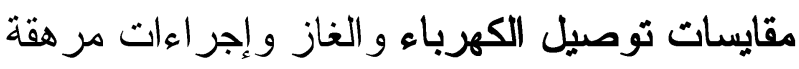

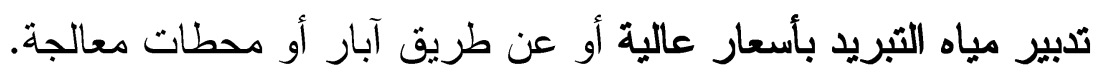

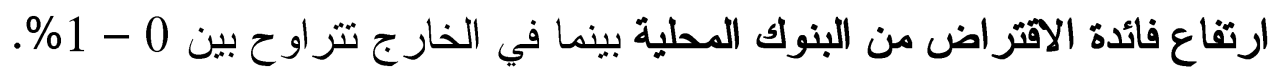
تحصيل دفعات تحت حساب الضر ائب للخاسر وقيمة مضافة محبوسة لاي المالية. لا توجد أرصفة موانئ مخصصة لصناعة الصلب مثل باقي الدول ومعدلات التفريغ بطيئة مدا يؤدي إلى غر امات انتظار للسفن. يتم محاسبة المصانع على تعريفة الغاز حاليًا أعلى من مثليها بالبلاد التي تتتج جزء من حاجنهار لإنها

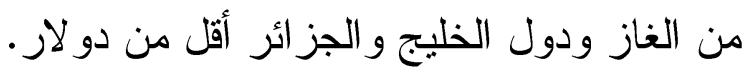
يحصل المصنع على الطاقة الكهربية بأعلى الأسعار باعتباره كثيف الاستهلالك. كما أن تعريفة الطاقة تشمل إهلاك محطة التوليد السابق سدادها. أسعار الطاقة للمصانع كثيفة الاستهلاك عالميًا أقل من أسعار ها للصناعات التهات الأخرى أو أسعار

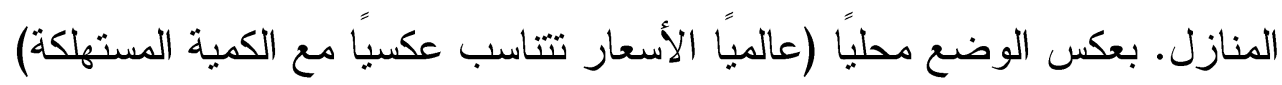
نقص الكفاءة أدى إلى أن عدد العمالة بالمصنع المصري أضعاف العالف العدد لنفس حجم المصنع الأجنبي،

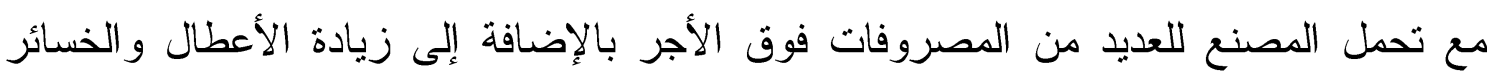

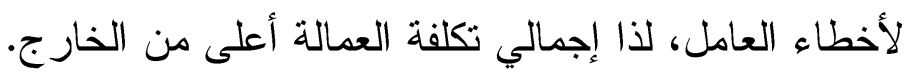

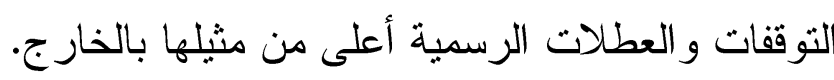

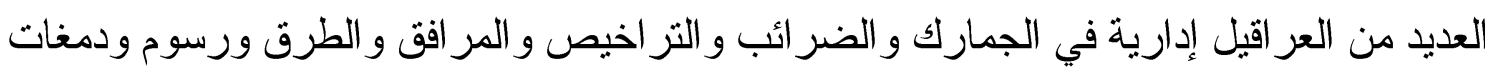
البنوك تتحول إلى مصروفات إضافية على تكلفة الإنتاج. 
- - - رسوم جمارك على مستلزمات وخامات الإنتاج تتز اوح بين 2 إلى 30\% و المنتج التام معفى.

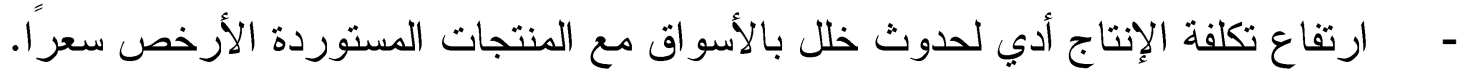
- - أغلب تلكك العر اقيل لم تكن موجودة عند إعداد دراسات الجدوى و التقام للترخيص عام 2007.

و التي اعتمدت على دراسات تسويقية للتصدير بكميات كبيرة.

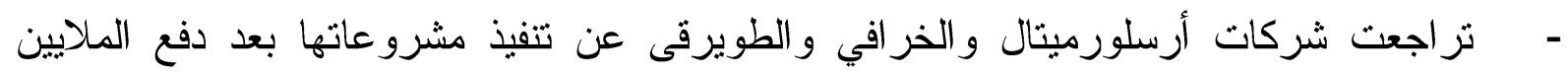

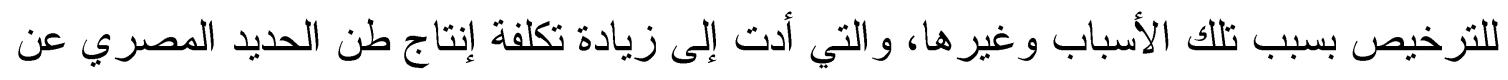
المستورد وصعوبة اقتحام أسواق التصدير لتصريف فائض الإنتاج. أضواء على قضايا الطاقة (كهرباء ووقود) مع صناعة الصلب تتحصر مشكلة الطاقة في ثلاثة محاور كالتالي: -

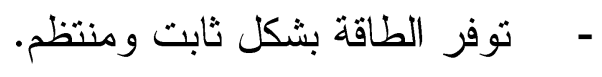
- - سياسة سعريه و اضحة ولفترات زمنية طويلة ومستقرة. - - عدالة في نظام التسعير بين أسعار المنازل و المصانع (الكثيفة وغير الكثيفة) القائمة والجديدة.

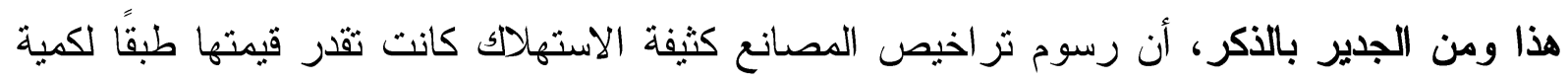

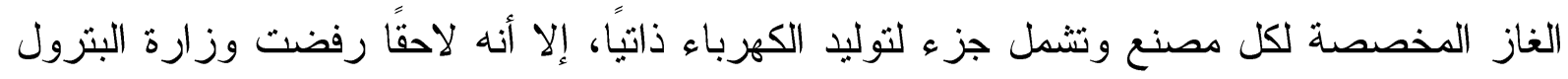

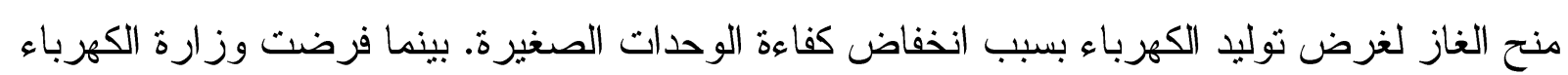
رسوم توليد للمشرو عات الجديدة كثرط للتعاقد معهم.

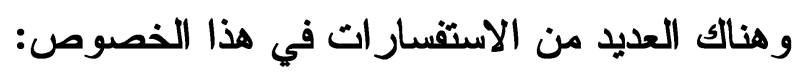
• هل تتحمل شبكة الغاز الموجودة كميات الغاز المستهدف استيرادها للوفاء باحتياجات الصناعة فلاء

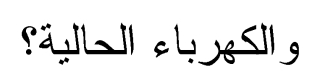

هل سيكون هناك أكثر من سعر للغاز للمصانع الجديدة وكذلك المصانع القائمة؟

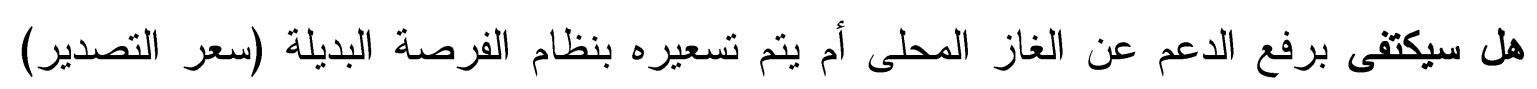

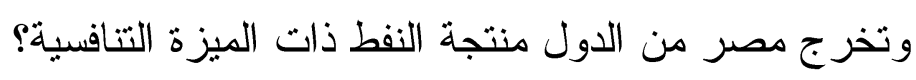

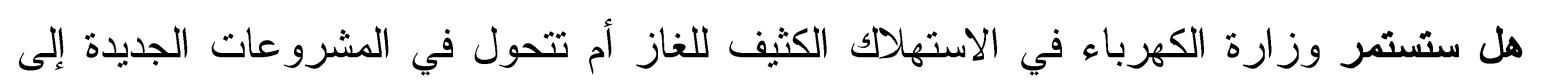

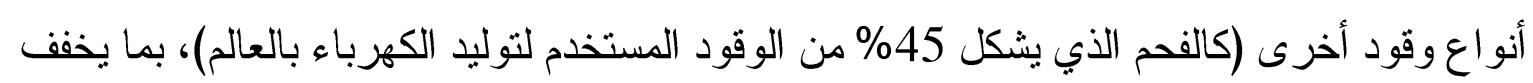

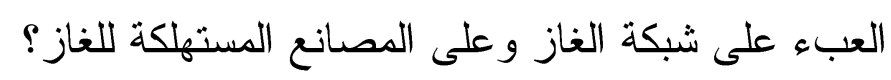
هدود مسئولية الدولة، فمن المعلوم أن الدولة مسئولة عن توفير عناصر الإنتاج و على رأسها الطاقة

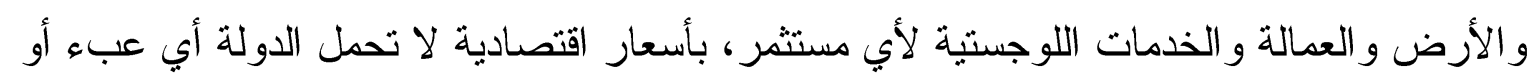

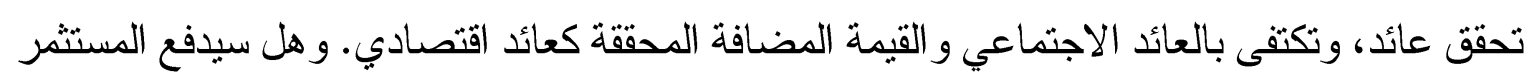

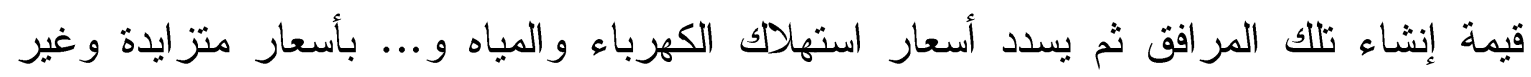
|قتصادية؟؟ 
سياسات تسعير الكهرباء، وهي مخالفة تمامًا لكل ما يجرى في العالم، فأسعار الكهرباء بالعالم

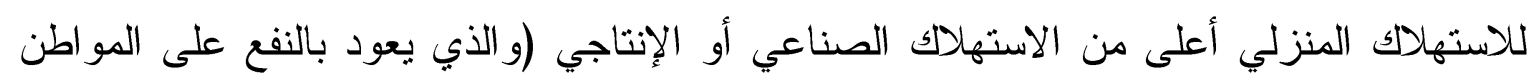

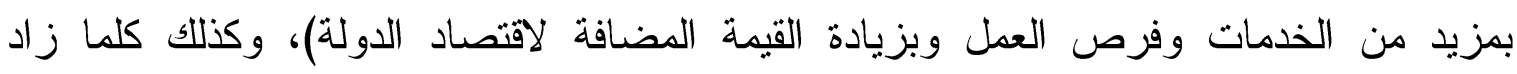
الاستهلالك من الكهرباء قل السعر .

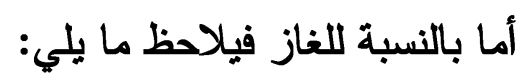
تفاوت استخدام صناعة الصلب للوقود والغاز والفحم طبقا للتكنولوجيا المستخدمة وكل منها يؤثر

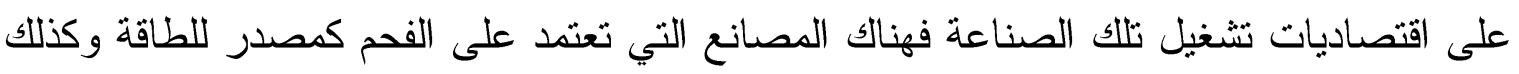

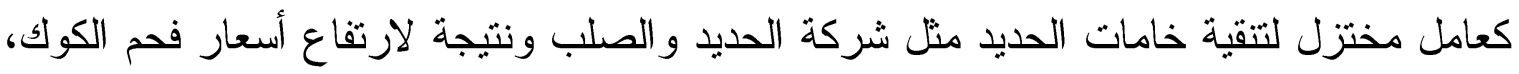
تتجه إلى زيادة استخدام الغاز لتخفيض نسبة الفحم المستخدمة.

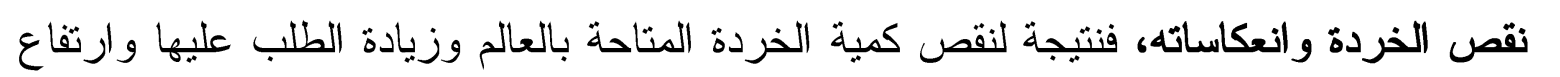

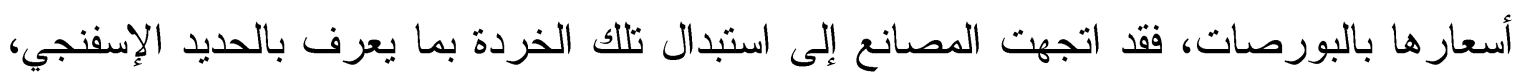

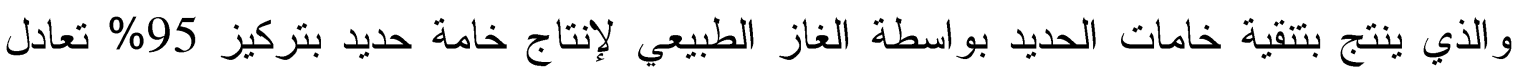
الخردة.

• استخدام الغاز في مصانع الدرفة، بغرض تسخين العروق وهي أقل معدلات استخدام للغاز و التي لا

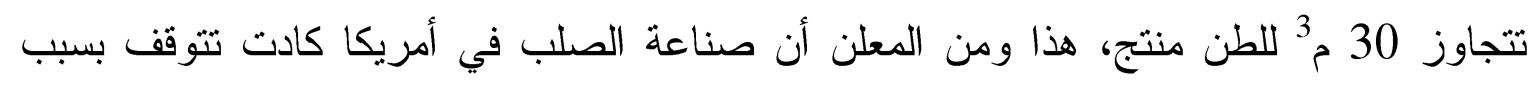
مشاكل استخدام الفحم لو لا التحول لاستخدام الغاز الطبيعي هناك. لهن.

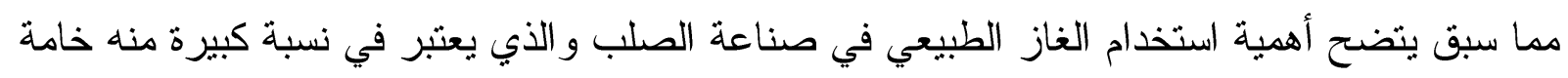
ضرورية لعملية استخلاص الحديد من الثوائب. ويجدر الإشارة في هذا الخصوص إلى بعض البيانات الأساسية التالية: • ارتفع سعر الغاز من 4 إلى 7 دو لار للمليون وحده.

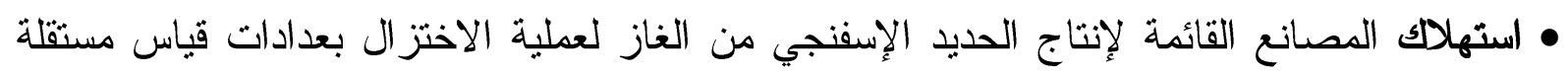
ضغط 20-25 بار تبلغ 1.5 مليار متر مكعب سنويًا. • استهلاك المصانع القائمة لتشكيل ولإنتاج الحديد باستخدام الغاز لعملية التسخين بعدادات فياس مسنقلة ضغط 4 بار تبلغ 350 مليون م3 سنويًا.

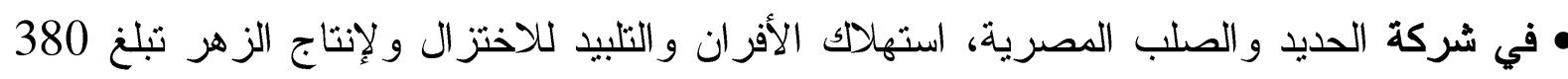

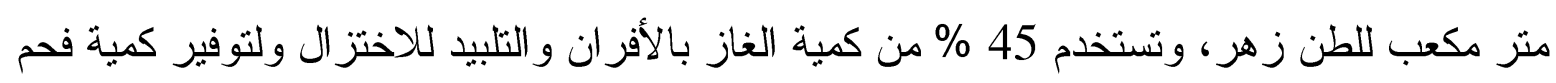

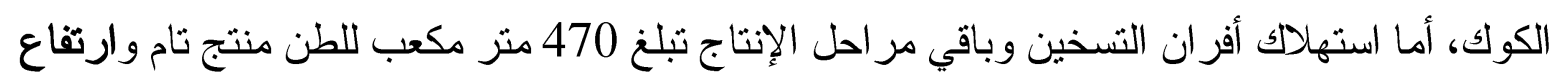
سعر الغاز من 4 إلى 7 دو لار لنفس كمية الإنتاج يكلف الثركة 190 مليون حنيله. • شركة الحديد و الصلب طاقتها الإنتاجية بالأفران العالية تبلغ الأتاج 1200 ألف طن بالسنة، وكمية الدرفلة للمنتج التام تبلغ مليون طن. 
في ضوء ما سبق، لذلك لا بد من إعادة النظر في أسعار الغاز لمصانع الصلب، - - تعديل سعر الغاز لمصانع الاختز ال ضغط 20-25 بار إلى لـ 4.5 دو لار للمليون وحدة.

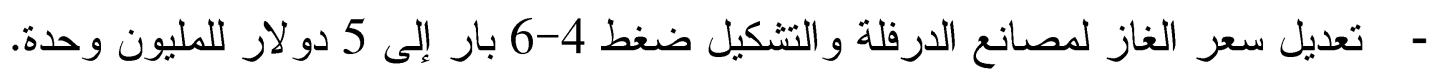

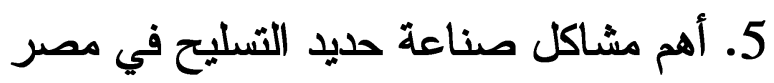

إن صناعة الصلب وهى صناعة استراتيجية تتعرض لموقف بالغ الصعوبة، حيث بلغ حجم

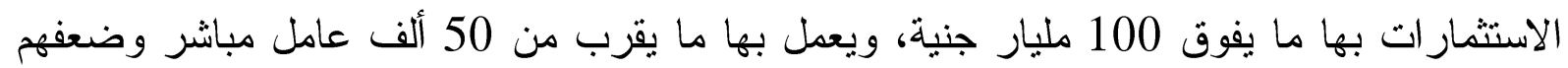

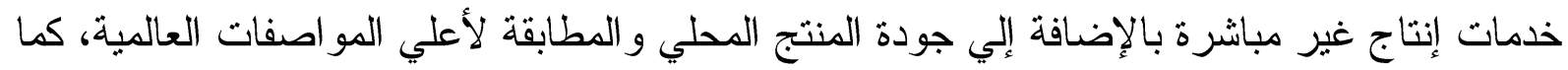

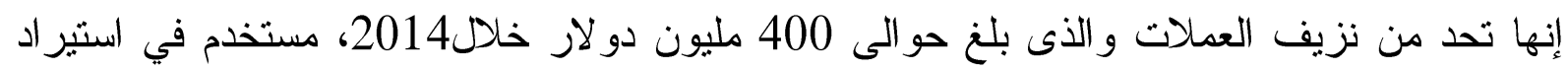

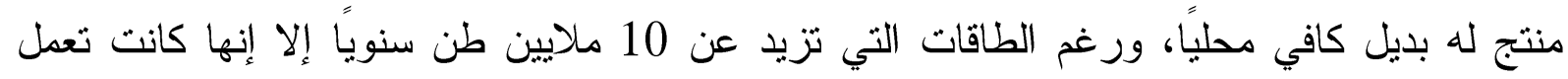
بحو الي 60 \% منها فقط بل ونوقف 4 مصانع عن العمل لصعوبة التسويق ويتر اكم المخزون بالمصانع، وذلك بسبب الو اردات الكثيفة خلال الفترة حتى أغسطس 2014. وقد تحملت الصناعة العديد من الظروف و التحديات التي مرت خلال الفترة الماضية من ارتفاع أسعار

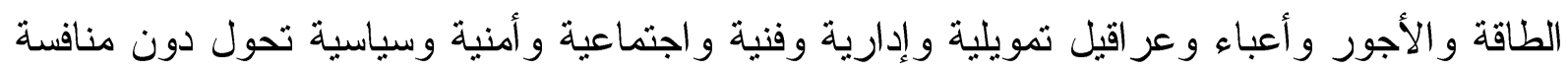

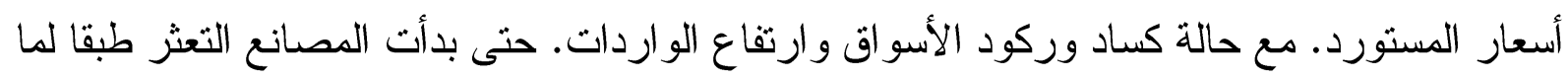
تؤكده بيانات الثركات المعتمدة و المرفوعة إلى جهاز مكافحة الدعم بوز ارة التجارة و والصناعة.

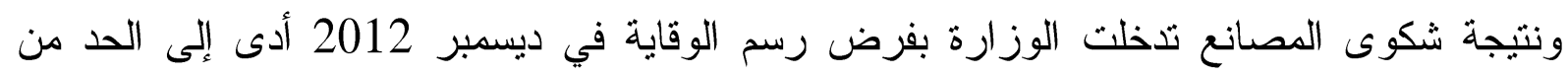

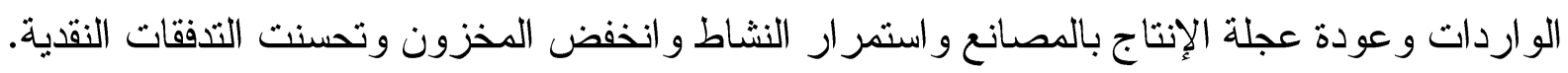

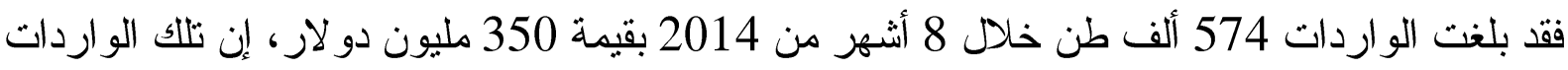

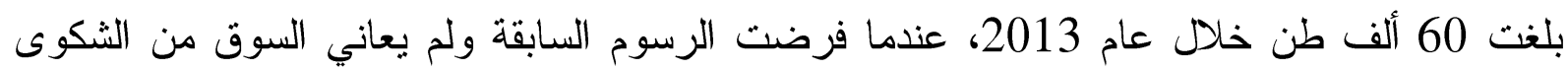

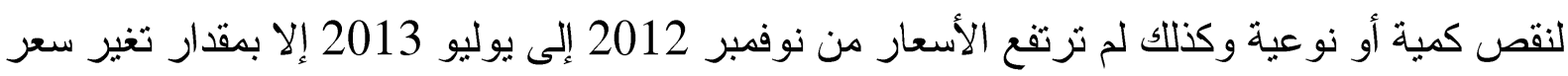
الدو لار (من 4300 إلى 4600 جنيه للطن الند).

وقد شهح النصف الأول من 2014 طوفان من الواردات شملت الحديد الأوكر اني الذي إنهار سعر العملة

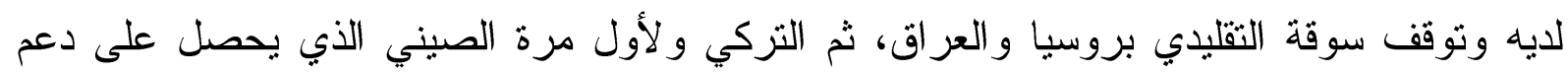

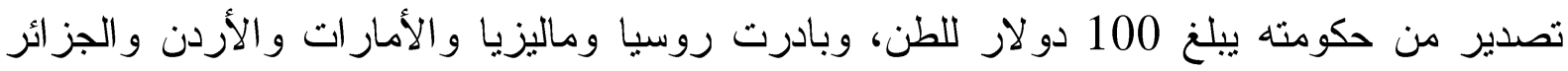

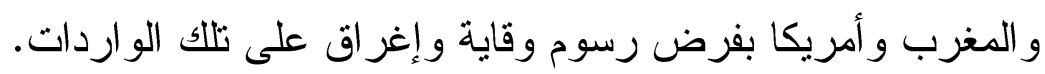
إن ما سبق يؤكد ضرورة بل حتمية فرض الرسم، حيث أن منطقة الشرق الأوسط أصبحت مستو مستهدفة

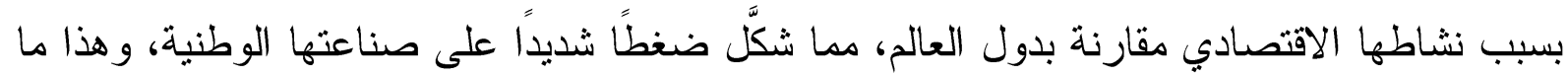
يفسر الدفاع المحموم للمصدرين لفتح السوق المصري أمام صادراتهم ويدفعون أمامهم المستوردين المحليين بشتى الحجج. 
ويمكن مناقشة بعض جوانب تأثير قرار فرض الرسوم على النشاط الاقتصادي فيما يلى:

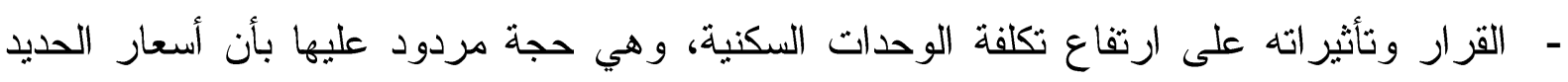

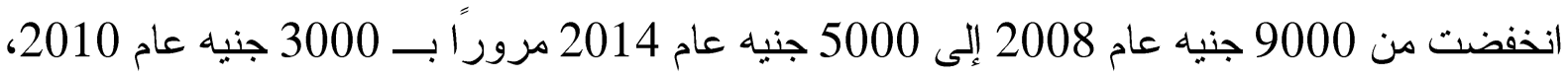
ومع ذلك لم تتخفض أسعار الوحدات السكنية بل ارتفعت. بما ينفى العلاقة بين أسعار الحديد والوحدات السكنية. كذللك إن الرسم البالغ 300 جنيه لا يمثل أكثر من 600 جنيه لسعر الوحدة 70 مثر البالغ 150

ألف جنيه. - إن شركات الحديد تضع سياستها التسعيرية اعتمادا على الأسعار العالمية للخامات وحجم المخزون

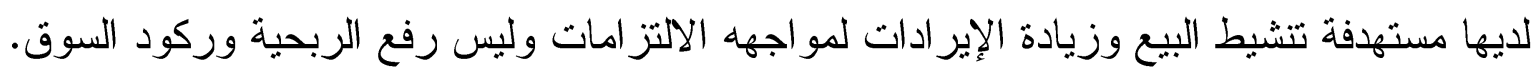

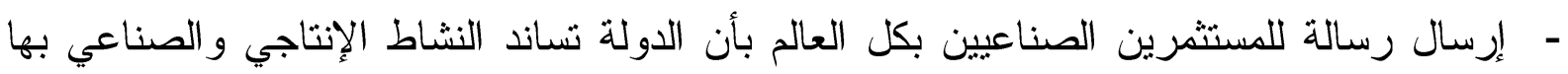
و هو الأجدر على خلق فرص عمل وتحقيق إيرادات للاولة وليس مساندة النشاط التجاري و المالي بالاستير اد و البورصة. - محاربة الادعاء بأن العمل بالقطاع الخاص الصناعي غير مأمون نتيجة لكثرة شكاوى وتوقف بعض المصانع و الاندفاع نحو الوظائف الحكومية. - عمل الصناعة المحلية بكامل طاقتها بما يعود على الدولة بزيادة الإير ادات من ضر ائب ورسوم ويحد

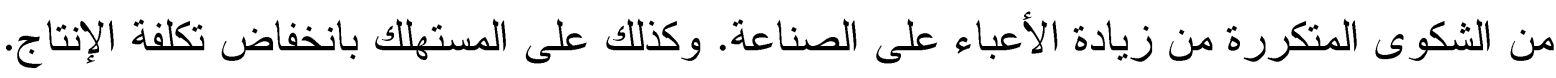
في ضوء ما سبق فإن غرفة الصناعات المعدنية تزى ما يلي:

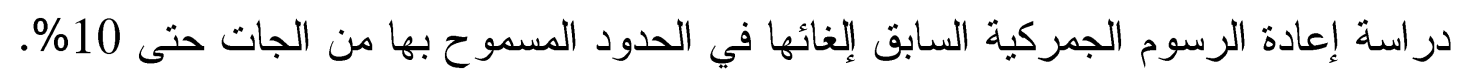
هالعودة إلى فحص الحديد على سطح المركب ومطابقته للمو اصفة المصرية فقط وذللك قبل السماح

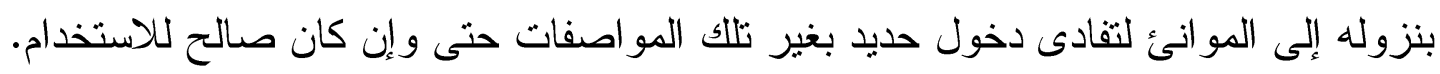

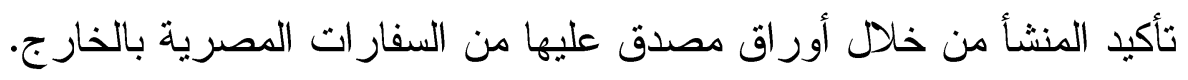

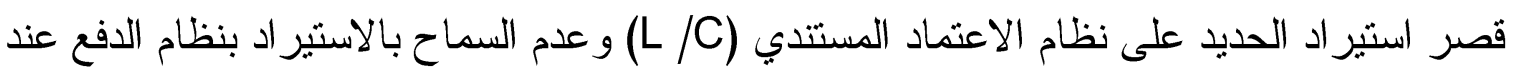
التسليم (CAD) وهي من التسهيلات التي يمنحها المصدرين بالخارج

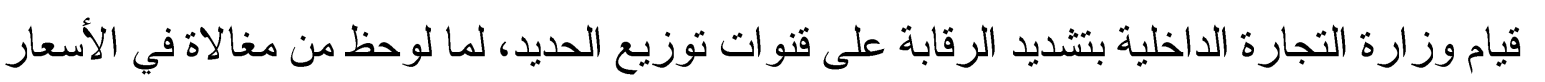

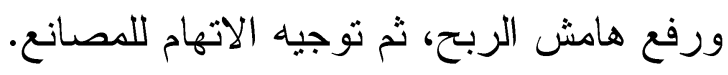

ونتيجة لجهود الغرفة في هذا المجال، تم فرض رسوم إغراق على واردات الحديد لمدة 5 سنوات من

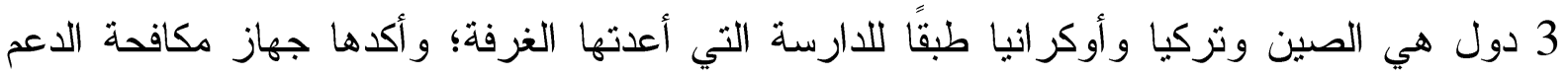
و الإغراق. 


\section{أهم التعليقات و المداخلات}

بعد انتهاء العرض بدأت المداخلات والتعليقات من أعضاء الهيئة العلمية بمعه التخطيط القومي وضيوف سيمنار الثلاثاء من خارج المعهد، و التي ركزت على النقاط الثالية:- تُعد صناعة الحديد و الصلب من الصناعات الثقيلة، وهي أساس لصناعات أخرى، ولكنها تعاني من بعض أوجه القصور من ناحية العمق من حيث اعتمادها على الاستير اد سواء الخامات أو المعدات والآلات والأفران، ووحدات الصهر، أو على مستوى التتويع، وتشكيلة المنتجات، فالمسيطر على هذه الصناعة هو حديد التسليح. - يمكن النظر لأوجه القصور في صناعة الحديد و الصلب، وما بها من تحديات كفرصة للبحث عن آفاق توطين وتعميق هذه الصناعة و الصناعات المعتمدة عليها. - درت صناعة الحديد و الصلب بفترة كان بسودها الاحتكار ، ولكن تراجع هذا الأمر مؤخرًا، فتر اجع الاحتكار و اتسعت رقعة المنافسة، حيث انخفضت نسبة تركز الصناعة، فمثلا انخفضت الحصة السوقية لأربع أكبر شركات من 95\% سنة 2007 إلى 72\% سنة 2019، بما كان يُعتبر نوع من أنو اع الاحتكار في حينه، ويستهدف الوصول إلى نسبة تزكز 40\% كمؤشر لزيادة التتافسية. - يلاحظ البعض ثراجع استهلاك حديد التسليح حتى قبل انتشار جائحة كورونا، وقوانين منع البناء في بعض المحافظات لبعض الوقت، فتر اجع الاستهلاك من 7.4 مليون طن في 2019 إلى 6.7 مليون طن في 2020، وذلك رغم النشاط الملحوظ في المشروعات القومية، ومشروعات البنية التحتية. - هناك بعض القصور، و النظرة الجزئية في إصدار بعض القرار ات التي من شأنها التأثثر على صناع الحديد والصلب، بمعنى التركيز على حل مشكلة جزئية دون النظر لتأثير ها على جو انب أخرى. - صناعة الحديد و الصلب لها بعد اجتماعي (العمالة) وبعد اقتصادي وبعد بيئي ويجب أن يتم تتاولها بشكل متكامل منظومي، من خلال حوار شامل بين جميع الأطر اف من الصناعة، وممثلين الحكومة، و مر اعاة الجوانب الاجتماعية و الفنية، وتحقيق الصالح العام. مان. - عانت شركة الحديد و الصلب من عدم ضخ استثمار ات لفترات طويلة فكان من الطبيعي أن تخسر وتثر اجع، وصولًا إلى قر ار التصفية.

- إذا كانت بعض مصانع وشركات الحديد والصلب تخسر، فمن الممكن تحمل هذه الخسائر في مقابل مساهمتها في دعم صناعات أخرى مثل صناعة الإسمنت الحديدي الذي بعتمد على " الر ايش و الجلخ " من مخلفات الحديد و الصلب. - يتطلب دفع عجلة التتمية أن تكون الدولة مستعدة لجعل الصناعة في مقدمة أولوياتها دون النظر لعو ائد أو موارد مالية منتظرة على الأجل القصير . 
- صناعة الحديد والصلب من أكثر الصناعات التي يثار حولها اللبس، رغم أنها تشهذ تحسنًا وتوسعًا ملحوظًا مؤخرًا على مستوى عدد المصانع، و الطاقة الإنتاجية، ومسنتوى المنافسة.

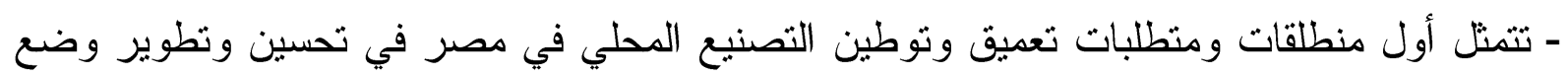

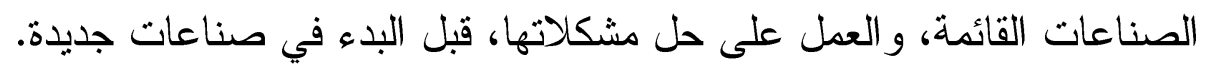

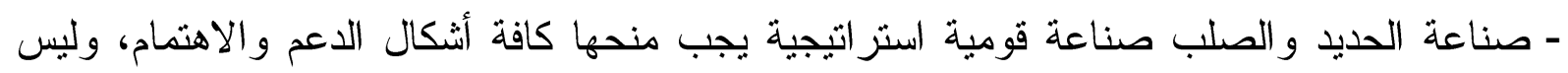

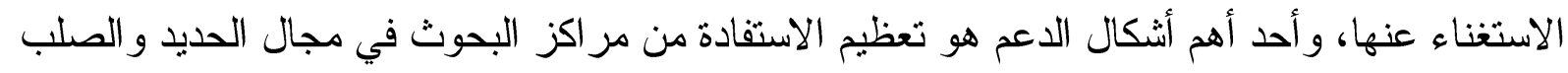

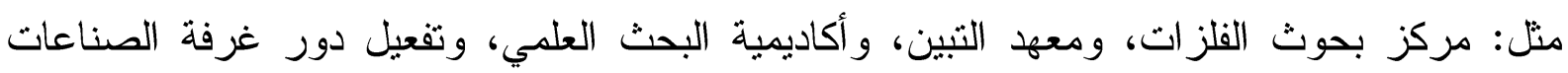

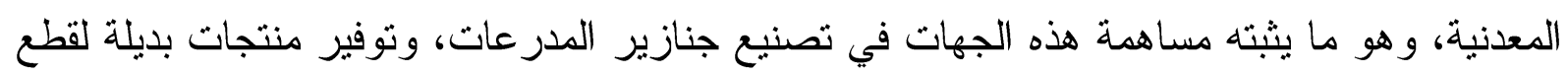
الغيار المستوردة، و المعدات الزر اعية، و السكك الحديدية.

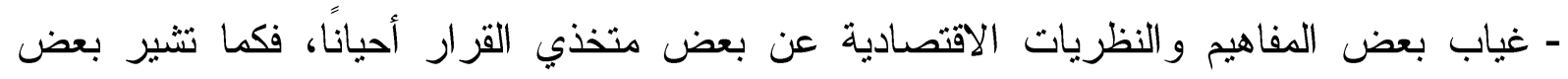

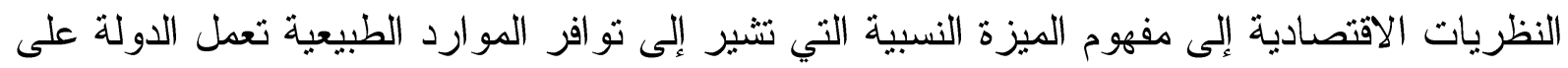

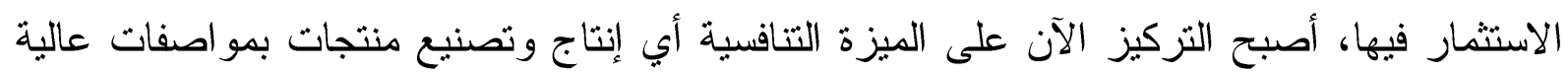
الجودة تسمح بالمنافسة و الاخول إلى السوق.

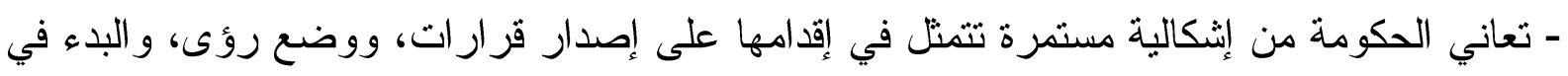
مشروعات دون الدراسة والإعداد الكافيين، ودون استثارة المتخصصين و أصحاب الخبرة و الكفاءة.

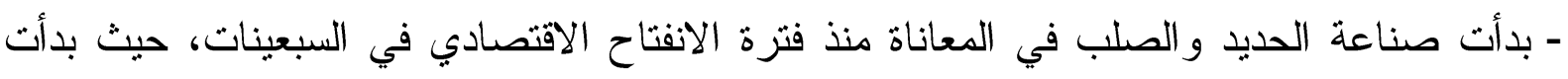

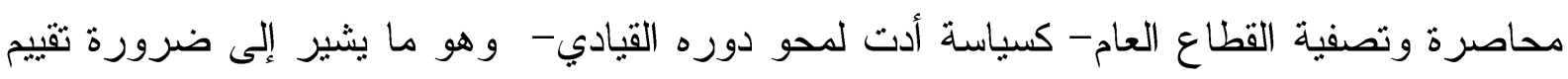
وتصحيح مسار اتتا التنموية. - يؤكد ما دار من اختلاف في وجهات نظر حضور حلقة اليوم، وعرض الر أي والر أي الآخر ، قيمة

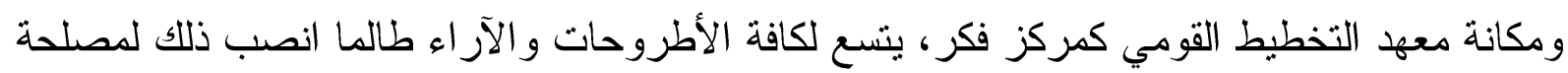
الوطن. - الون - عدم ضرورة خلط الموضوع الرئيسي لتعميق التصنيع المحلي في مجال صناعة الحديد و الصلب بقرار تصفية شركة الحديد و الصلب. - القضايا التي أثيرت في الحلقة تحتاج إلى جهود بحثية و علمية من المعهد و هيئته العلمية لمساعدة صناع القرار ور اسمي السياسات. 


\section{تعقيب المتحدث}

- شهدت الجلسات و الحوارات الني سبقت قرار تصفية الحديد والصلب ومشاركة المعنيين بالصناعة ومنهم غرفة الصناعات المعدنية.

- لا يوجد مجالا للنزاع أو الصر اع بين القطاع العام و القطاع الخاص في مجال صناعة الحديد و الصلب

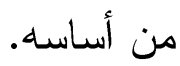

- لتعظيم الاستفادة من الناتج من صناعة الحديد والصلب، وتحقيق التو ازن بين العرض و الطلب لابد

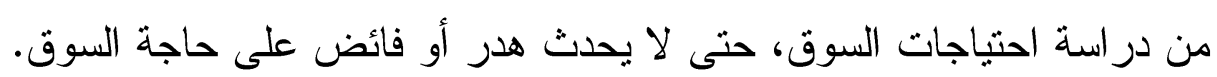

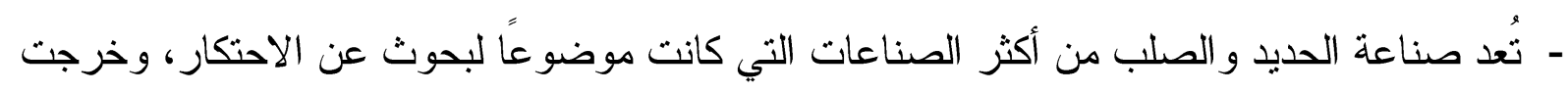

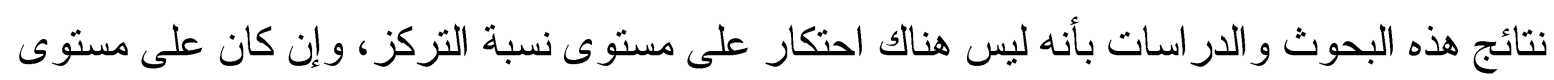
الممارسة هناك ملامح احتكار . - تراجع استهالك حديد التسليح إلى 6.7 مليون طن في 2020، وذللك رغم النشاط الملحوظ في

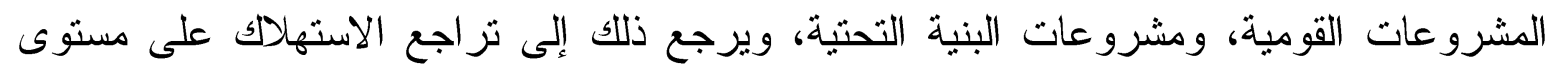
الأفر اد و الأهالي نتيجة قرارات وقف البناء في بعض المحافظات التي انتهت في نوفئه التهبر 2020. - ضرورة التتسيق و التكامل بين الوزارات و الجهات المختلفة ونبذ العمل بمبدأ الجزر المنعزلة.

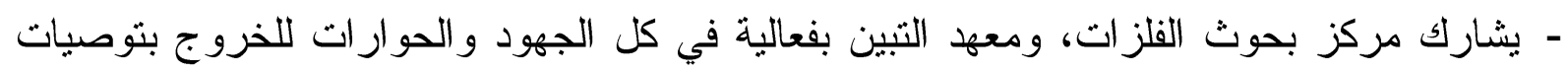
ل ل لجهات المعنية. - قرار تصفية شركة الحديد والصلب لا يعني إلغاء النشاط أو هدم المصنع، بل ضخخ استثمار ات في مختلف أقسام المصنع و أنشطته. - تم التعاقد مع شركة فاش ماش الأوكر انية لرفع تركيز الخام بمناجم حديد الواحات البحرية لرفع تركيز خام الحديد بالو احات باستخدام تكنولوجيا الفصل المغناطيسي الجاف. 